\title{
Moving at the Speed of Trust Radical and Progressive Change through Climate Justice Movements in Aotearoa
}

\author{
BY \\ Emma Yvonne Simons \\ Te Kura Tātai Aro Whenua, Te Wāhanga Pūtaiao, \\ Te Herenga Waka \\ School of Geography, Environment and Earth \\ Sciences, Faculty of Science, Victoria University of \\ Wellington
}

A thesis submitted to Te Herenga Waka | Victoria University of Wellington in partial fulfilment of the requirements for the degree of Master of Development Studies

Te Herenga Waka | Victoria University of Wellington 



\section{Abstract}

Human-induced climate change is already having an acute impact on many lives and livelihoods. This is expected to escalate, especially for "disadvantaged people and communities in countries at all levels of development" (Pachauri et al., 2014, p. 13). This thesis is situated within post- and critical development, enabling critique of mainstream development alongside the exploration of alternative, bottom-up forms of development, such as social movements. Following a social constructionist epistemology, it utilises qualitative methodologies (in-person and virtual in-depth interviews) to navigate the complex, fluid, and subjective field of climate justice.

This research situates the emerging climate justice movements in Aotearoa as key to understanding how radical, progressive societal change is articulated in the contemporary era to mitigate and adapt to anthropogenic climate change. Several core themes emerge as part of the research, including how various actors (organisations, sub-movements, and individuals) relate to each other and the world around them. This research asks and addresses not only what climate justice is in Aotearoa and who is involved, but also which theories of change operate within these emerging social movements?

The data in this research outlines that climate justice movements in Aotearoa are accessible, inclusive, relational, accountable and frontline community-led, the antithesis of the current dominant structures and systems of society. These movements build upon other rights and justice movements, notably: Indigenous justice, disability justice, intersectional feminism, workers' rights, and intergenerational justice. The development and negotiation of a collective climate justice identity is shaped by several interconnected tensions: partisanship versus non-partisanship, internal conformity versus diversity, and ecosystem versus 'egosystem'. These tensions can also impede connection and understanding, at times leading to substantial harm to individuals, communities, and climate justice more broadly. This thesis outlines multiple forces shaping the actualisation of justice in an Aotearoa experiencing climate change. Fundamentally, this thesis highlights that climate justice is an ongoing journey of relationships and negotiations that "move at the speed of trust".

Key words: Climate justice, climate action, Aotearoa, post-development, critical-development, collective identity, intersectionality, relationships. 


\section{Acknowledgements}

I want to acknowledge the mana whenua of Aotearoa, in particular Ngāti Raukawa ki te Tonga (Ōtaki), Taranaki Whānui ki te Upoko o te Ika (Wellington), Rangitāne o Wairarapa (Wairapapa), Ngāti Toa Rangatira (Wellington and Kapiti), Muaūpoko (Wellington and Ōtaki), Te Atiawa (Wellington) and Ngāti Kahungunu ki Wairarapa (Wairarapa) ${ }^{1}$, as I have spent most of my life living on and benefiting from their ancestral whenua (land). I am grateful for the significant contributions and collaboration of all my participants, many of whom are balancing employment, volunteering, COVID-19 and life alongside climate justice and climate activism. Moreover, I could not have completed this thesis without the unrelenting support of my supervisors John and Nayan, and my fellow thesis students. I am grateful to Te Herenga Waka for scholarship funding and paid tutoring work that allowed me to focus on this thesis, however, I am equally thankful to friends and family who reminded me there is life outside of university. Special thanks to Josh and Cassidy for holding space for my thesis-COVID-climate hybrid anxiety and reminding me to hydrate (tear fuel).

This thesis is dedicated to those who identify as part of the climate justice community and those working within climate movements who want to become more justice-oriented.

\section{Supervisors:}

John Overton, Development Studies, Te Kura Tātai Aro Whenua | School of Geography, Environment and Earth Sciences, Te Wāhanga Pūtaiao | Faculty of Science, Te Herenga Waka | Victoria University of Wellington

Nayanatara Sheoran Appleton, Pūtaiao ki te Pāpori | Centre for Science in Society, Te Wāhanga Pūtaiao | Faculty of Science, Te Herenga Waka | Victoria University of Wellington

\footnotetext{
1 According to the Greater Wellington Regional Council, http:/www.gw.govt.nz/mana-whenua-partnerships/ and http://www.gw.govt.nz/assets/Plans--Publications/Regional-Plan-Review/Draft-Regional-Plan-docs/Frontispiece-Foreward-andContents-Page.pdf and Te Puni Kōkiri Ministry of Māori Development, https://www.tkm.govt.nz/map/ .
} 


\section{Abbreviations}

\begin{tabular}{|c|c|}
\hline 350 & 350 Aotearoa \\
\hline BIPOC & black, Indigenous, person of colour \\
\hline COP & the Conference of the Parties \\
\hline COVID-19 & Novel Coronavirus 2019 \\
\hline ETS & Emissions Trading Scheme \\
\hline GenZero & Generation Zero \\
\hline IPCC & Intergovernmental Panel on Climate Change \\
\hline LGBTQI+ & lesbian, gay, bisexual, transgender, queer, intersex \\
\hline NGO & non-governmental organisation \\
\hline NSM & new social movement \\
\hline PD & post-development \\
\hline PfCA & Parents for Climate Aotearoa \\
\hline RMA & Resource Management Act 1991 \\
\hline SCA & System Change Aotearoa \\
\hline SD & sustainable development \\
\hline SMF & social movement family \\
\hline SMO & social movement organisation \\
\hline SMS & social movement studies \\
\hline SOUL & Save Our Unique Landscape \\
\hline SS4C & School Strike 4 Climate NZ \\
\hline TUI & Te Upoko o Te Ika \\
\hline UN & United Nations \\
\hline UNFCCC & United Nations Framework Convention on Climate Change \\
\hline UNCRPD & United Nations Convention on the Rights of Persons with Disabilities \\
\hline UNSDG & United Nations Sustainable Development Goals \\
\hline XR & Extinction Rebellion \\
\hline
\end{tabular}




\section{Table of contents}

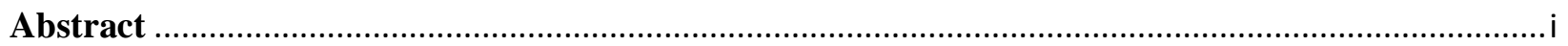

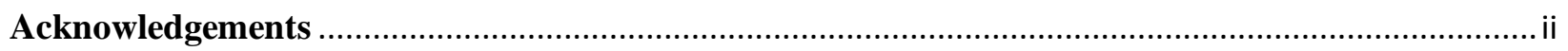

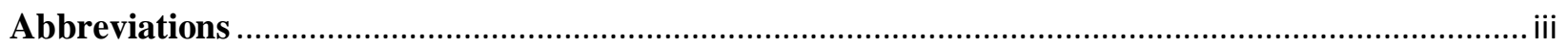

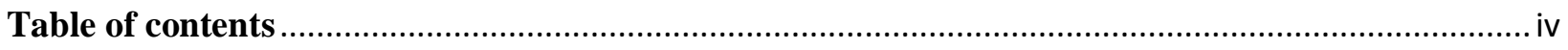

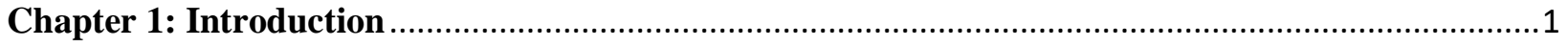

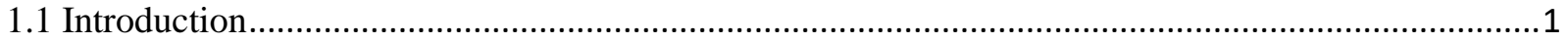

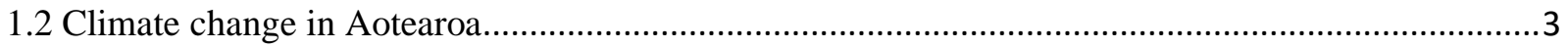

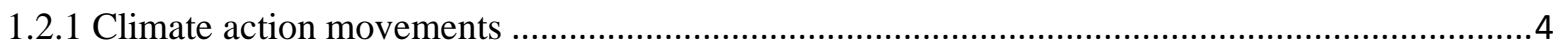

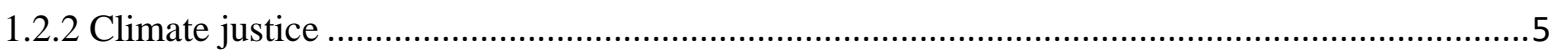

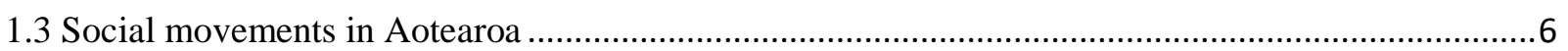

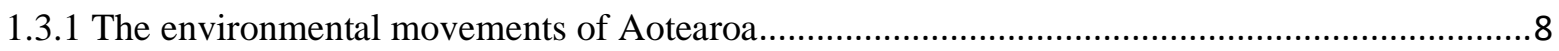

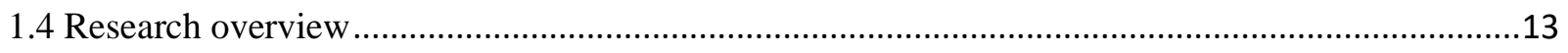

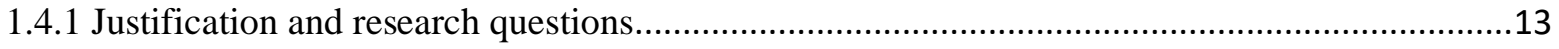

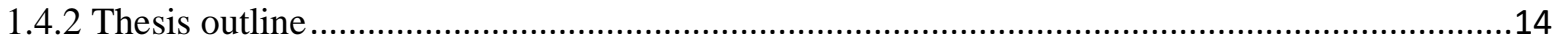

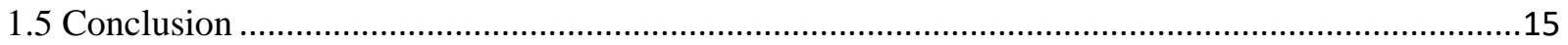

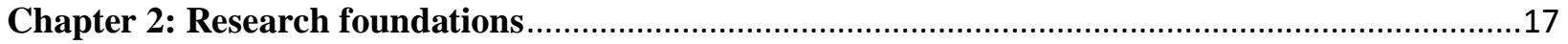

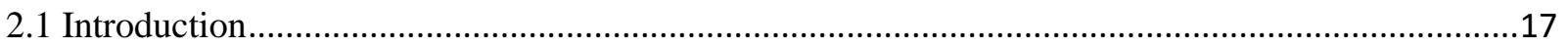

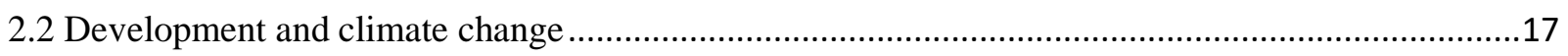

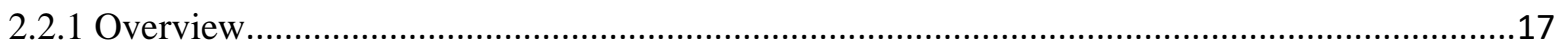

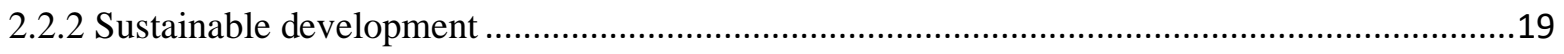

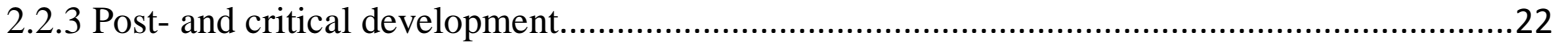

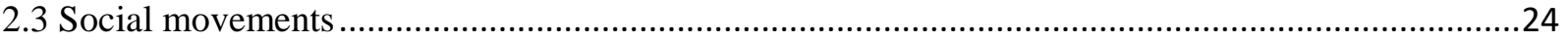

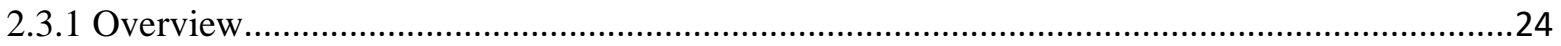

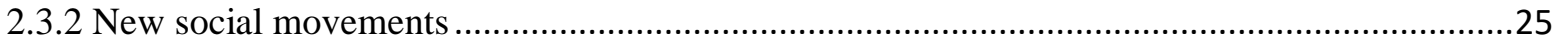

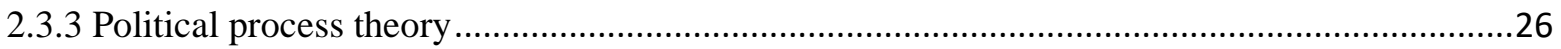

2.3.4 Environmental, climate action and climate justice movements...........................................27

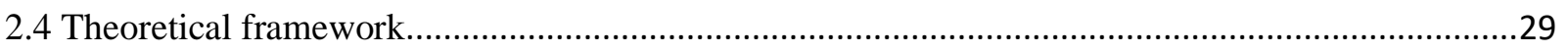

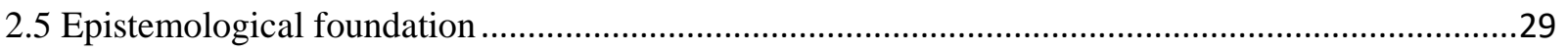

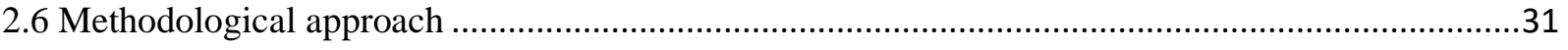

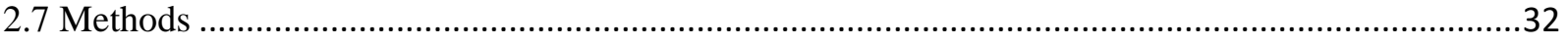

2.7.1 Data collection: semi-structured, in-depth interviews ...........................................................32 


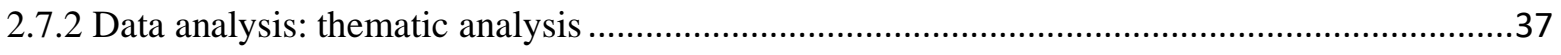

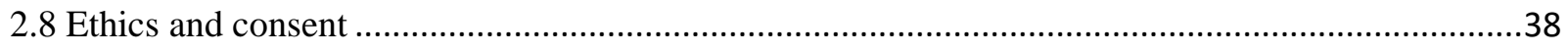

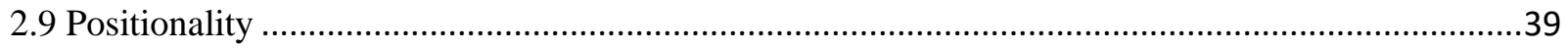

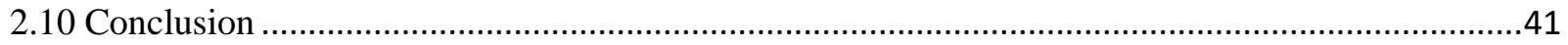

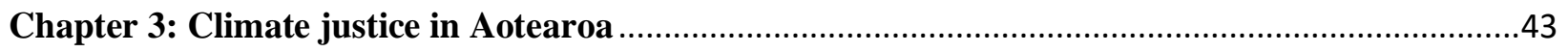

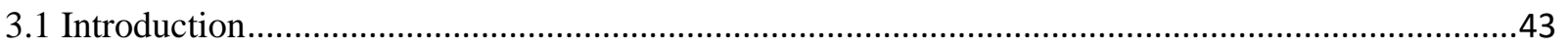

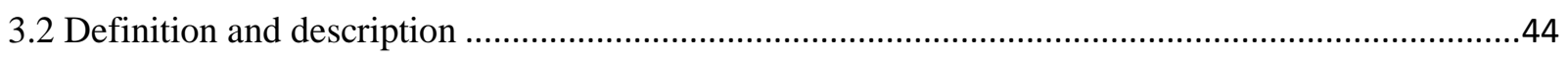

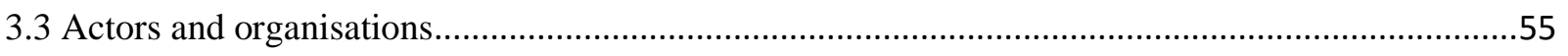

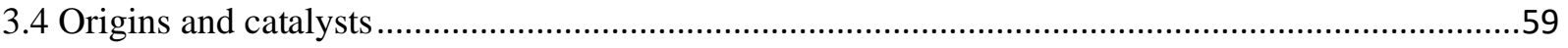

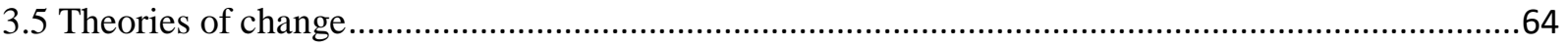

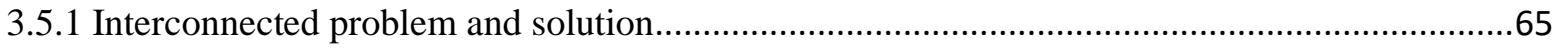

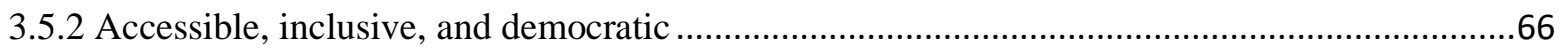

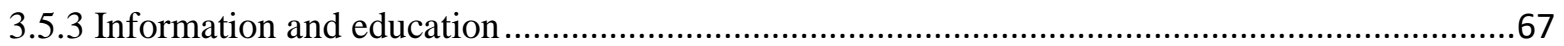

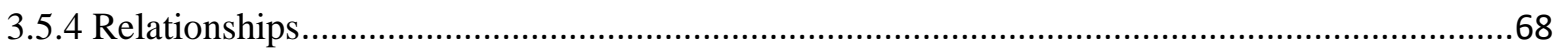

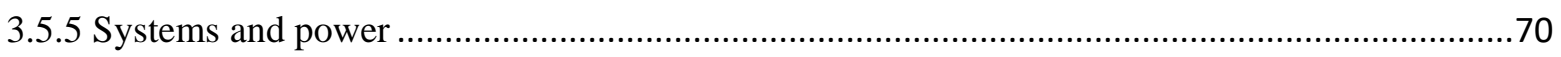

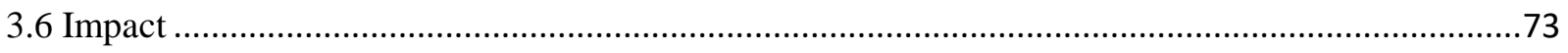

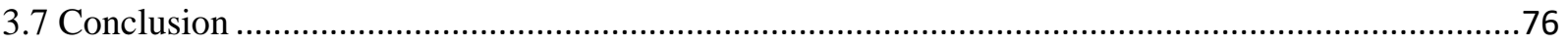

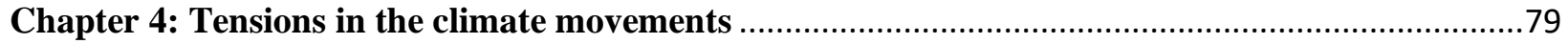

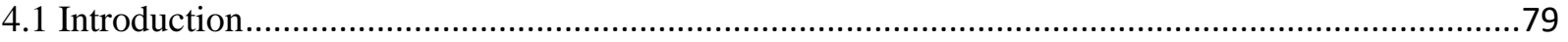

4.2 Tension one: partisanship versus non-partisanship ..................................................................

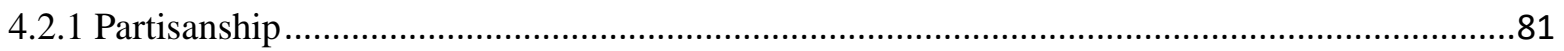

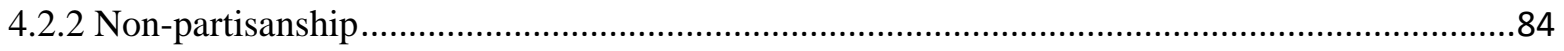

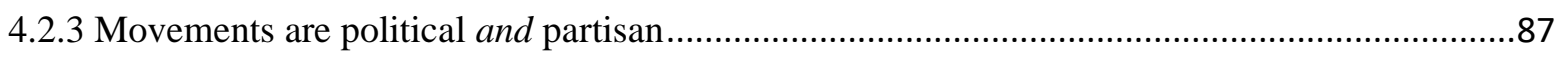

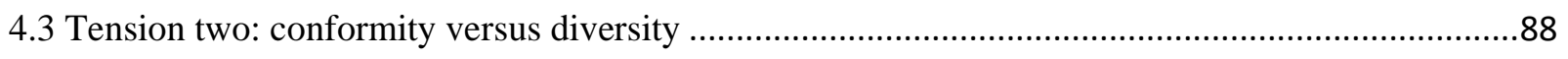

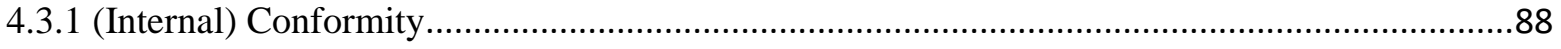

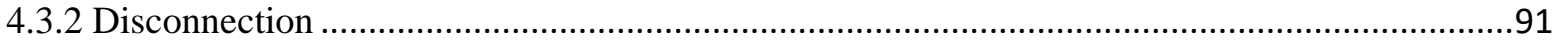

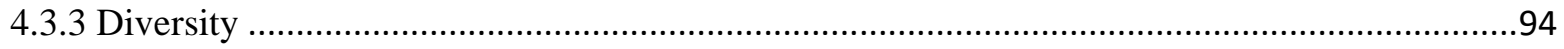

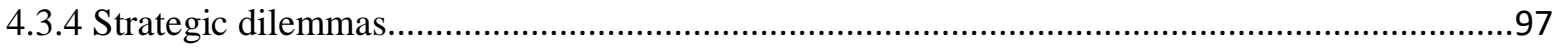

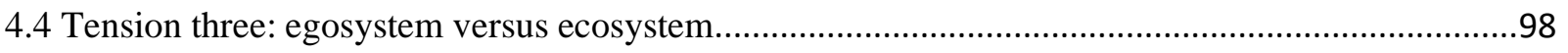

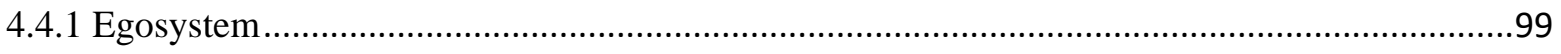

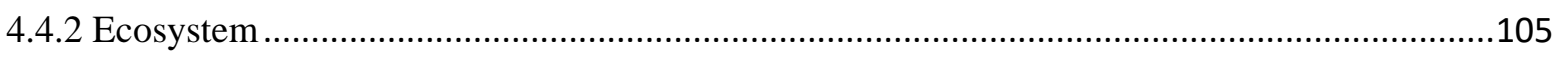

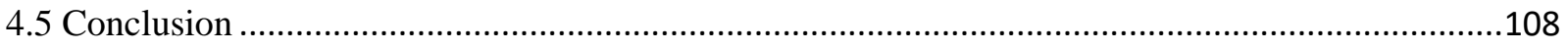

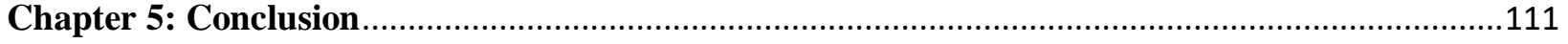


5.1 Introduction

5.2 Thesis summary.

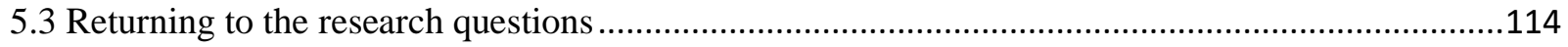

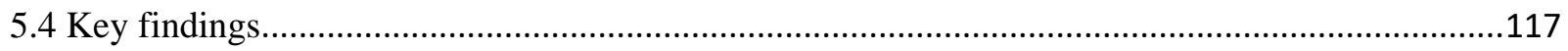

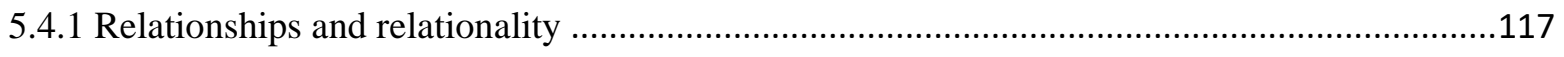

5.4.2 The role of development/development studies .................................................................120

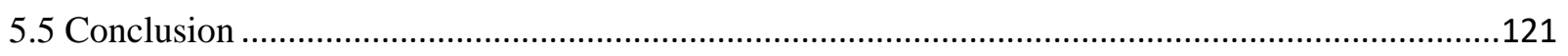

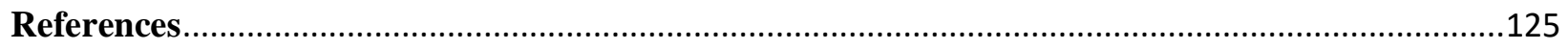




\section{Chapter 1: Introduction}

"There are climatic changes that are already baked in and, to a greater extent, our campaigning needs to be about how we're transforming the world that we're going to have to live in anyway ... it's about changing our relationship with each other and with the natural world so that we can live in this climate change world in a way that is kinder and more just."

(Greenpeace, interview, 24/08/2020)

\subsection{Introduction}

Human-induced climate change, the change in temperature, precipitation, ocean salinity, and sea level, has been observable since before the 1950s (Pachauri et al., 2014). Occurring due to the warming effect of increased greenhouse gas emissions in the atmosphere, these changes are potentially long-lasting and irreversible (Allen et al., 2018; Pachauri et al., 2014). Changes to our climate have devasting impacts, changing ecosystems and ecoservices that human and natural systems rely on (Allen et al., 2018). We are experiencing a sixth mass extinction event as freshwater, marine, and terrestrial vertebrates have declined by $81 \%, 36 \%$ and $35 \%$ respectively between 1970 and 2012 (Ripple et al., 2017). Climate change, increasing the frequency and intensity of floods, famines, droughts, and wildfires, is already a "matter of life and death" (Doig, 2020, p. 16). By 2070, a third of the world's population could be exposed to Sahara Desert-like temperatures with each degree Celsius of temperature rise equating to an additional 1 billion people outside of the optimal temperature range for human existence, necessitating migration $(\mathrm{Xu}$ et al., 2020). Climate change amplifies existing risks and creates new ones; these are distributed unevenly and are greatest for "disadvantaged people and communities in countries at all levels of development" (Pachauri et al., 2014, p. 13). 
Coming from a place of deep interest in the way in which society changes, this thesis seeks to understand how we in Aotearoa New Zealand ${ }^{2}$ might spur radical, fundamental, progressive societal change in order to minimise and adapt in the face of climate change. The need for systemic change, well embedded in grassroots discourse, has not yet eventuated into substantive political, economic or social change. Yet, in the face of COVID-19, throughout 2020 we saw rapid, substantial change advocated from above and below, and enacted swiftly. Leveraging off this unique moment in history, this thesis analyses development, climate change, and social movements from a post- and critical development perspective. It seeks to answer: 'what is climate justice in Aotearoa?'; 'who is involved?'; and 'what theories of change guide their approach?' All this in light of the fact that we know radical, transformative change is socially and politically possible, given the mobilisation for combatting COVID-19. Aware of these possibilities, this thesis then demonstrates that climate justice is a powerful and emerging movement and approach to climate change that emphasises the relational nature of activism, knowledge, societal change, and climate change. Relationships stand out in the research as crucial in collectively adapting to climate change in a just and equitable way, changing the way we relate to each other and the environment. They are an ongoing negotiation and, as demonstrated by conflictual interactions between climate justice and climate action, this process is not always experienced positively; however, it remains essential for growth. Furthermore, while climate justice can offer much to development and Development Studies, the nature of development's role in climate justice is unclear.

In order to understand climate justice in Aotearoa in the present day, this chapter introduces the history and context of social, environmental, and climate movements of Aotearoa as a necessary foundation. Additionally, predicted climate change impacts and how the government is responding are included to explain the landscape in which these movements operate. In particular, the legislative and policy frameworks driven by central government are crucial to understanding the opportunities and constraints for action on climate change in this country. This then leads to the research proposition and culminates in an overview of the thesis ahead.

\footnotetext{
${ }^{2}$ From here on Aotearoa will be used to refer to the country, society or movements, New Zealand (and then NZ) for the government/state.
} 


\subsection{Climate change in Aotearoa}

Aotearoa is already experiencing climate change. On average, temperatures have risen around 1 degree in the past century, and rainfall patterns are changing (Reisinger et al., 2014). Extreme weather events, flooding, droughts, storms, and wildfires are also more intense and frequent due to higher temperatures (Dean et al., 2013; Meduna, 2015; Renwick et al., 2016). With diverse climatic systems, Aotearoa will continue to be affected by a range of physical impacts that generally encompass the above trends and are expected to vary regionally and seasonally (Hopkins et al., 2015; Meduna, 2015; Reisinger et al., 2014). These changes are projected to substantially impact coastal ecosystems, infrastructure, health, agriculture, biodiversity, and water resources (Reisinger et al., 2014). These impacts are intensified by the economic and sociocultural importance of natural resources and climate stability (Hopkins et al., 2015).

The New Zealand government is involved in international negotiations through the United Nations Framework Convention on Climate Change (UNFCCC), including the Kyoto Protocol and Paris Agreement, and engages with the Intergovernmental Panel on Climate Change (IPCC) and Pacific Islands Forum, among many other organisations and frameworks. The Emissions Trading Scheme (ETS), Climate Change Response (Zero Carbon) Amendment Act 2019, and the Resource Management Act 1991 (RMA) are the current key government levers on climate change. These mechanisms have been criticised for lacking meaningful incentives, including preferential treatment of agricultural emissions, and lacking specific, strong, and short-term policies to meet the enshrined emissions targets (Climate Action Tracker, 2020; Hopkins et al., 2015). Additionally, while this is a changing landscape, with the ETS recently amended and the RMA currently under reform, government action continues to be driven and framed within international agreements and standards. Climate Action Tracker, an independent scientific analysis of global government action towards the Paris Agreement, notes that New Zealand's measures are 'insufficient', tracking towards a $3^{\circ}$ increase (not the $1.5^{\circ}$ target) ${ }^{3}$ (Climate Action Tracker, 2020). The projected impacts and government approach to climate change in Aotearoa form the landscape in which the climate justice movement and this research operate. It is from this foundational

\footnotetext{
3 The Paris Agreement's central goal is to limit global warming to 1.5 degrees Celsius above pre-industrial levels. Refer to the UNFCCC website for more information https://unfccc.int/process-and-meetings/the-paris-agreement/the-paris-agreement.
} 
understanding that this inquiry is launched, focusing from here on out on the alternatives to the mainstream avenues.

\subsubsection{Climate action movements}

An alternative approach to the government-focused mechanisms outlined above are social movements. Climate change as a significant protest issue in Aotearoa emerged in 2005 with growing awareness and frustration at the lack of progress (O'Brien, 2012).The transnational climate movement has been described as a limited but visible umbrella structure, where traditional NGOs are no longer the main players, replaced by a diverse membership and support base comprised of informal and loosely organised actors on international and local levels (Dietz \& Garrelts, 2013). These characteristics reflect the diffuse and complex nature of climate change, which is noted by Diprose et al. (2016) as hindering climate action. Climate action is a broad term that is often used to incapsulate all efforts to mitigate, transition and adapt to climate change - all climate related actions (for example note the 'Climate Action Tracker' website referenced above that analyses government actions). In this thesis climate action is used to differentiate between the mainstream climate movements and the emerging climate justice-oriented movements. A detailed definition of climate action is intentionally not developed and supplied within this thesis as there are many definitions and the focus is on climate justice and developing a working definition for climate justice within Aotearoa.

Movements endeavours to make climate action meaningful for the general public, progressing from a scientific consensus towards a social consensus of action and will for change (Oosterman, 2016b). Communication practices of the movement are a key part of this, and the growing literature reflects that. A deep-sea oil protest in Aotearoa drew on the inherent value of non-human beings and national subjectivities (who we are) to contest the mainstream and state emphasis on the monetary value of the environment (Diprose et al., 2016). At present, academic literature on the climate movements in Aotearoa tends to focus on specific case studies (such as deep-sea oil protests) instead of broader, holistic analysis of the movements at large (with the exception of Oosterman (2016a) who focuses on communication practices). Taking an explicitly holistic view of these movements, this thesis aims to fill a gap in the literature towards building a more complete picture of the climate movements. Furthermore, the focus on theories of change and how they are constructed by, and influence, movement identities is also a novel contribution of this thesis to the 
literature. Additionally, within this analysis of the climate movements, climate justice is the focus instead of the more frequently researched climate action.

\subsubsection{Climate justice}

Climate justice is often talked about alongside climate action, climate activism and climate change movements in literature and research, locally and internationally, obfuscating organisational and research associations with climate justice. Dietz and Garrelts (2013) position climate justice as the radical paradigm, wing or sub-movement within the climate change movement, with ecological modernisation (included within but not entirely representative of climate action in this thesis) as the moderate alternative. Climate justice in an Aotearoa context draws on Indigenous justice, and advocates for upholding Te Tiriti and giving iwi authority and decision-making over their land and people (Kelly-Costello et al., 2020). Kelly-Costello et al. (2020) highlight that in Aotearoa climate justice focuses on equity and inclusion, centring black, Indigenous, people of colour (BIPOC), women, rainbow, and disabled, not just because of the disproportionate impact they feel but also because of their expertise, which is systemically overlooked. Mobilised and articulated in different ways across different movements, this contemporary climate activism incorporates inter- and intragenerational justice (Cretney \& Nissen, 2019). These movements build on the legacy of activism led by Indigenous movements and communities in the 'Global South' contesting the dominant capitalist and colonial origins of climate change and the mainstream solutions currently suggested (Cretney \& Nissen, 2019; Featherstone, 2013; Whyte, 2017).

2019 was a crucial year for global climate activism, with movements gaining momentum and media coverage (Cretney \& Nissen, 2019). Thomas et al. (2019) note that this latest wave has given movements, which has struggled to build sufficient momentum, a necessary boost. Cretney \& Nissen (2019) note that "across Aotearoa and the world, movements for climate action and justice have escalated into prominence" (p. 15). A new generation of activists have arrived through organisations such as Fridays for Future and School Strike 4 Climate, and more controversial and disruptive activism through XR; both connect to Black Lives Matter and other social movements (Cretney \& Nissen, 2019; Doig, 2020). Oil exploration activism, Indigenous land movements, and government lobbying also feature within climate justice in Aotearoa (and globally) (Cretney \& Nissen, 2019; Diprose et al., 2016; Dodson \& Papoutsaki, 2017; O’Brien, 2013a). In this thesis, 
climate justice is defined as the on-going process of centring frontline ${ }^{4}$ communities in the analysis and solutions to climate change. This framework and associated movements are additional to (and sometimes in conflict with) the broader climate action framing which tends to favour mainstream and privileged perspectives.

\subsection{Social movements in Aotearoa}

Climate justice and climate action are contemporary iterations within the rich history of protest and reform in Aotearoa. The women's suffrage movement leading to the vote in 1893 and the nuclear free campaign are cornerstones of Aotearoa's identity and perception as a progressive nation. Downes (2000) considered the nuclear free campaign the most successful in terms of state engagement and closest to the 'insider' position. ${ }^{5}$ However, the relationship between movement and state was complex. Nuclear power was a relatively neutral issue regarding state imperatives (economic and security) given no state investment (Downes, 2000). Rather, siding with the antinuclear issue was a way to appease Labour's centre-left base, reducing risk from their nonmandated market-liberal reform and, in that sense, enabled state legitimacy (Downes, 2000). Initially part of the peace movement, the contemporary nuclear debate is just as relevant to the environment and climate change. However, opinion is divided, some viewing it as a solution to emissions intensive energy production (Sailor et al., 2000), while others note the maladaptation risks of nuclear energy (Jordaan et al., 2019).

Taylor (2008) observed the replication of international trends in collective action in Aotearoa, such as rifts between old and new social movements, entering a phase of renewal, and the merging of cultural and material grievances. Additionally, grassroots movements are often fostered by an interconnected global network (Alakavuklar \& Dickson, 2016). Political mobilisation and literature on movements, activism, and social change in Aotearoa developed in response to the consequences of market-liberalism (Alakavuklar \& Dickson, 2016). Unfortunately, knowledge gaps remain that impede praxis, particularly what sets Aotearoa apart from the rest of the world as movements shape and are shaped by local context (Alakavuklar \& Dickson, 2016; Boraman, 2016; Taylor, 2008).

\footnotetext{
${ }^{4}$ Those on the 'frontline' of the effects of climate change, through either geographic exposure and/or social vulnerability.

${ }^{5}$ Defined by Downes (2000) as successful and close engagement with the state, 'insider' position reflects the movement's relationship to the formal political system, the state.
} 
Within the local context, Te Ao Māori needs to be centred in discussions of development, climate change, social movements, and climate justice, particularly as a framework that enables different ways of relating to each other and the environment (Hartendorp \& Bradford, 2016; M. Jackson, 2020; Thomas et al., 2019). Te Punga Somerville (2020) notes that the role of Indigenous people is "to push back against colonial narratives", providing alternative perspectives and futures that create hope for change (p. 19). Likewise, Māori scholar Moana Jackson states that "being Māori is a political act" with the drive to understand right-ness and just-ness (M. Jackson et al., 2017, p. 28). Māori resistance to colonisation (and the associated environmental and human injustices) has been ongoing from the outset (Walker, 2004; Webb, 2020). Parihaka, in the late 1800s, is one of the most well-known examples. A 'model village' of pacifism, utilising protest and direct action, it remains a symbol of non-violent resistance and creating alternative ways of operating outside of the dominant system (Scott, 2014; Taylor, 2008; Walker, 2004). In the 1960s and 1970s the international Indigenous movement was growing alongside the civil rights movement (M. Jackson et al., 2017; Powless, 2012; Webb, 2020). This was mirrored by the resurgence of Māori resistance in the 1970s and 1980s: the revival of te reo, education, arts and media; occupations at Bastion Point, Raglan, and Pākaitore; annual Waitangi Day protests in 1970s; and the 1975 Land March (Webb, 2020).

Despite the depoliticising impact of neoliberalism and Treaty settlements, the decolonisation movement continues (M. Jackson et al., 2017). Māori resistance to colonisation and land confiscation endures at Ihumātao, a rare cultural heritage site and one of the oldest continuously occupied settlements in the country (McCreanor et al., 2018; Webb, 2020). Save Our Unique Landscape (SOUL) was formed in 2015, a mana whenua-led, community supported campaign that opposed the development of Ihumātao via the "fast-track, developer-friendly provisions" that sidelined mana whenua and the community (McCreanor et al., 2018, p. 139). Utilising evidence-based debate, demonstration, hikoi (march), petitions, occupation, UN visits, and legal processes, SOUL called for the government to ensure Māori consultation and the protection of land for future generations (McCreanor et al., 2018; Patterson, 2020). In late 2020, the land was purchased by the government, and a memorandum of understanding was signed between state government, local government and Kīngitanga (Patterson, 2020). 
Despite ongoing resistance, protest and inquiries led by mana whenua, colonial injustices "have never been formally addressed by the Crown" (McCreanor et al., 2018, p. 141). Colonisation radically changed the environmental and human systems in Aotearoa, and "emancipatory politics in Aotearoa New Zealand must address both colonisation and capitalist exploitation" (Webb, 2020, p. 75). The overriding discourse of settler colonialism is one of exploitation and subjugation of the environment and Indigenous people, rationalised as necessary for development (Mercier, 2020; Ross, 2020). Decolonisation is, therefore, an essential part of climate justice, as it challenges these systems of domination and develops alternatives built on trust and relationality (Whyte, 2020). The relevance of the decolonisation and Indigenous land movements to environmental and climate movements is becoming more salient. Aotearoa is a settler colonial state, and the legacy of colonisation has become more visible in 2020. The international Black Lives Matter movement enabled greater visibility for the decolonisation movement in Aotearoa, sparking new debates and petitions surrounding colonial statues, police reform, and Māori wards in local government (McConnell, 2020; Ngata, 2020; RNZ, 2021; Thom \& Quince, 2020). Alakavuklar \& Dickson (2016) noted that a growing proportion of Pākehā/Tauiwi activists are joining the decolonisation movement in Aotearoa, as demonstrated by Tauiwi mō Matike Mai Aotearoa. Likewise, Elkington \& Smeaton (2020) highlight that "Pākehā allied voices ... are important as decolonisation is the work of all of us, despite the need for decolonising efforts to be led by Maori” (p. 16).

\subsubsection{The environmental movements of Aotearoa}

In the 1960s and early 1970s, Aotearoa saw 'conventional' and conservation-focused environmental movements emerge, with the creation of various small-but-effective grassroots organisations, including the presence of international organisations Friends of the Earth and Greenpeace (Downes, 2000). Throughout this period, the relationship between the movements and the government was a primary shaping factor. The Muldoon National government (1975-1984) excluded environmental interests from policymaking, resulting in more groups with less conventional strategies directing action towards civil society and public to pressure the government (Downes, 2000). The Lange Labour government (1984-1990) engaged with the movements and restructured environmental institutions, but the relationship between movement and state became more ambiguous, with the government outwardly responsive but avoiding substantive concessions (Downes, 2000; Dryzek, 1996). Downes (2000) notes that in Aotearoa 
"Environmental concerns have not motivated sufficient support with which to threaten the legitimacy of the state" (p. 482).

The contemporary movements emerged in the 1960s with the Lake Manapouri protests (Mark et al., 2001; O'Brien, 2012). This was a drawn-out campaign which demonstrated the need for concerted action, the power of publicity and detailed and well-researched proposals, and the importance of relationship to government, providing a foundation for future contention (O'Brien, 2013b; L. W. Wright, 1980). Beginning in 1969 in Invercargill, the campaign mobilised in response to government negotiations to damn Lake Manapōuri in Fiordland National Park without public consultation (Mark et al., 2001; K. Mills, 2009; Nathan, 2015; O’Brien, 2012, 2013b). A petition to preserve the level of the lake was launched in 1970, and it gathered over a quarter of a million signatures, making it the largest at the time, and, as a result, the Labour Party government conceded (Downes, 2000; Memon, 1993; Wilson, 1982).

In the 1970s, movement focus then shifted to native forest logging, which required more direct action and disruption (O'Brien, 2013b). Major protests against the logging of native forests occurred between 1975 and 1985, prompting the creation of several environmental, forest-focused groups (Nathan, 2015). O'Brien (2013b) considers it an unsuccessful but important part of the reemergence of environmental movements, while others see it more as the foundation of modern environmental movements in Aotearoa (Downes, 2000; Wilson, 1982). The series of campaigns against logging was long-running and used novel tactics such as a travelling 'embassy' and declaration of independence for Aramoana (Downes, 2000). The Maruia Declaration in 1975 was circulated publicly and signed by 341,160 people before submission to the government in 1977 (Nathan, 2015; O’Brien, 2012). The West Coast Accord, an agreement between government, industry and environmental NGOs in 1986, included environmental groups as a primary stakeholder for the first time and altered the structure and approach of the movements (Downes, 2000). Viewed as a pragmatic compromise by environmentalists rather than a genuine blend of economic and environmental priorities, it enabled the state to balance popular support for ending native logging with economic reliance on forestry (Downes, 2000). This co-option of environmental values and groups by the government delegitimised the movement's claims. The Accord subsequently became a catalyst for division within the movement, notes Downes (2000), between those who entered and those who did not. Many groups devolved or merged to create new 
ones, creating internal tension, with some activists leaving the movement altogether (O'Brien, 2013b). The movement was revived in the late 1990s in the West Coast by Native Forest Action when a lack of political elite consensus enabled a sustained campaign to shift public opinion and, subsequently, the incoming government (O'Brien, 2012). With a tighter focus that didn't challenge economic imperatives, they were successful (O’Brien, 2012).

In the 1990s, environmental movements struggled to be politically influential. However, with the election of the Labour-Alliance coalition (reliant on seven Green Party representatives) in 1999, possibilities for formal political inclusion increased (Downes, 2000). The RMA made the relationship with the state more ambiguous, and while it outlined responsibilities for government and encouraged localisation, participation, and consultation, it was overly technocratic (Downes, 2000; T. Jackson \& Dixon, 2007; O’Brien, 2013b). Downes (2000) found that movement imperatives happened to be compatible with elements within the Lange Labour government and, as such, were included, but other government imperatives (economic; in this case market liberalisation) remained primary. A National Party government resulted in more unconventional actions, as without allies in government, protest became crucial for generating external support, although protests remained focused on issues rather than elections (O'Brien, 2012). Mainstream environmental issues have been incorporated by the government at the expense of movements (O'Brien, 2012). They are 'routinised', 'scientised' and made inaccessible to the public, which reduces the drama that enables mobilisation (Downes, 2000). With increased inclusion and complexity of issues, it has become harder to articulate clear positions in relation to the state (O’Brien, 2013b). Furthermore, while overt state exclusion enables movement unity, limited inclusion undermines it (Downes, 2000).

The environmental movements in Aotearoa have changed significantly since the 1960s (O'Brien, 2016). The scale, visibility, and significance of environmental movements reduced between the $1990 \mathrm{~s}$ and the 2010s due to a weakening support base, limited government action, institutionalisation and depoliticisation, and internal tensions (Bührs, 2003; O’Brien, 2012, 2013b). Movements split between institutionalisation (professionalisation), radicalisation, and involution (fragmentation, community groups - the dominant trend) (O'Brien, 2013b). There are a significant number of small, local, issue-based, grassroots groups with limited state access sitting in an 'outsider' position; they are more radical and public-focused (O'Brien, 2012). This growth 
in community-based groups meant movements were less visible but had latent mobilisation potential (O'Brien, 2013b). Additionally, the loose nature of movements enables actors to adapt their approach to each individual issue, maximising impact (O’Brien, 2016). However, involution presents a challenge to movement cohesion and the need to form connections and bonds of trust that can be utilised for broader causes (O'Brien, 2013b). Aotearoa's environmental movements are less centralised and professionalised than in parts of Europe and North America due to market liberalisation, strong connection to local groups, and devolution of decision making under the RMA (Downes, 2000). Many environmental groups have their base in Auckland (populationdriven) rather than Wellington (government-driven). Downes (2000) saw a localised approach as potentially enabling movements to reconnect to Māori, as demonstrated by Greenpeace in the 1990s, however, social and distributive justice still needed to be incorporated. Questions remain whether these movements are more fragmented or have simply taken on a new form to meet the current context (O'Brien, 2013b). While the environmental movements have become increasingly localised and small-scale, climate change protest is predominantly conducted nationally (O'Brien, 2016). This poses interesting challenges as the ability to shift between scales has been highlighted by O’Brien (2016) as important for sustainability and effectiveness.

This thesis treats the climate movements (and the emerging climate justice movements) as a continuation of the environmental movements due to the nature of the grievances, as well as the similarity and overlap in organisations, individuals, approaches, and tactics. Both the environmental and climate movements owe much to Te Ao Māori and the Indigenous movements, as demonstrated by the oil free movement, and have long been interconnected. While much of the literature notes the Save Manapōuri campaign as the beginning of environmental movements in Aotearoa, Māori had advocated for honouring the relationship to the environment since the colonisation of Aotearoa (Tina, interview, 12/08/2020). However, this is often neglected in the literature. The history of social and environmental movements in Aotearoa is foundational within this thesis, to understand the context that the emerging climate justice movements develop out of and continue to be linked to.

This thesis (this chapter in particular) follows a long history of the environmental movements of Aotearoa. Many key events have been detailed in this chapter. Here is a summary table of the 
events mentioned (note this list is not representative of all the key events in the environmental movements):

\section{Table 1: Timeline of key events in the environmental and climate movements of Aotearoa}

\begin{tabular}{|c|c|c|}
\hline Dates & Key events reference in 1.2 .2 and 1.3 .1 & Government of the time \\
\hline 1960 s-early & Conventional and conservation-focused & $1960-1972$ \\
\hline \multirow[t]{2}{*}{$1970 s$} & environmental movements emerge, including & National Government \\
\hline & international ENGOs. & \\
\hline 1969 & Save Manapouri campaign begins in Invercargill & \\
\hline \multirow[t]{2}{*}{1970} & Lake Manapouri petition launched, 264,907 & \\
\hline & signatures. & \\
\hline 1973 & Government 'concedes' to Save Manapouri & $1972-1975$ \\
\hline $1970 s$ & Focus shifts to native forest logging & Labour Government \\
\hline 1975 & Major protests against native forest logging & \\
\hline \multirow[t]{2}{*}{$1975-1977$} & The Maruia Declaration is circulated and submitted & 1975-1984 \\
\hline & to government with 341,160 signatures & National government \\
\hline 1985 & Major protests against native forest logging & $1984-1990$ \\
\hline 1986 & The West Coast Accord signed & Labour government \\
\hline \multirow[t]{2}{*}{$1990 s$} & Environmental movements struggle to be politically & 1990-1999 \\
\hline & influential & National Government \\
\hline 1991 & Resource Management Act 1991 introduced & \\
\hline \multirow[t]{2}{*}{ Late 1990s } & Movement revived on the West Coast by Native & \\
\hline & Forest Action & \\
\hline $1990 s-$ & Scale, visibility, and significance of environmental & 1999-2008 \\
\hline \multirow[t]{3}{*}{$2010 s$} & movements reduced. Involution or fragmentation is & Labour Government \\
\hline & the dominant trend. & $2008-2017$ \\
\hline & & National Government \\
\hline \multirow[t]{4}{*}{2019} & School Strike 4 Climate nation-wide marches: in & 2017-Present \\
\hline & March, approximately 20,000 students attended, and & Labour Government \\
\hline & in September approximately 170,000 people & \\
\hline & (students and non-students) attended. & \\
\hline
\end{tabular}




\subsection{Research overview}

\subsubsection{Justification and research questions}

Climate change is a global issue with wide-ranging and complex impacts. In Aotearoa, it impacts our everyday lives and the future of our society. The IPCC (among countless other experts) states that we have limited time left for our action to have a substantive impact on the outcome of climate change (Allen et al., 2018). As noted in the opening quote by Greenpeace, climate change is inevitable; nevertheless, we need to increase our efforts to ensure that how the change occurs is just and equitable.

Research is "a tool that can help us move forward" through improved understanding, finding workable solutions, evaluating success, and offering recommendations (O'Leary, 2017, p. 4). The aim of this research project is to support the movement towards climate justice in Aotearoa through understanding how climate justice is currently situated in Aotearoa. This work is underpinned by the questions:

"What is climate justice in Aotearoa, and how does it contribute to the advancement of radical, progressive societal change?"

Further, in this thesis I ask and answer:

\subsection{Who is involved?}

\subsection{What (theory of change) guides their approach?}

Theories of change are grand strategies that articulate the problem, the solution, long-term goals and the steps or conditions needed to achieve these goals (Hestres \& Hopke, 2020). These theories can illuminate underlying motivations, assumptions and potential impacts of movement actors and activities.

Through this research, a landscape of developing and contested climate justice movements emerges, often clashing with mainstream climate action movements. These tensions refine and shape climate action and climate justice. Relationality to each other and to the environment stands out as a vital component in a just climate change transition for our society. 


\subsubsection{Thesis outline}

This thesis began by providing an overview of the context of climate change and collective action in Aotearoa. In Chapter 2: Research Foundations, the thesis draws on two primary bodies of literature: Development Studies and Social Movement Studies (SMS), and outlines the methodological approach. While mainstream development approaches climate change through the sustainable development paradigm, this thesis builds on post- and critical development theories that critique the foundations of development as self-sustaining rather than sustaining the environment, and the inherent power relations within development (Shiva, 2010; Sidaway, 2014). Post-development focuses on the transformative potential of various alternative, bottom-up forms of development, such as social movements (Silvey \& Rankin, 2011; Veltmeyer \& Delgado Wise, 2018). This thesis utilises political process theory, the concept of collective identity from new social movement theory, and the emerging intersectionality theory to understand the contemporary climate action and climate justice movements. This research follows a social constructionist epistemology, recognising the social (and cultural) construction of knowledge and the existence of multiple truths. Utilising a qualitative methodological approach, data was collected through semi-structured, in-depth interviews with individuals involved with a variety of organisations, movements, and groups connected to climate justice, before being analysed using thematic analysis.

The next two chapters detail and discuss key themes identified in the data. Chapter 3 focuses on building a picture of the emerging climate justice movements in Aotearoa, describing climate justice communities and their origins, methods and practices. The contestations surrounding climate justice, and climate activism more broadly, are expanded in Chapter 4. This chapter highlights three key tensions (and catalysts for evolution) experienced by participants that exist throughout the climate movements (at times at the expense of climate justice): partisanship versus non-partisanship; internal conformity versus encouraging diversity; and the harmful reproduction of oppressive structures and ego at the expense of the movement ecosystem and frontline, marginalised climate justice communities.

The conclusion, Chapter 5, summarises the key findings of the thesis, outlining the way each of these chapters help answer the research questions, and then asks what it means for us. Why does it matter for us to pay close attention to climate justice movements? Throughout all themes and 
interviews, relationships stand out as a common element, particularly as we endeavour to move forward towards a more just movement and society. This research explores the variety of relationships encompassed by the climate justice and climate action movements, and how these shape the actualisation of a radical, progressive future.

\subsection{Conclusion}

The present day provides a unique opportunity for exploring the impacts of rapid and radical change within our society. Aotearoa's history of people power often reflects global trends, and contextual, cultural and local anomalies are not well explored in literature (Alakavuklar \& Dickson, 2016). With the effects of climate change being felt more, the need to understand how societal change occurs becomes more salient and pressing. Climate change impacts in Aotearoa are expected to mirror global trends, although the warming and precipitation changes will vary regionally, and the greatest sensitivities and risks surround the coastal concentration of population and infrastructure, unique ecosystem and reliance on global trade and relationships (Hopkins et al., 2015; Meduna, 2015; Reisinger et al., 2014; Renwick et al., 2016). The NZ government continues to frame its climate response within the $\mathrm{UN}$ frameworks and agreements yet received an 'insufficient' rating by the independent Climate Action Tracker.

Environmental movements developed during the 1960s and 1970s, and have ebbed and flowed since, impacted by major events, economic and political restructures, and ultimately the imperatives of the government of the time. Much of the contemporary actions and campaigns are focused on climate change, particularly offshore deep-sea oil extraction, but contemporary Indigenous movement efforts towards land reclamation, such as Ihumātao, are also frequently and overtly linked to environmental and climate justice. While Indigenous movements have a longer history, including concern over environmental degradation and violence, the nascent climate justice lens is bringing this to the mainstream.

This thesis is called 'Moving at the speed of trust' because trust is an essential component of successful climate justice. At present, the tensions experienced within and across the climate justice and climate action landscape, while crucial in shaping the development of collective identity, also present significant hurdles. In order to become fully-fledged and effective movements, Aotearoa climate justice requires a renewed focused on trust-based relationships and 
networks. Climate justice can only move at the speed of trust; failure to recognise this inevitably leads to the continuation of environmental degradation and political, social, economic and cultural inequality. 


\section{Chapter 2: Research foundations}

\subsection{Introduction}

This thesis aims to understand participant's perceptions of the structures and systems of our society, and their views on moving them towards alternative ways of living in order to mitigate and adapt to climate change. This requires a focus on the social institutions that govern human life, how they are made and reinforced, and how they can be changed. These processes are innately social and communal, and this has informed the research design. This thesis analyses societal change and draws on social movements and development as potentially complementary and conflicting mechanisms.

This research is grounded in an intersectional understanding of climate change and is influenced by a diverse and interconnected body of literature. Development is positioned in this thesis as the political, economic, social, and cultural vehicle of societal change through westernisation (McMichael, 2012). Under the pressure of climate change and ecological limits to development, it has 'evolved' to focus on sustainable development. However, sustainable development as the solution to climate change (and associated ills of development) is regarded by many as a fallacy (Sachs, 1999, 2010; Shiva, 2010). Post- and critical development theories are simultaneously critical of development while also acknowledging the need for development and therefore an alternative conception of development. Social movements are one such tool of societal change although they, unlike development theories and projects, are primarily grassroots or bottom-up. Social movement theory, particularly new social movements, collective identity and political process theory are drawn upon to understand the themes that were identified in the data.

\subsection{Development and climate change}

\subsubsection{Overview}

Part political ideology, and part ethics and morality, development is a programme of societal change formally constructed and promoted from the late 1940s (Desai \& Potter, 2014c). Development could also be understood as everything human civilisation has ever done or will ever do under the guise of improving the human condition (McMichael, 2012). Its origin and influence extend back to colonisation and imperialism, prior to its formalisation widely attributed to US 
President Harry Truman's speech in 1945, which coined the term 'undeveloped' and stated that a new era of post-imperialist international influence was upon us: the development era (McMichael, 2012; Sachs, 1999). Development Studies as a discipline developed from the 1940/50s onwards as a broad field that critiques and reshapes development theory (which then influences practice) (Potter, 2014). Social, political, and economic change is the focus and scope of Development Studies (Desai \& Potter, 2014b; Fforde, 2017). It tends to be normative, seeking to change the world rather than just analyse it (Desai \& Potter, 2014b).

Development theories and paradigms have evolved over time, shaped by the political hegemony of the time (Desai \& Potter, 2014c). It is ideological in that strategies are heavily influenced by political, economic, cultural, ethical, social, moral, and even religious norms (Potter, 2014). In its early days it was driven by right-wing stances, shaped by the classical economics of the 1700s that emphasised modernisation, comparative advantage, economic efficiency of global free trade, and capitalist strategies of economic development (Binns, 2014; Desai \& Potter, 2014c). Despite the multiple variations and 'rebrandings' there are core aspects and assumptions that are sustained throughout, largely focused on the supremacy of western economic ideologies (Sachs, 1999). Development is reliant on universalism and conformity, and requires othering (Power, 2014). Both it and Development Studies focus on the so-called 'undeveloped' or 'under-developed' nations and how they fare on the Western development path (Sachs, 1999). It is a set of idealised outcomes' to be emulated around the world, often through violent means justified by the ends (McMichael, 2012). The colonial nature of development is reflected in NZ's "inherited" influence over territories and countries in the Pacific, which continues in the present through development aid (Overton et al., 2019, p. 19).

Economic development and growth hold a central position in development. Potter (2014) notes that "both in theory and in practice, early perspectives on development were almost exclusively concerned with promoting economic growth" but argues that it now emphasises wider dimensions of change (p. 85). Development initially proposed a unilinear path of economic development based on the European experience, articulated in Rostow's stages of development, during the modernisation paradigm of the 1960s (Binns, 2014). While this theory was influential, it was also heavily criticised, particularly where it conflated economic growth with development (Binns, 2014). Development and economic growth are often (incorrectly) considered the same thing, 
embodied by the focus on production of goods, services, and income (Desai \& Potter, 2014b). It wasn't until the 1970s and 80s that economic growth was considered necessary but not sufficient alone, necessitating redistribution and incorporation of rights and welfare (Desai \& Potter, 2014b).

Competing critical theories of development from the 1960s onwards included neostructural approaches such as dependency theory, and alternative, bottom-up forms of development such as participatory development and Indigenous environmental knowledge. These critical alternatives emphasised the need to examine local constructions and conditions, histories, geographies, and sociocultural constructs, and to explicitly acknowledge Indigenous knowledge as valid (Briggs, 2014; Escobar, 1995). While Indigenous knowledge has been incorporated by some development agencies, it hasn't fundamentally challenged norms. Instead, Indigenous knowledge is seen as additional and providing context-specific solutions that are then integrated into Western sciencebased frameworks (Briggs, 2014).

Development is presently at a crisis and turning point, and has become more about surviving the future rather than improving on the past (McMichael, 2012). It has become normalised in modern discourse and is therefore difficult to rethink, and positive associations hard to shake despite the growing evidence of its negative outcomes (McMichael, 2012). Productivity and growth are likewise assumed to be positive, progressive and universal, despite the ecologically and socially destructive outcomes that are politically, spatially and temporally divided (Shiva, 2010). Development norms require critiquing and contrasting with alternative conceptions of societal change, such as climate justice. Considering how pervasive and wide-reaching development norms have become, understanding their origins and influence over government action is vital in identifying and addressing their impact.

\subsubsection{Sustainable development}

'Sustainable development' (SD) in research, policy, and discourse is often where development and climate change meet and is the current mainstream iteration of development. Anthropogenic climate change is the expected increase in temperature and extreme weather events, and the change in precipitation, as a result of greenhouse gas emissions from human activity (Pachauri et al., 2014). Climate change and development cannot be separated, as climate change is assuredly the result of decades of industrialised development that necessitates the burning of fossil fuels (Boyd, 
2014). SD has been centuries in the making but, with climate change as a call to SD, it has become a prominent focus of the UN (Matthew \& Hammill, 2009). SD history has three key periods; a pre1973 embryonic phase situated in the 'Global South' (particularly China and India); the 19721987 moulding phase; and the 1987-present developing phase (the last two have been dominated by the UN) (Shi et al., 2019). SD came into the mainstream with the 1987 Brundtland Report 'Our Common Future' and was central at the UNCED Earth Summit in Rio de Janeiro in 1992 (Desai \& Potter, 2014a; Elliot, 2016; Krueger, 2010; Matthew \& Hammill, 2009; Schreuder, 2010). Heavily influenced by the 'limits to growth' debate of the 1960s-1970s, SD recognises that the earth and its resources are finite (Schreuder, 2010). Industrialised countries had already included some form of environmental protection into their policies but the 'developing' world lacked the capacity and inclination to do so because of economic concerns (Schreuder, 2010). SD acknowledges that environmental concerns must also include matters of underlying poverty (Schreuder, 2010). It is about meeting the needs of the present and future, placing emphasis on inter-governmental cooperation, technology, and free market environmentalism (Schreuder, 2010). SD is embodied in the United Nations Sustainable Development Goals (UNSDGs), adopted in 2015. These are comprised of 17 goals and 169 sub-goals, and is a comprehensive and universal guide for the entire globe until 2030 (Sanneh, 2018; Shi et al., 2019). Shi et al. (2019) assert that SD has transformed the development paradigm. Whilst this is debateable, SD is the dominant discourse at present and is widely accepted geographically and sectorally (Carruthers, 2001).

While there is an assumption that SD global norms came from the North/West, with the South as a passive adopter, 'developing' countries and southern experts played a crucial role in the drafting of the UNSDGs (Fukuda-Parr \& Muchhala, 2020). These assumptions build on a long history in development of southern ideas being under-recognised and dismissed as too radical. Once adopted, credit is often given to westerners or western-trained southerners to provide legitimacy (FukudaParr \& Muchhala, 2020). SD emerged out of a challenge from southern intellectuals and governments that economic development and poverty were the result (not the source) of environmental degradation, and therefore environmental protection needed to encompass social equity (Fukuda-Parr \& Muchhala, 2020). This was a response to the aforementioned 'limits to growth' debates that suggested developing countries must accept some state of 'semidevelopment' and/or de-develop (Fukuda-Parr \& Muchhala, 2020). While the discourse and policies of SD are now detached from their origins, the practice of SD at the grassroots continues 
in earnest, embodied by the Indigenous and peasant ecological movements, ecological feminism, radical ecology, and post-development, bridging the gap between theory and practice (Carruthers, 2001).

However, environmental degradation continues and the inequality gap is growing (Klarin, 2018; Matthew \& Hammill, 2009). It is suggested that SD is oxymoronic, redundant, and vague (Matthew \& Hammill, 2009). It does not question the Western development model; it exists within, and premised on, the very same economic assumptions it initially opposed: that economic growth will equate to greater environmental care (Carruthers, 2001; Schreuder, 2010). The market-driven, non-radical nature of present-day SD is unsurprising given the influence and endorsement of private and public sector leaders, including transnational petrochemical companies at the centre of climate change (Elliot, 2016; Matthew \& Hammill, 2009). Misinterpretation of the theory in practice, and differing emphasis on intra-generational and inter-generational justice, is heavily influenced by the principles of groups and organisations rather than the original concept (Shi et al., 2019). Additionally, while the literature looks at the relationship between economy, environment, and social justice, mainstream analysis, concepts, policy, and practice overlook the crucial social justice element (Krueger, 2010; Matthew \& Hammill, 2009). As an apparently apolitical concept (co-opted by neoliberalism) SD cannot address the underlying issues of social organisation (Elliot, 2016). SD has lost its connection to the original environmental movements of the 1960s and 1970s that critiqued industrialised society (Carruthers, 2001; Elliot, 2016). It impedes the necessary reflexivity on the part of development as the root cause of climate change (Sachs, 1999). SD refers to the sustaining of development itself, not of nature, ensuring only the continued supply of raw materials for indefinite industrial production (Shiva, 2010). This demonstrates how development continually reinvents itself; as its destructive effects are recognised, the concept is expanded to be both the cause and the solution (Sachs, 2010). Nature is still viewed as a resource within SD, an approach that Shiva (2010) views as rooted in racist and sexist worldviews, with 'mother nature' as passive, manipulatable, exploitable, to be dominated by the Western patriarchy. SD sits comfortably within the development status quo and undermines radical, alternative approaches to climate change, necessitating a post-development approach. 


\subsubsection{Post- and critical development}

As evident from the above critiques of mainstream development paradigms, this thesis adheres to a post- and critical development approach. While development is an elusive and malleable word that can adapt to various approaches and needs, it remains a vehicle of Western ideological supremacy. It is both flexible yet inflexible to genuine transformation (Sachs, 2010; Shiva, 2010). Intrinsic to the project of development is the promotion of economic growth: that very process that produces and reproduces climate change, environmental degradation, economic inequality, and colonisation (Sachs, 1999). Post-development (PD) theory allows space for nuance and potential, with a variety of alternatives such as ecological swaraj, degrowth, buen vivir, common-ing, and food and energy sovereignty, attempting to transform the world towards a pluriverse where multiple concepts of the good life are possible simultaneously (Demaria \& Kothari, 2017).

PD arose in 1990s, driven by southern thinkers, writers and activists building on decades of development critique, while also dominated by middle-class and relatively affluent theorists (Carruthers, 2001; Sidaway, 2014). PD asks why development produces the opposite of what it claims, and why so called 'developed' nations have simultaneously excessive consumption and deprivation (Sidaway, 2014). PD states that development is always about power (Sidaway, 2014). Globalisation, the concentration and shift of power from national and local to global, is not natural, inevitable, and spontaneous, nor as politically or economically inclusive as it is depicted to be (Shiva, 1997). Neoliberal in nature, it removes limits on domination and destruction, enabling unelected and unaccountable corporations to run the world (Shiva, 1997).

Critiques and weaknesses of early PD highlighted that the need for development is not closed but should rather be refocused towards structural change to deal with inequality, injustice, and ecological collapse (Demaria \& Kothari, 2017). PD needs to move beyond critique, and towards focusing on alternatives, specifics, and narratives of those creating and retaining diverse ways of living (Demaria \& Kothari, 2017; Gibson-Graham, 2005; Sidaway, 2014). Gibson-Graham (2005) argue that post-development discourse can and should be "generative, experimental, uncertain, hopeful, and yet fully grounded in an understanding of the material and discursive violence and promises of the long history of development interventions" (p. 6). They practice this through a focus on diverse economies; the non-capitalist, relational exchanges that occur in communities (Gibson-Graham, 2005). PD acknowledges the counter-hegemonic and 
often ancient worldviews resurfacing that introduce other goals, values, ethics, practices, and imaginaries (Demaria \& Kothari, 2017). These worldviews, often coming from traditionally marginalised groups, differ in the context and diagnosis but recommend a common treatment: transformation of the structural roots of development beyond false solutions (Demaria \& Kothari, 2017). PD is a transformative agenda for activists, and alternatives are becoming more numerous, varied, known, credible, and viable, but are still marginal to the dominant paradigm (Demaria \& Kothari, 2017). However, Gibson-Graham (2005) argue that focusing on development alternatives within scholarship can increase their credibility.

Critical development studies is about transformative change and alternative development, including sustainability and the environment (Veltmeyer \& Delgado Wise, 2018). Heavily influenced by Esteva, Rist, Latouche and Escobar, it is critical of mainstream theories, including the very notion of development (Gudynas, 2017). It identifies the nature and history of development as violent, exclusionary, and co-optive, especially surrounding sustainability, participation, and gender (Silvey \& Rankin, 2011; Veltmeyer \& Delgado Wise, 2018). Critical Development counters this by presenting the systemic changes required to migrate to an alternative anti-capitalist system that prioritises social justice and environmental integrity (Veltmeyer \& Delgado Wise, 2018). Critical development challenges the North/South hierarchical and racialised framing of development and includes those previously excluded (Silvey \& Rankin, 2011). Therefore, it provides a space to acknowledge and focus on 'development problems' within the 'Global North' through a critique of neoliberalism, capitalism, and imperialism. Critical Development acknowledges the need to contextualise theory in the real world by paying attention to the formation of anti-capitalist social movements to bring about social change (Veltmeyer \& Delgado Wise, 2018). Social movements can be a tool of Critical Development, providing alternative ways to measure and make value, reject reductionist logic, and define politics beyond the state and markets, allowing space for complexity and political participation (Silvey \& Rankin, 2011). Through Critical Development and PD research, activism and academia can collaboratively create new ways forward. 


\subsection{Social movements}

\subsubsection{Overview}

Social movements are a "powerful human resource" that can lead to societal changes and transformations (Almeida, 2019a, p. 1). Movements, collectives and informal networks, utilise conventional (letters and petitions) and unconventional (marches, sit-ins, and demonstrations) strategies to challenge power and authority (Almeida, 2019a; della Porta \& Diani, 2015; Ilișanu \& Andrei, 2019). They are also involved in the collective and direct production of goods, alternative lifestyles, and service delivery in place of state or mainstream options (della Porta \& Diani, 2015). Movement actors are usually volunteers who are excluded from institutional, economic, and political power (Almeida, 2019a). Social Movement Organisations (SMOs) develop within or from a movement to support continued mobilization, often spreading transnationally (Almeida, 2019a). Many theorists exclude lobby associations, NGOs, and political parties from analysis, even though they are noted as sometimes originating from movements (Almeida, 2019a).

Social Movement Studies (SMS) began in the 1960s in North America and Europe, focusing on relationships, patterns of social conflict, cultural representations, rationality, and political and institutional context as it relates to movement development (della Porta \& Diani, 2015). Research on social movements looks at: how, why, and where movements occur; the actors, narratives, goals and identities involved; and the impact their collective actions have on politics or society more broadly (Ilișanu \& Andrei, 2019). SMS theories are conceptual frameworks for understanding the emergence, ideology, networks, recruitment, and outcomes of movements (Almeida, 2019a). This thesis utilises political process theory, collective identity from new social movement theory (NSM theory), and intersectionality to understand the climate justice articulation and mobilisation in Aotearoa.

Intersectionality, coined by Kimberlé Crenshaw in the late 1980s through her work on the employment experiences of Black women and the violence against women of colour in America, acknowledges that people's circumstances are shaped by multiple dimensions of their identity, for example, race and gender (Crenshaw, 1991; Phoenix \& Pattynama, 2006). Rather than being purely 'additional', such as the forms of oppression of race plus the forms of oppression of gender, intersectionality theory highlights the ways in which these dimensions and oppressions intersect 
to create new forms of oppression. It acknowledges the problems with identity politics, focusing on intergroup difference and ignoring intragroup difference; difference within groups that causes tensions (Crenshaw, 1991).

Many have noted that SMS has essentially ignored capitalism in recent decades, especially in the US (which has shaped much of the discipline), and that it needs to be re-integrated into analysis (della Porta, 2017; Hetland \& Goodwin, 2013; Taylor \& Grey, 2014). This was tied to the assumption that because materialist issues were not paramount to NSMs, they were no longer relevant (Hetland \& Goodwin, 2013). Capitalism remains important for movements, as it (Hetland \& Goodwin, 2013):

1. inhibits or facilitates collective identity and solidarity formation,

2. distributes power across classes, shaping movement evolution and outcomes,

3. creates class divisions that could fracture movements, and

4. influences movement strategies and goals through capitalist ideologies and norms

Della Porta (2017) noted that SMS theories, including NSM theory, needed to be updated in order to understand contemporary movements and contentions, particularly within a neoliberal capitalist context. Additionally, classical mobilising structures and resources (unions, NGOs, SMOs) previously used have been weakened or destroyed by neoliberalism (della Porta, 2017). Instead, movements utilise few resources and have heterogenous collective identities, and classical Marxism (on which SMS was formed) doesn't allow for the multiplicity of concerns and conflicts within current movements (della Porta, 2017). In this thesis, I contribute to SMS theories by pushing the conceptual boundaries to exhibit the way in which the emerging climate justice movement experiences opportunities and threats, negotiates collective identity, and formulates theory and strategy. These processes are related to and influence each other.

\subsubsection{New social movements}

Since the 1970s, a wider variety of movements have mobilised that do not fit the traditional definition of movements based on economic and material claims (Almeida, 2019a). Instead, these movements developed under "the changing configuration of capitalism" where exclusion occurs in many different contexts (Almeida, 2019a; Hetland \& Goodwin, 2013, p. 92). New social movement (NSM) theory is a framework developed for looking at new 'grievances', including 
environmentalism, LGBTQI+, feminism, disability, and cultural and ethnic identity, that have developed since the 1970s in response to macro-changes within society (Almeida, 2019a; della Porta \& Diani, 2015; Hourigan, 2001). NSM theory is post-Marxist and post-materialist, moving past social or class conflict to matters of minorities, identity, political participation, autonomy, beliefs, values, lifestyles, quality of life, and personal growth rather than economic redistribution (Almeida, 2019a; Hetland \& Goodwin, 2013; Ilișanu \& Andrei, 2019). NSMs involve new kinds of collective identities as mediators of understanding, perceiving and responding to structural conditions (Almeida, 2019a; Benski et al., 2013). They mobilise outside traditional cleavages of party and class, across a variety of sectors and groups, and are decentralised and participatory (Almeida, 2019a; della Porta \& Diani, 2015). Additionally, these movements are not generally led by the older generations of activists, and are highly self-reflective (Benski et al., 2013). Elements of NSM theory such as values, beliefs, collective identity as well as intersectionality have all proven relevant in this research.

\subsubsection{Political process theory}

Political process theory analyses the context in which movements operate, both politically and institutionally (della Porta \& Diani, 2015; Meyer, 2004). External resources and opportunities can enable, stimulate or inhibit mobilisation, participation, claims, alliances, strategies and tactics, and they directly impact mainstream politics and policy (Almeida, 2019a; Ilișanu \& Andrei, 2019; Meyer, 2004). Political process theory is the dominant and most influential theory in contemporary SMS, although there is no singular paradigm or theory that can account for the different elements in current movements (Almeida, 2019a; Benski et al., 2013). Developed in the 1960s, it can include political opportunity, political threat, resource mobilisation, and framing theories within the same analytical framework (Almeida, 2019a; Karampampas et al., 2020). Political process theory states that movements are most likely to emerge when a collective comes under threat and it is apparent that the situation will become worse or the collective will lose collective goods if they do not act, or, conversely, when a collective receives signals that there is opportunity for advancement, all of which is often triggered by government policies (Almeida, 2019a; Tarrow, 2011). Threats can come in the form of economic problems, environmental or public health threats, erosion of rights, or state repression (Almeida, 2018, 2019a; Tarrow, 2011). Examples of opportunities include institutional access (substantive or symbolic), elite conflict (instability, potential allies), changing 
political alignments of the general public (often during elections), relaxation of repression, and diverging centres of power (multiple options for leverage) (Almeida, 2019a; della Porta \& Diani, 2015; Tarrow, 2011). This theory analyses the way social movements and states interact, with both having the ability to shape and influence the other (Almeida, 2019a). While initially the focus was on the state, more recent scholarship in political process theory has included multi-institutional theory (Almeida, 2019a). Collective action can also inspire, and create opportunities for, other movements/issues, as well as trigger counter-movements and create opportunities for opponents (Benski et al., 2013; Tarrow, 2011).

Opportunities and threats are more complicated than some explanations of political process theory suggest, as perceptions of opportunities and threats also influence movement dynamics (Meyer \& Minkoff, 2004; Suh, 2001; Tarrow, 2011). Opportunities and threats are filtered through participants' perceptions towards a subjective conclusion (often inaccurate) that the movement will be promoted or obstructed (Suh, 2001). Additionally, movements can mobilise under contracting and expanding opportunities alike (Suh, 2001). Furthermore, all regime change comes from changes in opportunities and threats, but not all opportunities or threat changes result in regime change (Tarrow, 2011). The theory is not without its weaknesses; lacking uniform conceptualisation, giving mixed results, being too broad, neglecting agency, being static and unidirectional, and ignoring transnational trends (Goodwin \& Rojas, 2015; Meyer, 2004; Meyer \& Minkoff, 2004; Tarrow, 2011). Despite these weaknesses, this theory remains a useful theoretical tool within this research as political process, resources, opportunity, and threats closely aligned with the way in which participants (and literature) talked about the development of the movement.

\subsubsection{Environmental, climate action and climate justice movements}

Climate activism and climate justice, as both environmental and social movements, are increasingly addressed in SMS literature, which is woven throughout this thesis. Climate justice, potentially the most extensive transnational movements ever, gained momentum in 2000, utilising social media to coordinate across the globe, with public demonstrations often coinciding with UN climate summits (Almeida, 2019a). Many have called for radical social transformation to avoid climate change, including scientists, activists, and scholars, and Stuart et al. (2020) argue that the IPCC 2018 report "calling for 'rapid, far-reaching and unprecedented changes in all aspects of 
society" triggered the unprecedented global mobilisation that we experienced between 2018-2019 (p. 434). Almeida (2019) claims that sustained mobilisations (including on climate justice) have resulted in deep changes within society, however, this is debatable. While politicians have occasionally "backpedal[ed]" in response to these movements, as observed in 2020 these actions are neither sufficient, sustained, nor guaranteed (Almeida, 2019a, p. 5). Nevertheless, Almeida (2019b) asserts that future sustained progressive movement is likely to centre around climate justice.

The most intense and enduring mobilisations occurred in the 2000s, although large environmental campaigns had become increasingly rare in Aotearoa (and other Western democracies) since then (Bond et al., 2015; Tucker, 2013). Elements of political process theory have been utilised to understand environmental, climate, and climate justice movements and mobilisations in Aotearoa. O'Brien (2017) utilised protest event analysis to understand how political opportunities and threats were shaped by electoral politics, noting that the orientation of the governing body is important, with National Party leadership corresponding to closed opportunities, increased action, and sustained national campaigns. The National Party government and industry attempts to shut down deep-sea oil resistance paradoxically mobilised people (Bond et al., 2019). Conversely, a Labour Government previously entailed local scale action across a broad range of issues (O'Brien, 2017). Furthermore, despite their non-violent kaupapa during the fossil fuel divestment campaign, climate action and climate justice activists received a violent response from the public at the encouragement of the police (Diprose et al., 2017). Despite being issue-driven, the range and intensity of environmental protest in Aotearoa is shaped by political opportunities and threats (O’Brien, 2017).

NSM theory, through framing, collective identity, and networks, has also enabled a deeper understanding of the context of environmental and climate movements in Aotearoa. Diprose et al. (2016) examined the deep-sea oil exploration and drilling movement in Aotearoa to understand how to mobilise a critical mass demanding socio-political change. The use of national identity in narratives - eco-nationalism - was utilised to incorporate everyday New Zealanders into the climate change movement (Diprose et al., 2016). The movement also questioned 'business as usual' in their framing, and positioned themselves in direct conflict with state (Diprose et al., 2016). Tucker (2013) examined meaning making within the anti-genetic engineering movement 
core network, noting the relationship between collective identity and movement diversity in grievances, relationships, and strategies. Collective identity is fluid and flexible, necessary for incorporating multiplicity in actors, organisations, tactical preferences, and positions (Tucker, 2011, 2013). Pre-existing networks, Māori, organic communities, and environmental lobbies, were important in the early-stage formation, followed by the emergence of new groups (Tucker, 2013).

This body of literature confirms that political process, collective identity, diversity, and networks are relevant theories and concepts in relation to environmental and climate movements in Aotearoa. This thesis incorporates existing academic research on these movements into an analysis of climate justice as the contemporary expression of these movements.

\subsection{Theoretical framework}

The above body of literature is utilised to develop a theoretical framework to guide this research: a post-development approach to climate change that, through critical development, positions social movements as an alternative to development. In addition to the theoretical concepts outlined above (political process theory and NSM theory), structuration, a sociological concept, is also incorporated to enable an examination of the duality of structure and agency that plays out in development, social movements, and climate change (Gibbs, 2017). Structures influence the actions individuals take, which, in turn, reinforce or shape those structures (Gibbs, 2017). Structuration is a conceptual framework for analysing the way in which structures constrain behaviour, and how behaviour creates those structures (Phipps, 2010). It highlights the importance of context, the surrounding social and historical forces, from which social actions cannot be separated (Haslett, 2013). In the development and expression of climate justice in Aotearoa, this research shows that the overarching structures and norms of society (often negatively) influence movement relationships, actions, and strategy. However, participants as movement actors, while aware of the constraining and pervasive nature of structure, continue to visualise and exert alternative modes of relating to each other and the world around them, demonstrating the power of agency in the construction of structures and norms.

\subsection{Epistemological foundation}

Arising in the 1980 s and multidisciplinary in nature, social constructionism is critical of taken-forgranted knowledge (Burr, 2015; Hosking \& Bass, 2001; O’Leary, 2017). A social constructionist 
epistemology views knowledge (and truth) as produced or generated within human relationships and social processes that are historically and culturally situated (Gergen \& Gergen, 2012). All cultural and social reality, values, and actions are products of these social practices, whether deliberately constructed or not (Segre, 2016). Due to the historical and culturally specific nature of knowledge, social constructionism posits that there is no single truth, and that acknowledging the link between knowledge and social action also involves understanding the power relations that knowledge is bound in (Burr, 2015). Dominant 'truths' are agreed to and upheld by the community they belong to, and when truths are assumed to be universal, they undermine alternative conceptions across other communities and periods (Gergen \& Gergen, 2012). Therefore, participant knowledge is equally valid, and collaborative forms of inquiry are encouraged (Burr, 2015; O'Leary, 2017).

Knowledge is also socially distributed according to relevance (Segre, 2016). Likewise, scientific knowledge is socially interested and constructed, expanding the scope of belief systems by applying them to new cases, justified among peers (Weinberg, 2014). Knowledge is not detached nor disinterested; claiming so masks the influence of political and economic power (Weinberg, 2014). Objectivity is impossible, as all humans, including researchers, perceive the world through our perspective, influencing approaches, theories, and assumptions (O'Leary, 2017). We can't step outside of this part of our human-ness, even temporarily, as the concept of objectivity suggests (O'Leary, 2017). Therefore, social constructionism does not prioritise a particular methodology or methods, as neither guarantees objective knowledge, but rather reinforces and conforms to the practices of a community (Gergen \& Gergen, 2012). Social constructionism also requires a focus on the researcher's relationships with participants, audience, and society, through acknowledging the exploitative and alienating tendency of research towards the researched (Gergen \& Gergen, 2012). The use of collaborative writing and other accessible outputs can counter this by appealing to a wider audience, sharing the outputs beyond the community of academia (Gergen \& Gergen, 2012). Gergen \& Gergen (2012) also note that researchers must remember that research should serve the cultures or societies that it originated in, with the pressing concerns of society as the catalyst for research. Following the completion of this thesis, a report or zine will be co-constructed with interested participants in order to feed back the findings to the movement in a more accessible format. 
A 'soft' constructionist approach is utilised in this research, applying it to social systems, institutions, processes, and structures rather than 'brute' or natural 'facts' (Gergen \& Gergen, 2012). This epistemological framing has been selected for this research, as it promotes challenging oppressive organisations and discourses (particularly the limits of tradition) and encourages the collective creation of alternative futures (Gergen \& Gergen, 2012).

\subsection{Methodological approach}

As noted above, this thesis adopts the view that there are multiple truths, therefore different approaches and types of evidence can enable the social world to be understood in multiple ways, each valid for its own purpose (della Porta, 2014b). Qualitative methodologies can incorporate complexity and uncertainty across multiple, constructed, and subjective truths (O’Leary, 2017). This approach was chosen given the ambiguity and complexity of the subject matter, acknowledging the interplay between the researcher and the object of research (della Porta, 2014b). Qualitative research design is flexible and can be emergent, inductive or reductive, organic, and intuitive, allowing new concepts to emerge (della Porta, 2014b; O'Leary, 2017). It also enables exploring the depth of the opinions, experiences, and beliefs of a select community through utilising rich data, facilitating an intimate understanding while keeping the bigger picture in focus (O'Leary, 2017). Qualitative research seeks to explain and understand, although findings are context-bound and non-generalisable (della Porta, 2014b). It does not avoid politics, and does acknowledge the power relations in research, as well as social complexities (O'Leary, 2017).

A qualitative approach enables 'co-construction' of data between participants and the researcher (Kleres \& Wettergren, 2017), which is central to the purpose and epistemological approach of this research. Co-enquiry or co-construction sees the researcher working with participants rather than researching on or about them, often through an iterative process of action and reflection (Heron \& Reason, 2011). In co-enquiry, participants are engaged in the design and management, and sensemaking (Heron, 2014; Heron \& Reason, 2011). 


\subsection{Methods}

\subsubsection{Data collection: semi-structured, in-depth interviews}

Sixteen semi-structured, in-depth interviews with seventeen change 'actors' and 'experts' were conducted as the primary form of data collection for this research. Interviews can be deductive and inductive, flexible and open; they can clarify existing theories and generate new ones (della Porta, 2014a). They are useful for understanding events or issues that are not well-documented in media or historical archives, such as local grassroots movements (della Porta, 2014a).

Originally all interviews were to be conducted in person, however, the reality of COVID-19 required a mixture of online (via Zoom) and in-person. Interviews were approximately 40-120 minutes long and were recorded, then transcribed. In-depth interviews require trust and intimacy for the mutual disclosure that takes place (J. M. Johnson \& Rowlands, 2014). Reciprocity is important in building rapport, enabling participants to share deeply personal information (J. M. Johnson \& Rowlands, 2014). Informal conversational language and awareness of setting is important for acknowledging power and building relationships (della Porta, 2014a). While videoconferencing technology can be useful it can also impede the development of trust (della Porta, 2014a). I conducted the interviews in a conversational style to both facilitate rapport and trust in a remote setting and to enable the participants to exert agency over the content and direction of the conversation. The flexibility of this method was useful, as each interview required adjustments in approach, incorporating participant capacity, comfort and prior knowledge. All interviews, however, covered the same core elements to be explored by the research.

In-depth interviews enable researchers to gather rich personal data on ideologies, attitudes, motivations, emotions, behaviours, thoughts, observations, identities, perceptions, and ethics of movement actors (della Porta, 2014a; Ilișanu \& Andrei, 2019; Morris, 2018). These areas are where collective action arises from (della Porta, 2014a). The interviews, guided by the thesis research questions, elicited opinions, beliefs, perceptions, and experiences of the participants. An interview guide containing predetermined (but not prescriptive) open-ended questions or themes is often utilised and enables unforeseen topics to be explored (Almeida, 2019a; Ayres, 2012; della Porta, 2014a). In this research, prior knowledge, literature review, and participant selection 
research were used to develop an interview guide that followed the structure of the core research questions.

Semi-structured, in-depth interviews enable the participants to be actively involved in the construction of data, with some agency over what is gathered and analysed (Almeida, 2019a; Ayres, 2012; della Porta, 2014a). A co-enquiry approach influenced the structure and way the interviews were conducted, acknowledging that the researcher is not the knowledge holder. Interviews enable movement actors to provide detail, meaning, and authenticity on the movement; likewise, only through speaking to those impacted are researchers able to document microoppressions (Almeida, 2019a; Stone, 2015). The semi-structured nature enables versatility, balancing control and agency between researcher and participants, enabling the researcher to follow up and probe as required, and allowing the participant to include what they think is important (Cook, 2012; Morris, 2018). 


\section{Table 1: Participant list (in order of interview)}

Participant identification as specified on consent form

Abbreviation in

thesis

\begin{tabular}{|c|c|c|}
\hline 1 & $\begin{array}{l}\text { Melanie Vautier, Co-Founder of Te Upoko o te Ika (TUI) Climate } \\
\text { Community }\end{array}$ & Mel \\
\hline 2 & $\begin{array}{l}\text { Member of Extinction Rebellion (XR) Te Whanganui-a- } \\
\text { Tara/Wellington }\end{array}$ & $\mathrm{XR}$ \\
\hline 3 & $\begin{array}{l}\text { Chlöe Swarbrick, Member of Parliament for Green Party of Aotearoa } \\
\text { New Zealand }\end{array}$ & Chlöe \\
\hline 4 & $\begin{array}{l}\text { Sophie Handford, School Strike } 4 \text { Climate (SS4C) NZ Co- } \\
\text { ordinator/Founder and Kapiti Coast District Councillor }\end{array}$ & Sophie \\
\hline 5 & Tina Ngata, Indigenous Researcher and Scholar & Tina \\
\hline 6 & Jennifer Pannell, Organiser at System Change Aotearoa (SCA) & Jen \\
\hline 7 & Joseph Carolan, Organiser at System Change Aotearoa (SCA) & Joe \\
\hline 8 & $\begin{array}{l}\text { Alicia Hall, Founder of Parents for Climate Aotearoa (PfCA) } \\
\text { (formerly Millions of Mothers) }\end{array}$ & Alicia \\
\hline 9 & Nicky Hager, Investigative Journalist & Nicky \\
\hline 10 & Climate Campaigner at Greenpeace New Zealand & Greenpeace \\
\hline 11 & Tamatha Paul, Wellington City Councillor & Tamatha \\
\hline 12 & Co-Director of 350 Aotearoa & 350 \\
\hline 13 & $\begin{array}{l}\text { Lourdes Vano, Candidate for Manurewa, for Green Party of } \\
\text { Aotearoa New Zealand }\end{array}$ & Lourdes \\
\hline 14 & Jason Boberg, Co-Founder of Sustained Ability & Jason \\
\hline 15 & $\begin{array}{l}\text { Lesley Young, Yearly Meeting Clerk of Religious Society of Friends } \\
\text { (Quakers) Aotearoa NZ }\end{array}$ & Lesley \\
\hline 16 & Conor Twyford, Long-time Union and Community Campaigner & Conor \\
\hline 17 & $\begin{array}{l}\text { Kera Sherwood-O'Regan, Indigenous Rights Lead of Sustained } \\
\text { Ability }\end{array}$ & Kera \\
\hline
\end{tabular}




\section{Participant selection and recruitment}

Purposive sampling, where participants are intentionally sought based on specific characteristics according to the research topic, was employed in this research (Morse, 2011). This method was relevant, as there is a particular subset of New Zealanders that are the knowledge holders of the target information. Guided by della Porta's (2014a) experience of SMS research, participants were selected on a conceptual basis according to relevance and interest to climate justice, as well as the more practical basis of capacity. Participants are activists or advocates involved in radical, progressive (left-wing) societal change, with a particular focus on climate change. However, the scope also includes social justice, decolonisation, and constitutional reform as these areas are interconnected within climate justice. Participants were often members or representatives of an organisation or movement or an individual who advocates or had expertise that they shared online or in connection with multiple movements/organisations. In most cases, only one individual was interviewed from each, in order to provide breadth across the sector.

Potential participants and organisations were identified via online research and talking to friends who are involved in this work, particularly looking at the network built by Te Upoko o Te Ika (TUI) climate community. An initial map of relevant actors was developed based on prior researcher knowledge, Google searches, attending relevant events, and word-of-mouth discussions to identify key organisations, movements, and individuals within this space. However, as recognised within SMS research, knowing and finding contact information for specific people across movements is difficult (della Porta, 2014b). Snowballing proved useful here, involving building a participant list through iterative referrals from existing participants (O'Leary, 2017). Snowballing is particularly relevant for the study of movements as, at their core, they are networks of relationships, people and organisations. As a fringe member of this movement myself, I actively utilised common acquaintances or events (such as Otaki Summer Camp) to build connections. Pilot interviews can be useful to test the approach, guide, and assumptions, and it is useful to start with participants the researcher already knows (della Porta, 2014a). My first interview was with a fellow thesis student and friend who I knew was highly involved and connected within the climate movement in Wellington. As both someone known to me, and a thesis student, Mel was able to provide feedback on the interview guide and approach, as well as refer me on to future participants, starting the snowball part of my recruitment process. 
Part way through the interviews, I realised my participant base was predominantly Pākehā and represented large, mainstream climate action movement players rather than climate justice activists and communities. Subsequently I adjusted my approach to seek out the diversity within climate justice movements, including 'potential extremes' that could break theories. Despite the holistic and broach approach applied within this research to understand the landscape of climate movements there are several limitations of this thesis. Limited by my understanding, time, and capacity I was unable to incorporate all possible climate justice perspectives within Aotearoa. Additionally, my initial focus was on those within the 'change' sector who acknowledge the structural and systemic causes of climate change and inequality and are actively working towards changing or outright dismantling these structures and systems. It was not until near the end of the ethics process that I realised, through the literature and guidance of my supervisors, that this was climate justice. Therefore, this thesis only pays brief attention to class, LGBTQI+ and genderbased perspectives within climate justice (this is explained further in the definition and description section of chapter 3). Additionally, Indigenous in/justice is often the primary focus of discussions on racism within this thesis as a reflection of participants' comments and its central place in climate justice in Aotearoa. I also focus on theories of change and associated tensions and strategic dilemmas, rather than tactical or everyday choices of the movement.

\section{Pre-engagement}

Consultation with members of the relevant sector as potential participants was desired to gauge interest and brainstorm potential focal points of the research. This included several meetings with Action Station and attending an XR workshop in 2019 and informal discussion with Mel from TUI in early 2020. Additionally, pre-engagement with mana whenua was conducted for similar reasons, as well as to uphold my responsibilities of partnership with Māori under Te Tiriti o Waitangi as a Pākehā researcher in Aotearoa. Potential participants who are tangata whenua were contacted during the ethics approval process to seek their opinion on the proposed research design and focus. Only two responded and neither had any concerns. Given the relative inexperience of the researcher, and lack of understanding around the process of consultation prior to ethics approval, this consultation was not as thorough as it should have been for a co-inquiry research approach. However, the semi-structured nature of the interview and snowballing were put in place to continue this mutual conversation towards the research focus and findings. 


\subsubsection{Data analysis: thematic analysis}

Thematic Analysis (TA) is a theoretically flexible, creative and accessible qualitative data analysis method that identifies, analyses, and reports on themes and patterns across a data set (Braun \& Clarke, 2006; Castleberry \& Nolen, 2018; Terry et al., 2017). It is a foundational qualitative method involving core skills, and is well suited to early career researchers, as it does not require the same level of theoretical and technical knowledge that other methods do (Braun \& Clarke, 2006; Nowell et al., 2017; Terry et al., 2017). TA was chosen as a suitable analysis method given the focus on patterns of ideologies, concepts, and approaches within the change sector, fitting both the scope and intent of the research. TA is useful for examining perspectives and highlighting differences and similarities within a large data set (Lapadat, 2012; Nowell et al., 2017). A social constructionist approach to TA examines the effect that societal discourses, sociocultural contexts, and structural conditions have on accounts that participants provide (Braun \& Clarke, 2006). TA can be inductive (bottom-up and data-driven) or deductive (top-down, theory-driven); and semantic (explicit, surface meanings) or latent (underlying, implicit assumptions that inform the semantic layer) (Braun \& Clarke, 2006; Lapadat, 2012; Terry et al., 2017). As an early career researcher, coding began semantically and became more latent through my immersion in the data (Terry et al., 2017). The data was coded primarily inductively, making the process subjective, organic, flexible and iterative (Terry et al., 2017). There are various approaches to 'coding reliability', however, within qualitative methodology there is no single truth or way to analyse the data; therefore, accuracy is not applicable, rather, reflection demonstrates quality (Terry et al., 2017).

Six key phases were followed in the analysis of the research data based on the work of established social science scholars (Braun \& Clarke, 2006; Nowell et al., 2017; Terry et al., 2017):

1. Become familiar with the data - transcribe, read, note initial ideas

2. Generate initial codes - code data systematically, collate all data relevant to each code

3. Identify themes - sort codes into potential themes

4. Review themes - map out themes, aim for coherent, consistent, and distinctive

5. Define and name themes - ongoing analysis and refinement of themes

6. Produce report - select extracts to support chosen themes, relate themes and analysis to the research question and literature 
NVivo was used to help identify themes and organise the large data set. However, manual coding within NVivo was principally used and there were often overlaps in coding due to the deeply interconnected nature of this topic. Codes are features within the data - the most basic segment or element, which can form themes (Braun \& Clarke, 2006). Themes or patterns capture something important within and about the data, prioritised in relation to their 'keyness' to the research questions rather than just prevalence in terms of number of different speakers or individual occurrences within the data set (Braun \& Clarke, 2006). This flexibility in selecting themes is particularly useful for research on under-researched areas or where views are not well known (Braun \& Clarke, 2006). I prioritised transcripts and themes based on connection to climate justice frontline communities and principles; this fits within the 'keyness' to research questions approach to prevalence. This research can be a platform to amplify frontline community perspectives and highlight the tensions they experience. Non-frontline community interviews provide context, and sometimes examples, confirmation, or denial of the above tensions. In terms of excerpts chosen for the thesis I attempted to strike a balance between incorporating as many different perspectives as I could, including each participant that had spoken on a theme or subtheme present. I ensured that I centred frontline communities and incorporated the excerpts that either best embodied the subtheme or offered unique insight. Excerpts have also been edited down; as much context has been left in as feasible or paraphrased.

\subsection{Ethics and consent}

This research was approved by the Victoria University of Wellington Human Ethics Committee (application \#28570). Much of this application has been incorporated into the methodology section of this chapter. Other key components include:

- Informed consent was sought prior to conducting the interviews.

- I have been involved with various events and organisations connected to social, environmental and climate movements over the last five years. During this time and through events attended during the research I met several of my participants. It was made clear that they could decline to participate, and that there was no expectation on them to participate.

- Due to the nature of interviews, there was not an option for participants to remain anonymous. However, there was the option for participation to be completely or partially 
(selected comments) confidential to the researcher. The level of identification was informed by the participant's comfort with being named in the research and could be reviewed at the time of transcript review. Additionally, individual comments or sections were de-identified at the participant's request and, when used in the thesis, have been attributed as such.

\subsection{Positionality}

The circumstances in which knowledge is produced shapes that knowledge, and this includes the researcher's knowledge (Rose, 1997). Reflexivity by the researcher "of the researcher, the researched ${ }^{6}$ and the research context" is important in acknowledging that power and knowledge is contextual, partial, and subjective (Rose, 1997, p. 305). Coming from a social constructionist epistemology, the knowledge produced as part of this thesis is a cooperative and social process between myself, and the participants I interviewed. My background, upbringing, and values influence the ontological position from which I conduct the research, impacting the choices I make.

Given the political nature of the research topic, it should be noted that I am an economically left and socially liberal environmentalist. Previously, I have been a member of the Green Party of Aotearoa New Zealand (including holding the volunteer position of Secretary of the Wellington Central Branch in 2018). I have been very careful in applying my critical thinking lens and to not concede to reductive ideological biases in my research or writing. My positionality gave me access to people but was also a source of potential conflicts of interest with several participants (and organisations). All through the research process I have been extremely cautious to not let my personal background impact the research output, other than in the choice of topics. My relative inexperience in areas of academia and social (and environmental) justice has also shaped my research approach.

As this research is set in Aotearoa, and given the cultural (and historical) aspects of climate justice, it should be noted that I am Pākehā. I was born and raised in Te Ika a Māui (North Island), Aotearoa, primarily within Ōtaki and Whakaoriori (Masterton), and then briefly Tāmaki-makaurau (Auckland) and primarily Pōneke (Wellington) as an adult. My ancestry is English, Pākehā (New Zealand European), Scottish, Irish, and to a lesser extent, American (United States of

\footnotetext{
${ }^{6}$ Research participants or subjects.
} 
America), Australian and Spanish. Additionally, and connected to my ethnicity, I am middle class and, as a result of this privilege, I have achieved higher education. I am also a cisgender female who engages with intersectional feminism.

As a Pākehā researcher undertaking research within Aotearoa, it was important and fundamentally necessary for me to engage with scholarship that explores the way in which research is conducted within Aotearoa, and what roles and responsibilities Tauiwi Pākehā have. Tolich (2002) observed Pākehā early researchers and students being educated to avoid and exclude Māori from their research samples to avoid cultural issues, resulting in a "Pākehā Paralysis" (p. 164). However, in excluding Māori from general population research, researchers fail to 'cause no harm' within research ethics, and they neglect responsibilities under Te Tiriti o Waitangi to partner and protect (Tolich, 2002). Came (2013) notes that: "All research in Aotearoa is of relevance and significance to Māori, and that which includes Māori is of paramount importance" (p. 65). Te Ara Tika, as explained by Came (2013), is a framework to facilitate Tauiwi researchers to improve their relationship with Māori when conducting research within Aotearoa, drawing on Te Ao Māori and affirming Te Tiriti o Waitangi, while also embedding core Western ethical principles. Within the Te Ara Tika ethical framework there are four principles: whakapapa/relationships, mana/justice and equity, tika/research design and manaakitanga/cultural and social responsibility (Came, 2013). As a Pākehā with introductory (but expanding) understanding of Te Ao Māori and an inexperienced researcher with time constraints, I have chosen to have a kaupapa Māori’ and Te Ara Tika-influenced research design. This research does not come from an ontological or epistemological Māori standpoint, nor was it initiated in full collaboration with Māori. However, Māori potential participants were (albeit briefly) consulted early regarding the research design and are included in the research and outputs through participation in the interviews. The focus of the research is not centrally on Māori experiences but Māori are included within the general population of Aotearoa and, within that, climate justice and climate action. I am informed by the fact that Māori are an integral part of these movements, frequently leading progressive movements in Aotearoa long before they are accepted by the larger public. Additionally, Māori are overrepresented by the impacts of climate change in Aotearoa as "it is highly likely that climate

\footnotetext{
${ }^{7}$ A methodology or way of working (outside of research) that is built on Māori principles and values, Te Ara Tika is an example of a Kaupapa Māori orientation (Came, 2013).
} 
change will exacerbate many of the socio-economic difficulties and disparities already faced by Māori” (King et al., 2010, p. 101).

\subsection{Conclusion}

This thesis endeavours to understand how radical, progressive societal change is theorised and enacted in Aotearoa, specifically within the scope of climate change but recognising that many issues (and therefore movements) overlap and intersect. In order to this, this thesis draws on two primary bodies of literature: Development Studies and Social Movement Studies (SMS). From the outset of the research design process, it has been important to me that my choices in thesis topic and design align with my values. This is reflected in my decisions to focus on systemic change approaches to climate change (climate justice), apply a post-development theoretical framework, and utilise a social constructionist epistemology.

Mainstream development frames climate change through the sustainable development paradigm, embodied by the UNSDGs. This approach is inherently problematic. It is more focused on sustaining development than a sustainable relationship with the environment, it neither problematises nor challenges the ideological underpinnings and power relations within development as the root cause of climate change and environmental degradation (Sachs, 2010; Shiva, 2010). Therefore, sustainable development is limited in its scope and ability to understand or enact radical, progressive change. In contrast, post- and critical development critiques the foundational assumptions within development, and enables transformation through a pluriverse of alternative, bottom-up forms of development, including social movements (Demaria \& Kothari, 2017; Silvey \& Rankin, 2011; Veltmeyer \& Delgado Wise, 2018).

Given the focus on social movements as an alternative form of development, SMS and theories also form an important part of the foundations of this research. Political process theory, collective identity, and intersectionality theory are utilised to unpack the contemporary climate action and climate justice movements in Aotearoa and investigate how they interact with each other. Political process theory is particularly useful for understanding how the surrounding environment impacts movement theory, action, origins, and catalysts. Collective identity, a concept within new social movement theory, enables the intra-movement conflict to be placed within a broader, and more productive space of movement learning and evolution. Central to the definition and approach of 
the emerging climate justice movements is an intersectional understanding of climate change and structural inequality. These theories, alongside the concept of structuration, and existing literature on the climate and environmental movements are foundational in unpacking the rich data collected through this research towards understanding the climate justice movements in Aotearoa. 


\title{
Chapter 3: Climate justice in Aotearoa
}

\author{
"I think the definition of climate justice for me sits outside of the scope of \\ climate, in that climate justice is a process that happens when the appropriate \\ groups who have been oppressed are represented and we value their existence \\ and their knowing. ... Climate justice is different to climate action ... Climate \\ action sits within climate justice, it can't be the other way around."
}

(Jason, interview, 17/09/2020)

\subsection{Introduction}

A growing body of evidence indicates that existing inequalities will be exacerbated by both the impacts of climate change and the ways in which society responds to it, with poverty and power acting as amplifiers of negative impacts (Jafry et al., 2019). The underlying social vulnerability of marginalised communities, or "climate disadvantage", interacts with exposure to hazards creating inequity of impact (Knox, 2019, p. 114). Additionally, there is an inequity in the cause, response (cost and benefit of policies), and governance of climate change (Knox, 2019). Climate justice explicitly recognises this inequity as well as the need to confront it through focusing on the root causes and transformational change (Jafry et al., 2019).

The quote at the start of this chapter by Jason of Sustained Ability is emblematic of the definition constructed by participants in this research of what climate justice is in Aotearoa. It highlights several key aspects: the centring of oppressed communities (also referred to as vulnerable, marginalised, or frontline); the importance of representation and knowledge; climate justice as an ongoing process (not just an action or end goal); and the view that it is separate or additional to climate action. Jason also alludes to the complicated relationship that climate action and climate justice have (this is expanded upon in the next chapter). However, in this chapter, I focus on the way climate justice is articulated, experienced, and explained by my participants, who are involved in these movements to varying degrees. 
This thesis intends to understand the landscape of climate justice as it develops in Aotearoa. As shown in the previous chapters, the histories of social and environmental movements in Aotearoa are interconnected. The recent references to (narratives) and examples of (actions) climate justice in Aotearoa are the latest evolution of transformational social change. In this chapter I unpack what climate justice is in Aotearoa in terms of movement classification, local definitions and descriptions, who is involved and in what ways, and where it comes from. I also discuss how climate justice is enacted by participants and the associated theories of change, including relationship building. Additionally, participants highlighted their struggles in creating and determining their impact, an area that requires further research. The parameters of a climate justice movement or movements in Aotearoa are unclear and constantly in flux, with the term used in diverse ways and contexts by a variety of actors. Furthermore, it became apparent as the interviews progressed that the use of the word 'movement' is potentially premature. However, SMS literature indicates that the definition of a 'movement' is also changing (della Porta, 2017).

\subsection{Definition and description}

As noted above, climate justice is an on-going process that centres the needs, knowledge, and representation of the frontline (oppressed, vulnerable and/or marginalised) communities of climate change. In this section the core principles of climate justice as articulated by members are outlined: frontline community led, accessibility, accountability (and responsibility), and challenging current societal norms and systems. These principles describe and define climate justice in Aotearoa and were often implied or stated as lacking in climate action movements. Delving further into the concept of 'frontline' communities, in this section I also highlight key interrelated forms of justice raised by participants: Indigenous, disability, intergenerational, gender, and socioeconomic status. Finally, is climate justice a movement, or is it a framework, lens or space within wider climate movements?

Prioritising the interconnection between inequality and climate change, participants argued that climate justice needs to be led by those at the 'frontline' of the impacts. Kera noted: "Climate justice to me is from the community that is most impacted, and that is grounded in thinking around collective care and collective justice" (Interview, 02/10/2020). Frontline community leadership in climate justice enables solutions to be grounded and better informed by the needs of those most impacted, making it more effective in developing the right solutions. Tagg \& Jafry (2018) see the 
marginalised of the North and South as the face of climate justice. However, they often lack the resources and structures required to have their views recognised, represented and incorporated (Jafry et al., 2019). Nevertheless, by sharing their lived experiences and wisdom, frontline communities shape the political and strategic nature of climate movement actors (Tokar, 2019). Climate justice focuses on local impacts and the contextual inequitable vulnerabilities of communities, prioritising community voice and sovereignty as part of the solution (Schlosberg \& Collins, 2014). The earlier environmental and conservation movements were often driven by the privileged, and the climate change movements of the 1990s and early 2000s concentrated on the advanced capitalist countries and institutional channels (Almeida, 2019b). Almeida (2019b) contends that the disproportionate impact of climate change on the world's marginalised highlights that "the climate justice movement cannot continue to be directed by relatively privileged strata in the global North or South" (p. 977).

For diverse frontline communities to participate in, let alone lead, climate action and solutions, participants noted that increased accessibility of collective action is important. Many, like Lourdes, referred to the need for a more accessible politics of climate and justice through talking about the inverse: the problems with the current political climate:

"Politics should be about wellbeing and livelihoods, and it is, but it is played up with drama and lingo and language that hardly anybody understands, and so it's polarising and it's kept in this very small box that only a few people can open."

(Interview, 07/09/2020)

Most participants recognised that democratic movements need people to be able to engage with them, and to feel like they can contribute.

Accountability and responsibility were also frequently referred to by participants in relation to climate justice in two main ways: the responsibility of the government to act and the need to hold them accountable to their claims and actions; and internal accountability within movements and within communities:

"What accountability looks like in this space ... for both justice organisations but also particularly for a lot of other members of the wider climate movement who are 
trying to be more justice focused but maybe don't know how to go about doing that."

(Kera, interview, 02/10/2020)

Lack of accountability or ability to hold people accountable is an issue that participants experience. 350 raised this issue regarding XR's structure: “... explicit stuff that's harmful, then who's accountable right? When there's no clear person to go to in XR" (Interview, 27/08/2020). Likewise, Jason noted that this concern surrounded groups who co-opt climate justice language: "It's terrifying because there's no way to hold them accountable" (Interview, 17/09/2020).

Accessibility, accountability, and leadership from frontline communities are the antithesis of the current system. Climate justice is described by participants as antithetical to the dominant institutional structure of society, seeking to dismantle these structures:

"I don't see us addressing climate change without dismantling capitalism, without dismantling ableism, without dismantling the colonial state that we live in" (Kera, interview, 02/10/2020).

Part of dismantling these systems through climate justice is through challenging the societal norms that reinforce them. Participants' frustrations with the current economic and political systems were frequently raised throughout interviews. These comments were often followed by the assertion that these systems need to be replaced entirely, rather than reformed. Anti-capitalist sentiments were explicitly mentioned by ten out of the seventeen participants. While this implies that climate justice in Aotearoa is not exclusively anti-capitalist it is certainly a strong feature at present. Several other participants critiqued the economic system without referring to capitalism or capitalists directly. Neoliberalism was also highlighted by eight participants, compared to globalisation and imperialism which were only explicitly referenced by three participants each. Colonisation/colonialism was by far the most prevalent system identified as part of the problem, with fifteen of the seventeen participants discussing it in some regard. Decolonisation is a core principle of climate justice in Aotearoa.

Similarly, the literature states that climate justice is a critique of the mainstream social, political, and economic response to climate change (Boran, 2019). Climate justice is sceptical of market 
mechanisms and commodification, and states that technological innovation cannot address the whole picture (Jafry et al., 2019; Tokar, 2019). Tokar (2019) notes that climate justice highlights the limitations in the status quo and the need for systemic approaches. To address the impacts and underlying causes "the current development paradigm with its roots in capitalism" needs to be explicitly addressed (Atapattu, 2015, p. 96). Furthermore, climate justice aims to challenge oppressive hierarchies within the movement as well as in society more broadly (Tokar, 2019).

So far, the focus has been on participant definitions of climate justice in terms of core principles. Climate justice is an accessible and accountable on-going process that centres and is led by frontline communities to challenge the status quo which is both responsible for climate change and impedes climate solutions. What follows details participants definitions and perceptions of climate justice in terms of whose justice we are referring to, who they identify as 'frontline.' There were various intersecting concepts of justice highlighted in the interviews covering: Indigenous, disability, intergenerational, gender, and class issues. Additionally, the intersections highlighted were often (although not exclusively) raised by participants from those communities, reinforcing that justice and climate justice is fluid, contextual and subjective. Academic climate justice literature tends to favour the North/South framings of climate injustice, and this is reflected in the lack of various intersections in the literature.

Indigenous peoples were the most widely recognised frontline community and element of climate justice in the interviews. This speaks to the context of Aotearoa as a settler colonial country and to the associated substantial structural inequality that Māori face. Colonisation is a form of anthropogenic climate change; it changed the ecological tipping points of Indigenous lands, disrupting the kin relationships to species that Indigenous peoples have had for generations (Whyte, 2020). Crucially, this change was harsher than what most non-Indigenous people fear in a 2-degree temperature rise through climate change (Whyte, 2020). Many participants recognised that colonisation is a fundamental part of the problem. Therefore, decolonisation and Indigenous justice is a fundamental part of the solution:

"The doctrine of discovery was the driver of all Indigenous dispossession, but it also underpinned a mindset and philosophy of extraction and pollution, and the right to impact on other people's bodies, ... places and territories as well ... not just for Indigenous groups but for all groups who are being colonised through the way 
that pollution colonises our bodies, ... our food systems, the way that all of us, of all races and groups, are being colonised now by corporations."

(Tina, interview, 12/08/2020)

Participants view Indigenous worldviews as part of the toolkit to challenge the status quo, and in many ways, Indigenous resistance is seen as an asset to climate movements, historically so in Aotearoa:

"I think the strongest element of the fight against exploration was the Indigenous resistance in New Zealand ... that was just a game changer"

(Greenpeace, interview, 24/08/2020)

Similarly, Powless (2012) contends that the Indigenous movement is the most engaged non-state actor on climate change. However, this is not well reflected in local academic literature, with Indigenous involvement in the early environmental movements in Aotearoa hard to find within written accounts that are often devoid of matters of ethnicity or culture. The role of Te Whānau-aApanui and Ngāti Porou in the anti-offshore oil exploration campaign has been (briefly) recognised and is the only explicit example of Māori involvement in environmental movements in the academic literature (Bond et al., 2019; Diprose et al., 2016; O’Brien, 2013a; Thomas, 2018). Furthermore, this is often phrased as the movements' relationship to Māori, rather than Māori as a part of these movements. Bond et al. (2019) and Diprose et al. (2016) went into the most depth and articulated Māori as instigators of action rather than a party to consult with. Other references to Māori involvement in environmentalism are largely regarding Te Tiriti obligations (and failures) or noting that Māori participation tends to be regional and local (Downes, 2000). These observations of the literature also support Tina's comments on weak allyship and Kera's comments on Māori individuals not identifying with these movements. Fortunately, this appears to be changing, and climate justice is a crucial part of the increase in awareness of Indigenous perspectives in climate movements.

Participants noted that Indigenous communities have long had solutions, and that decolonial solutions are solutions for climate change: 
"We've already got a lot of those answers to the problems that we've got. We just need to apply them to modern day. ... I think most solutions to Indigenous justice and climate justice would interconnect ... giving land back, having meaningful consultation with iwi from the very beginning of the discussion ... and supporting Indigenous people."

(Lourdes, interview, 07/09/2020)

As noted by Lourdes, support as well as constitutional change are ways for these co-solutions to be realised. Additionally, as articulated by Tina, "protecting Indigenous ways of knowing, and being, and doing, is an act of climate resilience, and is an act of climate justice in and of itself" (Interview, 12/08/2020). Pākehā participants likewise acknowledged that "Māori are at the forefront of climate adaptation" (Conor, interview, 29/09/2020). Kera explains this is because Indigenous communities have been feeling the impacts of climate change and environmental degradation and have adapted. Indigenous rights movements are "inextricably linked" to climate justice, as Indigenous worldviews prioritise planetary well-being (Tina, Interview, 12/08/2020). Yet Indigenous people continue to be excluded from decisions, despite extreme risks and damage, countered by a strong presence of Indigenous women activist leadership (Perkins, 2019). While climate justice is not an Indigenous concept, Indigenous communities, already feeling the effects of climate change, have joined these movements (Nuñez, 2019), and by doing so socially legitimised them. Whyte (2020) states that when Indigenous perspectives and needs are overlooked, environmental injustice will continue, regardless of whether the 'best-case' scenario of a 1.5-degree rise is achieved or not.

While most participants spoke of Indigenous justice as part of climate justice or one and the same, Tina experiences climate justice as a part of Indigenous justice, existence, and survival (not the other way around):

"The climate justice movement plays a role within my existence as a wāhine Māori ... Being born with my whakapapa Māori ... and wanting to maintain that and pass it in on to my children requires me to ... exist in a way that resists the system. ... Climate justice is one facet of that. ... All those things play a facet in my role of surviving on this planet ... as a part of this planet, and protecting her as a part of protecting me, ... my ancestor's legacy, and ... my future generations.” 
(Interview, 12/08/2020)

Tina's perspective on how she relates to climate justice reiterates the importance of centring frontline communities who engage in climate justice out of necessity instead of altruism or interest.

Disability justice was not mentioned widely, but was the primary focus for two participants, and was included by several others. Being frontline community-led, participants noted that as one of the most impacted communities, disabled people need to be included. As with Indigenous justice, disability justice and climate justice are seen by participants as inherently connected. Additionally, ableism within climate movements and climate justice spaces needs to be acknowledged and recognised as a reproduction of the oppressive structures that they claim to stand against:

"Ableism in climate work is inherently tied to colonisation and industrialisation and the stigmatization and devaluation of disabled bodies."

(Jason, interview, 17/09/2020)

Furthermore, disabled activists have been operating in innovative ways prior to COVID-19, and the wider climate movements could learn from them. Jason noted that:

"This concept of slacktivism is inherently ableist, disabled people organise in the online space, our interconnectedness through nonphysical mediums has been part of our continued work."

(Interview, 17/09/2020)

In the academic literature I reviewed on climate movements, environmental movements, and climate justice there was little or no mention of disability. This demonstrates, as discussed in the following chapter, that ableism is still present in movements and academia. However, there is a growing body of alternative literature online that fills this gap. ${ }^{8}$

Intergenerational justice also featured loosely throughout interviews and is a more widely accepted aspect of climate activism generally as depicted by its wide referencing in academic and popular literature and the UN forums. Alicia, from PfCA, spoke of the practice of intergenerational

${ }^{8}$ For example, see Sustained Ability's 'Reading list' on their website https://www.sustainedability.org/. 
activism in several ways. As a parent-focused climate advocate, she sees intergenerational activism as a duty that parents owe their children:

"We wanted a way of centring our kids' voices, the ones under $10 \ldots$ without exposing them because they have a right to childhood. ... We're stealing kids' ability just to be kids and not have to worry about this stuff."

(Interview, 20/08/2020)

Additionally, intergenerational justice is not just participation or representation of youth and future generations, but also the power in multiple generations uniting behind the cause. This is useful for cutting through the patronising response of government to youth-led movements:

"Having different generations come and speak, rather than having government just box you in whatever, and it's easy to put away. But when you've got three different perspectives .... that we all want this"

(Alicia, interview, 20/08/2020)

Joe of SCA also recognised the intergenerational nature of activism in the way in which youth activists learn the possibilities of strike actions from adults around them: "Kids' kind of thinking that their strikes were because our teachers had strikes, and our nurses had strikes" (Interview, 18/08/2020). The youth strikes then encourage actions from workers, making climate justice a process of reciprocal intergenerational learning. As explained by Tina, intergenerational justice is an inherent part of an Indigenous approach. Nairn et al. (2021) also found this to be true when they compared the conception of time between Ihumātao and Generation Zero (GenZero). Ihumātao activists had an Indigenous conception of time with past, present, and future as intertwined in a spiral, folding back onto itself (Nairn et al., 2021). GenZero had a linear, colonial conception, framing the younger generation as carrying the burden of dealing with climate change, hence the demands for intergenerational justice (Nairn et al., 2021). The former is an expression of intergenerational justice; the continuing, shared responsibility across generations, guided by an evolving relationship between place and people (Nairn et al., 2021).

The gendered nature of climate change and activism was not featured as widely nor frequently in interviews as was Indigenous and intergenerational justice, yet it plays an increasingly larger role 
in the literature. Tina, Alicia, and Connor referred to the unique position of women in climate movements, and Alicia noted specifically the sexism within these movements:

"Part of the name comes from so many articles saying 'Millions of mothers around the world are impacted by climate change'. Women are predominately going to be impacted ... that was always missing from the conversation so dare I say it I think there is a bit of sexism."9

(Interview, 20/08/2020)

The gendered impact of climate change is well articulated in the literature, often referencing the extreme weather events in early 2000s as demonstrating the gendered vulnerability during and after disasters, magnified by biological and cultural roles and socio-economic disparity (Perkins, 2019; Terry, 2009). When feminism and the disproportionate impact on women was mentioned in interviews, it was referred to in an intersectional way: "Solutions must include marginalised, women of colour, and women in poverty so they aren't disenfranchised even further" (Alicia, interview, 20/08/2020). There were also parallels drawn between women's bodies and the planet in terms of violence and agency, "gender-based violence and planetary violence are one and the same" (Conor, interview, 29/09/2020).

Tokar (2019) sees climate justice as bringing intersectionality to the climate movements, and Perkins (2019) calls an intersectional feminist perspective ethically vital, efficient, theoretically fundamental, and inspiring. Perkins (2019) also notes that women have been leaders in environmental movements for some time and, alongside Indigenous womanism and land-based cultures, gendered meanings and implications are transformative and emergent in climate justice. Supporting Alicia's comments on sexism and lack of gender analysis in climate activism, Perkins (2019), Terry (2009), and Tokar (2019) noted that climate change strategies, policies, and finance lack gender scrutiny to ensure the priorities and interests of women are included, reducing their overall effectiveness and potentially increasing inequalities. The mainstream discourse and state emergency responses remain masculine and top-down (Enarson, 2012; Perkins, 2019). While gender wasn't a prominent topic across all interviews, thirteen of the seventeen participants were female and there is a gendered element to both activism and volunteering in Aotearoa.

${ }^{9}$ PfCA was originally called Millions of Mothers. 
Class or socioeconomic status was one of the least prevalent forms of injustice mentioned across the data set. Workers' rights featured prominently in the interview with Jen and Joe from SCA and they connected this to their climate analysis and climate justice work. This was not surprising given their involvement with the union movement and Socialist Aotearoa. Whilst several mentioned workers, just transition, or poverty briefly, the XR Member was the only other participant who dedicated a significant portion of their interview to the 'working class'. This was primarily in the context of their perceptions that at present the middle-class climate movements are detached from the working class. The XR Member was trying to understand how "do we build solidarity on the basis of a cohesive green working-class movement?" (Interview, 22/07/2020)

Even more so, LGBTQI+ injustice was barely referenced at all throughout the data set, despite several participants belonging to that community. Queer rights in the context of climate justice rights and queer communities in the context of frontline communities was included in only one interview, and the 'LGBT' community referenced only once regarding inclusivity. Despite being members of the LGBTQI+ community, these individuals did not belong to climate organisations or groups that had this at their core. Participants may have chosen to focus their answers within the scope of their organisation they had agreed to represent as part of this research.

Throughout this thesis I have chosen to give greater focus to Indigenous and disability perspectives within the climate justice parameters identified above. The overall working (as it is influx) definition of climate justice in Aotearoa utilised in this thesis began with the predominantly international literature and then refocused on principles and common themes as articulated by my research participants. With each interview this definition was tested and refined, with additional weight placed on the interviews of participants that directly belonged to 'frontline' communities, and in particular Indigenous and disability. In several interviews these elements of climate justice came across as both contextually relevant to Aotearoa and important for the progress of climate movements that are often dominated by the abled and Pākehā. These interviews also tended to be those in which interviewees used the term climate justice more frequently and with more confidence. In focusing on these perspectives, I was able to centre the perspectives of frontline communities that have not been sufficiently acknowledged in existing literature on the environmental and climate movements of Aotearoa. This is taking a climate justice approach to my analysis, centring the knowledge and experiences of marginalised communities. Following a 
quantitative approach to prevalence where the definition is built from the numerical strength of participant comments, rather than the qualitative strength or 'keyness' would have been counter to both the research design and ill-suited to the study of marginalised perspectives. Narrowing down the focus also enabled me to include greater depth. Furthermore, there were often socioeconomic implications within the discussion across all forms of injustice as these are also communities who are marginalised within our current economic system. For example, the disparity of resources across communities and movements reflects their on-going socio-economic struggles. Additionally, all forms of injustice identified in the interviews as relevant to climate justice in Aotearoa, as outlined above, often intersect and share common threats.

Through the interview process, it became apparent that an assumption of movement status for climate justice in the case of Aotearoa is premature. Participants did, from time to time, refer to it as the climate justice movement, although this was influenced by the articulation of it as such in this research, from the outset, in the recruitment emails, information sheet, consent form, and interview. As this realisation developed, it informed my line of questioning and, in the final interview, we explicitly spoke about whether it is a movement or not (unlike all other interviews):

"I think a lot of people use language and narratives around climate justice ... but I would say that on the whole I don't think the wider climate movement actually gets climate justice, in the way that I define it and in the sense of structural change ... I think there's an emerging movement, I would say that's it probably still emerging now ... I'm not sure about the technical definition of a movement, but when I hear the word movement, I think both of a scale but also of an interconnection."

(Kera, interview, 02/10/2020)

While there is potential for a climate justice movement or movements, at present it is still emerging. Instead, climate justice was referred to in numerous other ways throughout the interviews. This includes climate justice as: lens, work, problem, process, concept, space, outcome/s, groups or organisations, title, approach, facet, idea, and term. The range of ways in which it is referred to demonstrates the subjective and changing nature of climate justice in Aotearoa. Likewise, within the literature, climate justice is referred to as a: part of critical climate change research; robust lens; concept; research agenda; legal and ethical framework; framing for a new agenda for climate activism; complex activity; theory and practice; driver of change in civil 
society and activism; and grassroots response (Boran, 2019; Chatterton et al., 2013; Jafry et al., 2019; Tokar, 2019). Furthermore, when referring to movements, participants sometimes opted to speak instead of climate action movements, environmental movements, green movement, and/or other interconnected and associated movements such as unions/workers, disability, and Indigenous rights. Climate justice is seen as connected to, and developing out of, other justice movements. Noticeably, some participants did not even use the words 'climate justice' when talking about their actions or theory. Again, this highlights the complexity and nascence of climate justice in Aotearoa.

\subsection{Actors and organisations}

Climate justice actors include groups, networks, federations, coalitions, organisations, collectives, NGOs, trade unions, politicians, journalists, and concerned individuals (Chatterton et al., 2013). A mixture of the above were mentioned in the interviews, some classed as climate justice or not, and as allies or problematic. Not all individuals described or listed which actors they would label as climate justice. Additionally, when talking about individuals or groups, whether positively or negatively, it appeared they were often speaking to the broader climate action movements. As such, it is difficult to clearly map out the parameters of climate justice within Aotearoa from the data set. Internationally, new networks have emerged with a climate justice approach, led particularly by communities of colour, including anti-capitalist and eco-socialist groups (Tokar, 2019). While climate justice remains peripheral to mainstream environmental organisations, characterised as a loose, multi-scalar coalition of groups enabling flexibility and radical democracy, this is changing (Dawson, 2010). Participants indicated that climate justice in Aotearoa is largely following these global trends. Bond et al.'s (2018) work on the oil free campaign, cited as climate justice, also observed groups emerging around key events operating independently but occasionally sharing resources and co-ordinating actions. These observations align with my participants' comments, with key events as catalysts, and some cross-movement support and coordination while remaining formally independent.

Four key groups were highlighted as being explicitly climate justice from either a disability, Indigenous and/or Pasifika perspective: Sustained Ability, Te Ara Whatu, Pacific Climate Warriors, and 4 The Kulture. The first three originated in global contexts, primarily engaging with the UNFCCC or as an offshoot of an international organisation. 
Two participants explicitly defined and reserved the title of climate justice for groups or organisations coming from the most affected communities and focused on people and justicecentred approaches, including Kera:

"I think my definition changes depending on the context that I'm in. ... Are they led by communities that are most impacted? Are they focused on our rights? Indigenous people's rights, disabled people's rights, queer ... are human rights at the centre of that? ... To me it feels like more mandate in terms of being ... grounded within a specific community."

(Interview, 02/10/2020)

While noted as contextually dependent and therefore leaving some room for variation and subjectivity, the community-led and grounded definition of climate justice organisation fits with the 'frontline' community-focused element and attention to inequality and power dynamics that many participants mentioned. Furthermore, climate justice work is seen by Jason as something that frontline communities do inherently:

"You're a disabled person, you know a lot about how we campaign in our history and you've been fighting for our rights. Isn't that working for climate change? ... the more our rights are embedded, the more our voices are heard ... that is climate action work."

(Interview, 17/09/2020)

Additionally, climate justice work or approaches aren't exclusive to those who label themselves as climate justice or operate with a climate specific focus:

"I think that there are plenty of hapū and iwi who are doing ... climate justice. I think there are heaps of individual people who maybe don't even recognise themselves as climate activists. There've been a lot Māori in particular that don't resonate with the label around climate change or climate activism because it's seen as more kind of interconnected, and also just feeling that the 'climate movement' is extremely white, and able-bodied, and privileged, and not feeling like they associate with that." 
(Kera, interview, 02/10/2020)

This speaks to a fundamental and recurring issue of Pākehā domination of activism and the climate movements in Aotearoa. Similarly, Dietz and Garrelts (2013) observed that "members of the climate movement often have closer and longer lasting relationships with each other than with the collective movement itself' (p. 7). One of my participants didn't even initially consider themselves or their organisation as part of the climate justice movements but then later in the interview, after greater discussion of what climate justice means, changed their mind. This reinforces that the definition and parameters in Aotearoa are unfixed at present.

Even though climate justice should be led by frontline communities, this does not mean that other communities and individuals cannot participate in climate justice. There are roles within movements outside of leadership, including as allies seeking to transition to a climate justice approach. Greenpeace, 350 Aotearoa, SS4C, Oxfam, Tauiwi mō Matike Mai Aotearoa, New Zealand Alternative, and Action Station were considered by one or more participants as allies. The prevalence of specific organisations being identified by participants as allies varied across interviews with ten (excluding the individual representing that organisation) being the highest any single organisation (SS4C, followed by Greenpeace on eight) was referred to positively. This included the term 'allies' specifically and in less explicit terms, i.e., through referring to their active participation in climate justice workshops or joint protests. A virtual workshop, carried out during COVID-19 lockdown in April 2020, demonstrated which so-called climate justice groups or allies were genuinely willing to engage on climate justice through acknowledging and learning about ableism in the climate movements. This included 350, Greenpeace, Oxfam, Te Ara Whatu, Sustained Ability and Pacific Climate Warriors (350, interview, 27/08/2020). Other groups and organisations were mentioned but neither explicitly as climate justice, allies nor problematic; this included Sea Shepherd, Peace Action, Coal Action Aotearoa, and ClimAction. There was variation across participants on who is considered an ally or problematic, being intrinsically tied to personal experiences and remaining highly context dependent. Climate justice is also not consistent within each organisation or group with intersectional understanding and reflexivity often left to the individual level rather than organisation level. While organisational level change is often driven by individuals, it is also hamstrung by organisational process and structural elements of society. 
XR, GenZero, the Green Party, SS4C, Action Station, and Forest and Bird were mentioned as problematic by one or more participants. Of those, XR was the most widely and explicitly referred to, followed by GenZero. The reasons why participants found XR problematic largely surrounded their lack of critical analysis that influences the actions they take, overlapping with key intersections of race, indigeneity, class, and disability. Their use of the intentional arrest tactic was an example of this: "The fetishisation of mass arrest ... I could see how that would alienate working class people" (Joe, interview, 18/08/2020). Additionally, as previously noted, their nonhierarchical, autonomous structure made it more difficult for people to hold them accountable and identify who to avoid or work with. Tina, Joe, Mel (below), and the XR member, noted that much of the problematic image and application of XR comes from the international group, but that this also impacts the image of national and local groups in Aotearoa:

"The name is quite problematic because it brings so much baggage, overseas baggage, and it can be really off-putting and ... feel really unsafe for a lot of people who might otherwise be keen to join."

(Mel, interview, 08/07/2020)

As well as groups, several individuals were cited by participants as climate justice leaders: Tina Ngata, Sina Brown Davis, Steve Abel, and Teanau Tuiono. Additionally, while groups were largely the focus of complaints, James Shaw was predominantly seen as the face of issues with the Green Party. Often the origins and even the continued operation of groups or organisations are tied heavily to individuals:

"Our [Te Whanganui-a-Tara] group was formed by a very vibrant, strong personality who was also a little problematic, and it got to a point where ... that person left the group ... all the energy and drive, and all the positions were really occupied by this one person."

(XR, interview, 15/07/2020)

Individuals are experienced as shaping and driving collective action through their leadership of organisations and movements. In some cases, my research participants see this as a positive, enabling autonomy, speed, and accountability, and when anti-racism work is undertaken by the individual, it positively influences the group. In other situations, it is viewed as negative, restricting 
capacity and therefore ambition and impact, particularly when there is turnover and knowledge is not institutionalised. Likewise, when analysing climate communication in Aotearoa, Salmon et al. (2017) noted that individuals have a disproportionate influence on public perceptions of climate change.

\subsection{Origins and catalysts}

Many of the participants, both individually and on the organisational level, draw their origins and catalyst for action from international and/or national government stimulus. Climate justice movements are also seen as a continuation of climate movements, environmental movements, and connected to other justice and progressive movements. Threats are often catalysts, although this is sometimes framed as an opportunity by participants, alluding to the influence of perceptions within political processes (Suh, 2001). Additionally, most of the groups have arisen within the past five years. Participants have noted that their origins have lasting impact on how they conduct themselves (as noted by XR's former problematic leader) and the makeup of their membership base:

"I think given that we started where we started in 2008 ... very climate sciencebased calling for particular things, means that we do have a fair number of older white men who are into science, who send us angry emails when we say stuff about honouring Te Tiriti."

(350, interview, 27/08/2020)

As Tina demonstrates, often a mixture of domestic government and international institutions such as the UN are the catalyst for action, and these political process influences often come in the form of threats:

"I became aware of the doctrine of discovery through going to the United Nations ... and then once the government started to make it more and more apparent that there would be multi-million dollar investment [Tuia250] in platforming those systems, and glorifying those systems to an extent, more of us started to make noise about it from that truth of ... we understand the process of colonisation to be one that is inherently destructive of Indigenous ways of being ... and two is directly, inherently destructive of our environment." 
(Interview, 12/08/2020)

There are several, internationally imported organisations and movements operating in the Aotearoa climate movements. Of the participants interviewed, XR, SS4C, 350, Greenpeace, and Quakers come from overseas. As described by the XR Member, XR Te Whanganui-a-Tara's origins are complicated, being imported from the UK (rather than developed within and from our own local context), based off flawed research (the $3.5 \%$ theory $)^{10}$, and orchestrated by someone with poor judgement. ${ }^{11}$ They noted that their timing coincided with IPCC, UN, and SS4C, potentially aiding their initial success:

"I think because they came out with their plan a couple of months after the UN ... These two things collided, and it created this perfect storm and took off everywhere ... I don't think it was planned anywhere else it ... it just spread ... it just happens because it builds up and builds up and people are just looking for something to attach their frustration to; a catalyst right? And there's just a spark ... as deeply flawed as the idea behind it was.... A lot of these things [IPCC, SS4C] seemed to happen all at the same time."

(Interview, 15/07/2020)

350, on the other hand, was intentionally set up by the US founding group to be an accessible, science-based, grassroots, localisable, international movement. However, as Aotearoa was not a priority, it still developed organically from concerned individuals previously involved in environmental groups observing what was happening overseas. This unique relationship to the international organisation has enabled an ongoing autonomy for the Aotearoa group:

"New Zealand has always stayed separate. So, we're not part of 350.org, we're an affiliate ... Technically we could go off and do something completely different, but we see use in being linked into this global strategy."

(350, interview, 27/08/2020)

\footnotetext{
${ }^{10}$ For more on the issue with the 3.5\% theory, refer to Anisin (2020) and Ahmed (2019).

11 The XR member referred to poor judgement and "phenomenal lack of thought" by XR leadership in several ways, in particular: basing the movement on flawed research which is then applied out of context, and referring to the coming environmental disaster as "the worst holocaust ever" on German television. Issues with XR leadership were mentioned in regard to the UK founders as well as the individual who helped form Te Whanganui-a-Tara's group (XR, Interview, 15/07/2020).
} 
The organic nature of movements migrating to Aotearoa, driven by those who see what is happening overseas, is also supported by Sophie's account of the origins of SS4C:

"I saw some of that kind of seeping into the New Zealand media, and at the beginning of 2019 pulled together some friends from high school. ... I was feeling pretty powerless but seeing what was happening in Australia, especially thousands of people out on the streets, that is powerful."

(Interview, 10/08/2020)

As noted above, emotions, particularly fear and powerlessness, were often cited as part of the catalyst to creating (or joining) groups. These emotions are experienced across the board, by youth (SS4C) and parents (PfCA) alike:

“There's a lot of anxiety amongst parents because we're right in the thick of raising these kids. ... You're supposed to bring them up to the best they can be in the future world. No one really talks about the solutions or localises it ... and then the 2040 film ... started flipping the narrative and talking about what we can do."

(Alicia, interview, 20/08/2020)

Emotions, particularly eco-anxiety, can also lead to apathy and denial, and youth involvement in these movements plays an important role in challenging this (Thomas et al., 2019). Additionally, as noted above, various forms of media and other movements also act as catalysts. Moreover, according to political process theory collective action can inspire and create opportunities for other movements or issues (Benski et al., 2013; Tarrow, 2011).

Several participants spoke to wanting (or needing) to fill gaps they had found through their personal experience of being involved in these movements:

"I was thinking for ages that it would be nice to have social events for environmentalists ... get together and make friends ... to keep the whole movement a bit more resilient too. ... Social connections is an important part of activism and for keeping people involved. ... Often the best part of a meeting is having unstructured space to talk to like-minded people and see what comes out. ... [TUI] 
was also set up as a hub ... there's a lot of random things going on, and they often don't know about each other."

(Mel, interview, 08/07/2020)

The most common type of gap noted was around representation, particularly for the young, but also for Indigenous people:

"I think especially after Chlöe ran for Auckland ... that brought our attention to the potential of local government. ... The climate context of last year contributed to it as well, the school strikes really made a lot of older people think about the fact that young people and their interests, especially intergenerational, future interests aren't represented around the table, and so many decisions are made with a current mindset, and that leads to so many failures."

(Tamatha, interview, 24/08/2020)

Applying the language and framing of political process theory, the 'representation gap' as a catalyst for individual action is a response to the threat of inaction and worsening conditions if inadequate representation continued that also utilises the opportunity for increased institutional access for youth created by the groundswell of youth candidates and shifting societal norms. Sometimes personally being the one to fill these gaps was seen by participants as temporary, rather than necessary:

"I think we need more people in more spaces doing something about climate change and representing the voices of our planet. ... At the beginning I didn't really know if I was the right voice, and I still don't know if I am, but it's kind of like almost having someone in there to create some space or be a place holder."

(Sophie, interview, 10/08/2020)

Additionally, Jason found that finding allies and those within the same community with the same concerns enabled the creation of groups to fill gaps (Interview, 17/09/2020).

Climate justice, within the narrative of my participants and the literature, developed out of the failure of mainstream environmentalism to incorporate frontline communities' perspectives, disproportionate focus on false solutions of 'green capitalism', and the failure of the UN system, 
in particular the 2009 COP in Copenhagen (Almeida, 2019b; Chatterton et al., 2013; Dawson, 2010; della Porta \& Parks, 2013; Nuñez, 2019). Rapidly growing since 1990, the climate justice frame tends not to be linked to a single group or individual, instead developing in open and public debate (della Porta \& Parks, 2013).

The origins of climate justice are firmly rooted in other movements. Sustained Ability's origins are in disability rights and justice movements (and, to some degree, the civil rights movement in the US):

"Being a disability rights and justice org as well, that's where we take our kaupapa from ... because that's where our knowledge is and that's where our strength is. ... These learnings of decades of rights campaigning and theories of change testing from our community ... there's such a wealth of knowledge ... - Crip wisdom ${ }^{12} . .$. We don't find our source of knowledge from the climate movement."

(Jason, interview, 17/09/2020)

Much of the interview with Joe tracks his journey to SCA, clearly linking it to anti-capitalist and union movements overseas as well as previous climate groups in Aotearoa such as ClimAction. There are also overt links to the union movement, as Joe works for a union, and socialism, as "probably primarily most of us who are leading the development of System Change were involved [with Socialist Aotearoa]" (Jen, interview, 18/08/2020). Greenpeace's origins are tied to a movement that forms a part of Aotearoa's identity, fostering a strong and long-standing relationship:

"Greenpeace emerged from the anti-nuclear movement, and so New Zealand was a very early host of Greenpeace for that reason; because of the protests against nuclear testing in the Pacific ... historically there has been a sort of close connection between Greenpeace and New Zealand identity in terms of that nuclear-free history."

(Greenpeace, interview, 24/08/2020)

\footnotetext{
12 The skills and knowledge that exist within the disability community and the disability rights and justice movements.
} 
For Tina, Indigenous movements have always been a part of the climate discussion, even if not heard in the mainstream channels (or reflected in the literature). Environmental advocacy is inherent to Indigenous culture in that sense there is not so much an origin or catalyst, although colonisation could be considered one:

"The Indigenous rights movement has been combating climate crisis and climate issues and planetary assault ... for decades and generations as well ... since colonisation arrived and the way that colonisers treat the planet. ... So, the Indigenous rights movement really was there at the very birth of - and I would go so far as to say were the birth of - the climate movement as well."

(Interview, 12/08/2020)

To understand climate justice, we need to understand the histories of social movements that have developed the concept over the past decades (Schlosberg \& Collins, 2014). There are clear cultural and ideological ties between climate justice and environmental justice, Indigenous and land-based people's movements, anti-nuclear, organised labour, and the civil rights movements (particularly in the US), as well as similarities in organising tactics, principles, and demands (Dawson, 2010; della Porta \& Parks, 2013; Schlosberg \& Collins, 2014; Tokar, 2019).

\subsection{Theories of change}

The concept of theories of change is utilised in practice yet not well developed in environmental activism literature (Hestres \& Hopke, 2020). Literature on the environmental, climate action and climate justice movements in Aotearoa tends to focus on the level of tactics and pays closest attention to protest actions. Articulating the experiences and strategies behind these tactics, Bond et al. (2018) identified several 'approaches' of oil free and climate justice activists. The similarity between these approaches and the theories of change articulated by participants are outlined below. Theories of change are the overarching strategies that inform tactics and approaches. Hestres and Hopke (2020) note that "by grasping a campaign or movement's theory of change, we can understand its ultimate goals, the strategies and tactics it intends to use to achieve them, and how those tactics cohere (or not) into a strategic whole“ (p. 373). The five theories of change clusters outlined below were identified throughout the interviews as overarching strategies that included problem, solution, and long-term goals. Given the paucity of literature on the concept, in this thesis 
'theories of change' is also applied literally as the theories participants hold of what kind of changes are required and how these will and/or should occur. I observed some tension between the 'will' (belief of actual) and 'should' (ideal) elements which could benefit from additional research. ${ }^{13}$ 'People power', the power of collective action cuts across the five clusters and forms the overarching theory of change. The five theories of change clusters: Interconnected problem and solution; accessible, inclusive and democratic; information and education; relationships; and systems and power enable and are enabled by 'people power' as the super theory of change.

\subsubsection{Interconnected problem and solution}

Some participants stated that climate justice will be achieved by focusing on social justice. If people's needs are met, they can focus on the climate:

"Maybe just fixing our social systems will, as a by-product, fix the climate stuff, because if people are in warm dry homes, living locally, living as communities, getting what they need... their mental, ... physical ..., emotional wellbeing $\ldots$ are being met.... Then we've got the mental space to really care about the world around us and look after others and ... our environment.”

(Alicia, interview, 20/08/2020)

Additionally, this approach forms a proactive part of "creating a better world for everyone, that's fairer and more just" (350, interview, 27/08/2020), and making it tangible and meaningful to "ordinary people ... rather than just being purely abstract" (Jen, interview, 18/08/2020), and thereby increasing engagement. These points link to Nicky's views on the process and relevance of decolonisation. They are not separate; they are interlinked and occur at the same time:

"It's not like you decolonise and then solve these problems.... You fight the current fights and that's part of the decolonisation. .... It's not like first we have to decolonise before we can do these other things.... What we're doing now ... is part of the decolonisation."

(Interview, 22/08/2020)

\footnotetext{
13 This tension was particularly apparent in discussions on COVID-19 which have largely been omitted from this thesis due to length constraints but will be the focus of a subsequent publication.
} 
Community care and wellbeing in the form of support networks during the oil free campaign created alternative futures and space to debrief, enabling maintenance of energy in the face of delegitimization, censure, and dehumanisation (Bond et al., 2018). This approach speaks to this interconnected problem and solution theory of change, which sees the means and ends of change interconnected and enacted simultaneously. This theory of change also links to Wrights' concept of interstitial strategies and escape logics, where the focus is placed on creating alternatives to the current system (Stuart et al., 2020).

\subsubsection{Accessible, inclusive, and democratic}

Participants agreed that climate justice activism must be accessible and inclusive because "movements aren't movements unless everyone is part of it" (350, interview, 27/08/2020). There is an awareness among participants that creating spaces that people feel they can identify with is an important part of this:

"It's quite daunting looking [from] outside. ... just making space for people and giving them the resources that they need to feel comfortable enough to act within it."

(Lourdes, interview, 07/09/2020)

To make climate justice and activism more accessible, participants noted that these movements must also look beyond their spaces to people themselves:

"Switching on people's imaginations and turning off their cynicism ... to feel 'I'm an agent of change and my decisions matter.'... I think most people feel disconnected from the systems that govern our everyday life because they don't feel represented, or they don't feel that it's accessible, they can't participate in the system."

(Tamatha, interview, 24/08/2020)

Part of making these movements more accessible and inclusive is about bringing activism to people through doing locally situated work and decentralising movement power: 
"We wouldn't run a campaign where the only way that we can use power is by lobbying officials in Wellington. ... The campaigns that we run are distributed on purpose, and always make sure that if you're in Tauranga or if you're in Invercargill there's ways that you can be feeding in."

(350, interview, 27/08/2020)

Furthermore, being locally grounded can enable greater connection, resource and, in Chlöe's argument, enable normalisation:

"If we put down roots in a space ... then we're able to deal with people at the coal face of issues and for me that's what grassroots change actually is ... having a geographical area which normalises your kaupapa and stops you being perceived as on the fringe."

(Interview, 07/08/2020)

Bond et al. (2018) noted that oil free and climate justice activists mainstreamed or universalised their concerns, focusing on smaller, more relevant issues to build critical mass. This approach relates to the accessibility theories of change cluster, as well as the information and education cluster outlined below. Oil free and climate justice activists also attempted to mainstream activism as something comprising everyday New Zealanders. However, this created tension around whether they were compromising to win the middle class over and, by mainstreaming debate, creating binaries which impacted their ability to connect with iwi and hapū (Bond et al., 2018). While mainstreaming would sit within accessibility, the debate about courting the middle ground speaks more to the collective identity debates explored in the next chapter.

\subsubsection{Information and education}

Education and accessible information were also a common thread of how to create the change needed. While the need to reform the formal (settler colonial) education system was mentioned "we all know that the education system is dying for a total overhaul" (Tamatha, interview, 24/08/2020) - the use of education as a tool was often referred to in more informal ways: 
"I place a huge amount of focus on education, and engaging people, and storytelling, and telling that story through a wide range of ways, telling it in a way that resonates, especially for Māori and Indigenous people.”

(Tina, interview, 12/08/2020)

As previously mentioned, Alicia, approaching climate justice from a parent's perspective, is attuned to the generational nature of social progression; the ways in which generations (and different cultures), through broadening perspectives, educate each other. Conversations were frequently referred to as an important everyday tool for education and social change, utilising social capital to influence others "at the school gate or on the sports fields" and to connect dots, each one building on the other to create "a ripple effect" (Alicia, interview, 20/08/2020). Tamatha speaks to the power of communication in her role as a local government representative, pushing back against the idea that elected members need to be experts:

"It's more about the way that you communicate that to people. ... There's two sides ... feeding into the structural kind of element of what options will be made available for people, but then $75 \%$ of that is also how do you communicate to people to pick the climate friendly option. ... You want the person leading these areas to be someone who can actually connect in with people."

(Interview, 24/08/2020)

Similarly, Nicky refers to political change as "people talk[ing] new ideas into existence" over time, through repetition, creativity, and persistence (Interview, 22/08/2020).

\subsubsection{Relationships}

Relationships were referred to by all participants, supporting the emphasis on a social constructivist research approach. Sometimes referred to as the 'invisible work', relationships were the most consistently mentioned element across interviews as a feature, definition, and theory of change of climate justice:

"We inherently see that the relationships are the work ... and the actions, the protests, those kinds of things fall out of the relationships. If we're in good relationship with each other, then we can organise a protest effectively that is safe 
and appropriate for all our communities ... and then we don't we have to spend as much time trying to craft this big narrative around why we're mandated to do something, because you're actually mandated to do something, because you have those relationships."

(Kera, interview, 02/10/2020)

Several relationship categories exist within these discussions: human-to-human, human-toenvironment, and human-to-structure or system. Within human-to-human there are also several types: within and across movements, to government, to industry, personal, and cultural. The increased urgency and likelihood of catastrophic climate change is seen as increasing the importance of relationship work as highlighted by Greenpeace in the opening quote to the introduction chapter:

"It's about changing our relationship with each other and with the natural world so that we can live in this climate change world in a way that is kinder and more just."

(Interview, 24/08/2020)

Climate justice work is structured and driven by relationships or the social aspects of activism; this includes friendships as well as more formal, organisational relationships. Personal relationships have shaped the organisational relationships of 350 :

"I've been doing climate stuff for ages, and heaps of my friends work in the climate space. ... The closeness is just as much relational as it is our organisations. One of my best friends is now the climate campaigner at Oxfam. 350 and Oxfam don't have heaps in common, but we talk most days to help each other out with our work because campaigning is hard in a pandemic. ... That's closeness based on [friendship]. In terms of organisational closeness, again ... the person that was formerly the director of 350 had a lot of friends at Greenpeace."

(350, Interview, 27/08/2020)

Within the relationship work, Pākehā climate justice allies have responsibilities in educating other Pākehā: 
"I think a big part of it is making sure that our spaces are spaces for non-white people. ... bringing our existing people that have been on our mailing lists for ten years ... making sure that everyone who interacts with 350 is brought on some kind of justice journey. Our role is to deepen people's understanding of what climate justice means and how different issues intersect with climate change. ... I think this is our job as Pākehā individuals: [ to] not write people off and to cancel, but instead to spend time with people to help them understand."

(350, interview, 27/08/2020)

Additionally, Pākehā support of frontline communities involves relinquishing the power over decision-making that currently exists in those relationships instead of setting the agenda:

"A big part of that is relationships that are not 'oh how's this going to benefit us?' ... this is more invisible work ... how can we offer support and money for other activist groups ... as well as building relationships with communities that we see ourselves as accountable to ... in ways that work for them more than they work for us? ... It's more about hearing what's needed and responding to that and being active about going out asking people what they need."

(350, interview, 27/08/2020)

The centrality of relationships in climate justice is evident in the following chapter as well as explicitly expanded upon in the conclusion chapter, as climate justice is a politics based in connection, grounded in existing communities and capacity (Derman, 2019).

\subsubsection{Systems and power}

There were also many references to high-level, strategic concepts of how to enact climate justice, centred on systems and power. As noted in the literature and by participants, the actual dismantling of current systems that are seen as the root cause are both a goal and action. Given that the current systems are the issue, it also requires approaching change through every one of those systems:

"It really does require a systemic change, there's no way that you can tweak the current systems that we have in place to gear ourselves up to deal with that ... through every system that we have in place." 
(Tamatha, interview, 24/08/2020)

Power, and building a counter people power was a clear and obvious theory of change amongst all participants. However, there was variation in how participants thought this could be best achieved. Several who worked in unions recognised the institutional setup of unions as being well-suited to do this work, and workplaces as the place where capitalism is "weakest and where we're strongest" (Joe, Interview, 18/08/2020). Several participants viewed unions as a crucial tool for building community power:

"Nowhere better is there to do that than the union movement because it's organised, it's resourced, it's where the rubber hits the road in terms of people's lives and work."

(Conor, interview, 29/09/2020)

Revolutions were also referred to, but in abstract ways, in part due to the variation in definitions. Nicky noted that there is a "need to define exactly what they mean by that, because we don't have many revolutions" and in his view "the things which are revolutions of ideas happen through essentially public movements" (Interview, 22/08/2020). A revolution is seen as close, just requiring increased connection by Lourdes: "The revolution is one meeting away, people just need to sit down, be connected to each other, and all have similar thinking" (Interview, 07/09/2020). Likewise, Tamatha referred to the movement's initial perceptions of COVID-19 as a possible trigger point for a revolution, with capitalism brought to its knees (Interview, 24/08/2020).

Both Chlöe and Tamatha, currently politicians, theorised change as operating across two interconnected spheres: structure and culture:

"Within the structural you've got legislation, regulation, funding, taxation ... which is the blueprint, and there's a disproportionate amount of focus placed on that when we don't talk about culture. ... being a shared set of values [that] enables us to live in a diverse society where people come together. ... I think that my role in parliament, whilst absolutely I have the potential ... to try and change structure ... is far more within the realm of culture and ... to influence that collectivisation ... create that environment that's conducive to structural change." 
(Chlöe, interview, 07/08/2020)

A collective mind-set culture is developing within the culture sphere, also referred to by other participants, contrasting the current dominance of neoliberalism. Tamatha draws this change right back to colonisation:

\begin{abstract}
"What reinforces climate change is an individualist mind-set because you're not thinking about your impacts on the environment because you're thinking about yourself. ... and that's why the whole decolonisation conversation is important.... The fundamental change when colonisation happened in New Zealand is that you went from a collective mind-set where there was collective ownership and responsibility over the environment and our actions to an individualist mind-set ... property rights and your individual title and responsibility."
\end{abstract}

(Interview, 24/08/2020)

Despite the urgency of climate change and climate justice, there was an understanding that transformational social change is a long-term process. Conor referenced the Springbok tour protests which “didn't just happen overnight, that was decades of organising, and then moment came when there was like a zeitgeist of this not being okay, and it split the country" (Interview, 29/09/2020). Nicky likewise refers to political change as a marathon requiring persistence (Interview, 22/08/2020). Furthermore, after theorising of a rapid revolution brought on by COVID19, Tamatha noted that societal change is more realistically:

“A real slow-burning process about igniting people's sense of collective ownership over those systems so that they can realise that if they're not working then we need to throw them out."

(Interview, 24/08/2020)

Many participants referred to more than one theory of change in their interview. Sometimes this was the case of individuals holding a different (and potentially conflicting) theory of change to the organisation they belonged to. Other times this conflict was internal, a tension between how they think the change should occur versus how they believe it will occur. This is an area that could do with further research and analysis as well as whether the theories of change that movement actors 
describe aligns with their actions. Crucially, the five theories of change clusters identified in the data set are complementary rather than mutually exclusive. They were often discussed and deployed in conjunction or considered enabling or a pre-requisite. As they are all interrelated, it would be difficult and potentially futile to attempt to sequence or create a hierarchy, instead they should be viewed as theories of change that operate simultaneously, reinforcing and supporting each other in a symbiotic relationship. This is worth remembering when seeking to understand the conformity versus diversity tension outlined in the following chapter.

\subsection{Impact}

Impacts look at what changes can be attributed to the actions and existence of movements, explicitly or implicitly, ranging from individual participants to political culture, state policies, other movements, or an improvement in circumstances (Almeida, 2019a). This is difficult to determine, and, as such, there is less academic consensus on outcomes, particularly around ability to control for non-movement influences (Almeida, 2019a). Participants were highly reflexive on both climate action and climate justice in Aotearoa, not just drawing on historical examples or literature, but also reflecting on their own impact. Recent examples of successful impact were often limited to awareness or empowerment. Having no impact was deemed a failure, as were actions that had a negative impact. Nicky observed that unsuccessful actions reinforce disengagement:

"Ordinary people have [heard] for a long-time people saying this is the biggest environmental issue in the history of the world ... and then they've watched relatively ineffectual ... political activity, which is fundamentally discouraging, because you can't ... emotionally accept that there's a really big crisis and then change your lightbulb and think everything's alright. ... There has to be the possibility of doing things which make a difference on the scale of the problem.... It is totally rational that people would switch off ... because it's just so disappointing and impossible."

(Interview, 22/08/2020)

Noticeably, participants found it difficult to measure the impact, and this created disillusionment. In general, there was a sense of confusion around impact and "what's success or [what it would] 
look like or feel like because it [feels like] there will always be more to do" (Sophie, interview, 10/08/2020). There was also a palpable questioning of the significance of smaller or fleeting milestones that are seen as occasionally taking over focus: "It's so flash in the pan. ... Have we actually achieved anything because someone wrote an article? Do people read it?" (Alicia, interview, 20/08/2020). And in Mel's case, this caused her to leave XR:

"It's really hard to tell with XR, and that's one of the reasons I think I've kind of drifted away from it is that it is just so woolly, and the demands are ... hard to see and I don't know if it had any affect."

(Mel, interview, 08/07/2020)

The lack of tangible impact on government decisions was also an issue raised by participants: "with that amount of people, I kind of hoped that we would've had more of an impact directly on linking in with the legislation and policy" (Sophie, interview, 10/08/2020). Likewise, Knox (2019) notes that while climate justice framings are relevant to the 'developed' world it has not gathered as much consideration in policy and practice.

Several participants also recognised that they didn't expect to achieve or see the successful outcome any time soon, or even within their lifetime (Lesley, interview, 23/09/2020): “I don't expect to achieve them tomorrow, next week, next month, even next year. ... I just assumed that this would fail" (XR, interview, 15/07/2020). Occasionally, this confusion, intangibility, and perceived lack of impact feeds into a sense of pessimism regarding impact: "An established fact on the left that if we don't do something about climate change in the next ten years then we're going to pass a tipping point and it doesn't matter what happens after that" (Joe, interview, 18/08/2020). However, this is more often seen as being pragmatic: "I think we're realistic enough and been involved in social action for long enough to not have too high expectations of rapid transformational change" (Lesley, interview, 23/09/2020).

Success, when recognised, was often measured in numbers, and what size was considered success varied based on context. 40 newcomers accounts to a successful meeting for XR (XR, interview, 15/07/2020), and a climate worker strike of 60-70 during the end-of-year holidays, was successful for Auckland (Joe, interview, 18/08/2020). Several participants, including Sophie, referred to the surprising and impressive numbers at the September 2019 strike: 
"Because the movement's still kind of young and we did not expect it to kind of grow as quickly as it did, especially September, did not expect quite that many people. ... 170,000 people."

(Interview, 10/08/2020)

There were several other examples given by participants of success, such as the broad appeal of the September SS4C march demonstrating that people do care, regardless of age:

"It opened up possibilities which have felt closed down for a long time. ... When it's blocking the whole street of big cities, and it's not just young people, but it's definitely not just old people; therein lies the hope for possibility of change."

(Nicky, interview, 22/08/2020)

The divestment of funds and other outcomes also demonstrate what campaign tactics work - a success in itself (350, interview, 27/08/2020). There was a sentiment across interviews that it was important to acknowledge success where you can, not even having to be a complete success: "I would say it's like $80 \%$ won, there's a crack in the door still but pretty much this movement ${ }^{14}$ has been successful" (Greenpeace, interview, 24/08/2020). Despite the limited specific examples of success, there was a tangible sense of optimism amongst participants, and this was consistent with the optimistic framings used in the social change conferences I attended in 2020 (DevNet 2020, SMRSC 2020). This belief that the movement will continue to grow is based on several influences, societal norms, necessity, and belief in the goodness of people:

“There's no way it's not going to grow and get stronger, because impacts are going to keep happening and ... it's going to be shifting to vital importance. ... It's pretty ingrained that the good will win. ... In every movie we ever watch it's like stick to your principles and you'll come out on top.... People at heart are decent and people are at heart compassionate, that's proven."

(Mel, interview, 08/07/2020)

\footnotetext{
${ }^{14}$ Referring to the movement against offshore oil exploration.
} 
This sense of hope also leverages off movements and movement leaders of the past such as Martin Luther King Jr's 'The arc of the moral universe is long, but it bends towards justice':

"I hold on to things like [that] ... things are really going to start breaking down, and that is going to throw up some really challenging situations but also some opportunities."

(Conor, interview, 29/09/2020)

Once again, threats (or challenging situations as diplomatically put by Conor), and opportunities are discussed simultaneously by participants. This yearning for an optimistic outlook sometimes ran explicitly counter to 'evidence'. "I immediately can see how flawed that whole [3.5\%] idea is, but you hold on to the hope" (Conor, interview, 29/09/2020). Optimistic but realistic constructions of success are noted in the literature as important for longevity. Cretney et al. (2016) noted that the definition of success was an important factor in sustaining momentum and engagement in the Brooklyn Food Group, a subgroup of the Brooklyn Transition Town group, which had a relational approach to scale, realistic goals, and celebrated smaller achievements. The impact of movements - what works and what does not - was highlighted by most participants as an area of interest within this research. While an implicit analysis of what works and what does not is present in both this chapter and the next, further research explicitly focused on measuring the impact of movements and specific campaigns and tactics would be beneficial to these movements.

\subsection{Conclusion}

In this chapter, building on the experiences, perspectives, and knowledge of my participants, a picture of climate justice in Aotearoa begins to form. It is distinct from climate action - the dominant paradigm within the climate movements of Aotearoa. Climate justice centres frontline community perspectives - those who are least responsible and most impacted by climate change. Unsurprisingly this justice focus is built upon the foundations of previous justice movements: environmental justice, Indigenous justice, and disability justice. Which justice is emphasised varies depending on the individual and is often tied to their own community or those who they have formed relationships with.

Given the contextual and subjective nature of climate justice, who is considered a part of these emerging movements is likewise contentious and fluid. There are several groups that operate 
within climate justice spaces from an explicit climate focus, including Sustained Ability, Pacific Climate Warriors, Te Ara Whatu, and 4 the Kulture. However, there are also many individuals who do climate justice work, including those who do not associate with the term or as climate focused activists, particularly Māori. This is an issue of collective identity that these movements, both climate justice and climate action oriented, needs to address. Other groups, including mainstream and well-known movements, and NGOs interact with climate justice to various degrees and levels of success.

Origins and catalysts are often negative and reactive, although the optimistic opportunity framing is sometimes applied. International events and organisations, including the UNFCCC and IPCC, continue to have a significant influence; most of the participants' organisations started out as a result of these influences, either directly or indirectly. Additionally, the national government also frequently spurs action; supporting the inclusion of political process theory in this thesis.

The overarching, super theory of change remains 'people power', but there are numerous interpretations of what this means and how to achieve it. The most prominent theories of change involved education, information, relationships, and systems, with accessibility, inclusion, interconnection, and democracy as more than guiding principles. Movement actors, including my participants, are highly reflective, particularly when it comes to impact. Understanding or perceiving the impact at present is a mixture of pessimism and optimism. There is substantial confusion and frustration, however, small, tangible wins and hope drive these movements onwards.

Climate justice is an emerging, fluid, and subjective space that challenges the political, social, economic, and cultural structures and norms that are seen as inherently connected to climate change. In doing this, it not only conflicts with mainstream climate governance, but also with mainstream climate action movements. The next chapter explores these tensions that exists within the climate movements of Aotearoa between climate justice and climate action. 


\title{
Chapter 4: Tensions in the climate movements
}

\author{
"What are the forces that are shaping the conditions in our society for dealing \\ with this bigger problem?"
}

(Greenpeace, interview, 24/08/2020)

\subsection{Introduction}

Contentious politics, a concept that encompasses social and climate movements, analyses contention between actors, and often focuses on the tensions between movements and state, corporations, and societal structures (della Porta \& Rucht, 1995). Tension, however, also exists within movements, as the power dynamics, ideological conflicts, and identity and material grievances that generate the above exchanges likewise influence relationships between movement actors. In particular, the iterative development and negotiation of collective identity and diverse coalitions has been noted as generating conflict (Fominaya, 2010; Gawerc, 2019; Steinfort et al., 2017). Dietz (2013) noted that debates within climate movements are a source of conflict and negotiation as actors actively attempt to shape and guide these movements.

Above, Greenpeace's climate campaigner refers to the forces within society that shape society's ability to deal with climate change. These same forces are replicated within climate movements, as these movements exist and operate within society, aware of these forces but unimmune. Likewise, these forces impact the movement's ability to embody and enact climate justice, resulting in tensions and conflict. This goes beyond political process theories, and into the realm of structuration, examining the ways in which structures and agency interact.

This thesis intends to unpack the overall picture of climate justice in Aotearoa, including who is involved and what guides their approaches. As I showed in the previous chapter, climate justice is an emerging movement or collection of movements that build on the history and knowledge of previous justice movements as well as, and often more so than, the climate movements in which it sits. Definitions of climate justice are subjective, contextual, and fluid. Dietz (2013) also observed the varied use, definition and implementation of climate justice. However, while there is no 
coherent concept, conceptualisations are similar and no significant conflicts amongst actors arising out of these differences were noted, although intra-movement communication has occasionally become aggressive and disrespectful (Dietz, 2013). Similarly, when conducting interviews with a diverse range of activists involved in the climate movements of Aotearoa, the subjectivity of climate justice is echoed in the choices, theories of change, and actions they make in the name of climate justice. Several distinct 'tensions' became visible: partisanship versus non-partisanship; internal conformity versus diversity; and individual ego versus the collective ecosystem. These tensions speak to the interactions taking place between the emerging climate justice and the existing mainstream climate action framing, shaping both movements in their ongoing collective identity negotiations that drive theory and practice. These three tensions are both explicitly and implicitly linked to the mainstream climate action movements more than the emerging climate justice movements, with the exception of where the two meet and co-option takes place.

Building on Dietz's (2013) overview of conflict in climate change movements, this thesis takes a closer look at the way in which inter and intra-movement tensions impact relationships, theory and practice, and collective identity. In this chapter, I show that the climate movements of Aotearoa are far from a unified field of action. Before conducting this research, I was aware of some tension within these climate movements, namely issues individuals and communities have had with Extinction Rebellion (XR) and the Green Party. However, as I explain in this chapter, these organisation-specific issues are part of a much larger picture of contention across these movements.

\subsection{Tension one: partisanship versus non-partisanship}

The decision on whether to be partisan (strongly and/or explicitly supportive of a particular political party) or non-partisan is something that impacts both individuals and groups involved in climate action and climate justice. Given that movements operate in both partisan and non-partisan spaces, and that the choice is often tied to individuals' theories of change and experiences, this tension is unlikely to be easily resolved. Partisanship is linked to social movement identity, the "us versus them" mentality serves as a motivator and defines identity boundaries (Bugden, 2020, p. 3). Political parties can act as umbrellas under which a variety of movements co-exist (Bugden, 2020; McAdam \& Tarrow, 2010). Bugden (2019) sees climate change as a "profoundly partisan 
issue", as partisanship is the most powerful factor in influencing actions, attitudes, and beliefs (p. 19).

\subsubsection{Partisanship}

While there are constraints to being partisan, particularly in job opportunities, Lourdes and Chlöe see a benefit in working within the system to change the system. The decision to become partisan for Lourdes arose when she was involved in SS4C, as they were having these discussions as a group regarding potential organisational allegiance. She stated:

"I really wanted to be engaged in politics ... and it has limited me in some ways. Both Luke and I [thought of] going to work at Greenpeace a while ago but we can't because of partisanship ... but it's also opened ... a lot of different connections that we've been able to make. ... At the time because everything seemed to be just getting worse and worse and worse over time and ... we're being acknowledged but nothing was being done about it, so I think part of it was impatience and frustration" (Interview, 07/09/2020)

More than just a desire to engage in politics through parliament, Chlöe and Lourdes expressed a perceived need to be involved in the 'inside' process of decision-making. Choosing to be partisan while identifying as part of the movement sits within 'symbiotic strategies' of social transformation, working within the system to create reforms, collaboration, and compromise, while dependent on pressure from movements (Stuart et al., 2020). It is also one interpretation and approach to the systems and power theory of change cluster identified in the previous chapter. Additionally, Stuart et al. (2020) and Wright (2016) note that climate change will require an increased role for the state. This is echoed by Goodrich (2019), who asserts that central government is the sole institution capable of implementing change on the scale needed to rapidly transition. Admittedly, no other single entity has a comparable reach across the various sectors and industries required for substantive climate action. Additionally, alliances between political parties and movements also provide important institutional links to the movement, as well as environmental credentials to parties (Dalton, 1995). 
Chlöe and Lourdes expressed awareness of the limitations of working within the system. However, Lourdes notes that this isn't the case for everyone who engages in societal change through the Greens:

"I've got a lot of internal conflict about theories of change and whether or not parliament is the best medium to solve any of our problems or ... should exist in the first place. ... that limitation in having to function within the system to try and get rid of it. At least I am aware, because I do see it within some of the Greens that they're not aware"

(Interview, 07/09/2020)

While there is a perception of freedom in non-partisanship, it comes at the cost of limited effectiveness through remaining outside of the decision-making structure, and movements are never free from the state's influence (O’Brien, 2012). Movements must respond to state intervention and organised opponents, which define movement scope, shaping both the need for, and perception of, success (Gale, 1986; O’Brien, 2012). Alignment with state imperatives is the strongest predicator of movement success, and the level of access to the state determines the scope of possible actions (O'Brien, 2012). Ironically, the formal political system that some participants and movement actors choose to avoid is ultimately the space in which change is sought.

Social movements need to organise themselves as a political party or build relationships with political parties in order to be involved in formal political action as parties are central in selecting representatives and setting the agenda (Dalton, 1995). ${ }^{15}$ The representation and valuing of frontline community perspectives on climate change is paramount to climate justice, as indicated by the interviews and the literature, therefore, representation in central government for the movement could be logical, as one avenue for representation. Jenkins \& Klandermans (1995), also look at the central role of the state in movement activity as the target, antagonist, sponsor and arbiter. The state is the regulator of the political environment in which movements take place, and movements ultimately either implicitly or explicitly (as with climate justice) aim for political representation (Jenkins \& Klandermans, 1995). Early NSM theory contended that NSMs tend to work outside institutional frameworks (including partisan politics) but its assumptions are not always correct,

\footnotetext{
${ }^{15}$ Formal political action and formal political inclusion (below) relate to activities or inclusion in the formalised political system of governance, this includes but is not limited to elections, submissions and petitions.
} 
with Dalton (1995) finding that, contrary to theory, ecology groups are more likely to work with parties despite their unstructured, non-bureaucratic NSM form.

In Lourdes' experience, being partisan has also impacted the formality of ties within these movements:

"Pacific Climate Warriors; they're also non-partisan, and I think that will go for a lot of the groups that I'm not formally a part of but will work with, just because I'm very partisan at the moment. So that's why I've kept out of, but still support, a lot of what Pacific Climate Warriors are doing and Te Ara Whatu is doing."

(Interview, 07/09/2020)

The informality of connections and general disconnect within these movements is explored further in the next tension: conformity versus diversity. Downes (2000) also states that differing levels of formal political inclusion, limited inclusion, and exclusion, have different impacts on intermovement unity and can lead to fracture. This excerpt also highlights that decisions on partisanship status are not fixed, noting that Lourdes is partisan "at the moment".

\section{The Political Party: The Greens}

Downes (2000) states that the introduction of mixed member proportional representation made parliamentary representation more achievable for the environmental movements, with a successful introduction to parliament for the Greens. The two Green Party participants see the party as being a part of climate movements as the "parliamentary branch" (Lourdes, Interview, 07/09/2020), and these grassroots movements as vital to the party (Chlöe, Interview, 07/08/2020). Contrarily, Rucht (1999) considers whether green parties are vital parts of movements or outgrowths to be treated separately. Based on their electoral and parliamentary politics focus and adoption of the structure of established parties, he concludes that they are separate. Nevertheless, the presence of green parties still effects environmental movements, including pushing other parties towards taking on board environmental concerns out of competition (although at times tokenistic), or through affecting decision-making if their numbers are sufficient (Rucht, 1999). Additionally, by referring to green parties and using their strength (parliamentary numbers) as an indicator of the impact of environmental movements, Rucht (1999) implies a partisanship to these movements. Dalton (1995) notes that movement individuals and groups often play roles in the emergence of green 
parties. Both the literature and participants imply an inherent partisanship but avoid addressing and discussing this explicitly.

While most participants are formally 'non-partisan' (except the Greens), many made comments that implied an inherent partisanship individually and collectively as a movement. Despite individuals or organisations not being formally connected to a political party, they were often either informally connected (through friendships, history, or solidarity campaigns) or in support of one. Dalton (1995) noted few formal ties between environmental movements and European parliaments at the time, but there were partisan perceptions and informal contacts indicating latent partisan tendencies. Instead of partisanship, Dalton (1995) saw temporary and contentious relationships between parties and movements, usually informal and personal. These observations of the European environmental movements and politics are visible in the comments made by my participants. Participants explicitly and implicitly acknowledged that when it comes to climate change (and justice) that some parties are more supportive. As environmental and climate movements are most closely linked to the Greens, both within and without, much of the critique of partisanship and party politics was directed at them. Similarly, during Dalton's (1995) research interviewing environmentalists many avoided questions around partisan preference. Nonpartisanship was the norm, although sympathetic parties could be named if pressed.

\subsubsection{Non-partisanship}

Dalton (1995) theorises three partisanship options for environmental movements: alliance with an existing party; with a new 'green party'; or to be non-partisan, as “environmentalists cannot (or should not) develop alliances with political parties, and instead should work outside of the established channels of partisan politics" (p. 306). Some environmental groups are hostile to parties due to (perceived) conflicting goals and philosophy, assuming parties are "uninterested in true environmental reform" (Dalton, 1995, p. 306). NSMs are more oriented towards civil society and bottom-up change (Downes, 2000).

Many participants see benefit or necessity in a sense of neutrality, real or perceived: "a neutral platform" (Mel, interview, 08/07/2020); “independent ... in premise” (Sophie, interview, 10/08/202); and "not pushing any particular political views" (Lesley, interview, 23/09/2020). Dalton (1995) notes that organisations may present themselves as a non-partisan interest group 
without any loyalties, preferences, or duties in order to maximise their political influence. Formal political inclusion within the environmental movements in Aotearoa can enable movements to have direct influence on decision making, but it also means having to compromise and engage with elite structures (Downes, 2000). Engagement isn't on an equal playing field, as movement actors operate at a resource disadvantage (Downes, 2000). Polarisation is replicated in the general population; people interpret partisan protests through partisan reasoning, ultimately limiting the ability to increase public support for movements (Bugden, 2020).

Many participants stated that currently no party is sufficiently climate justice-oriented to warrant a partisan stance. Specifically, they referred to the need for a bolder anti-capitalist and decolonial approach:

"I see a lot criticism of the Green Party; that they're not green enough ... trying to be in the middle to please everyone, and everyone kind of switches off from it."

(Mel, interview, 08/07/2020).

Participants argued that political parties also frequently co-opt movements, both historically and at present. Furthermore, by being a political party they are engaging with (and therefore reinforcing) the very political structures and systems that these movements seek to change:

"The environmental movement, the Green Party tries to shape that movement. You cannot simultaneously face both ways towards green capitalism and towards ecosocialism. The green parties ... can quite rapidly betray the people who voted for them, who are voting for something like system change, subconsciously or consciously."

(Joe, interview, 18/08/2020)

There is tension between electoral politics and movements through co-option and pacification by the former of the latter, such as the nuclear freeze movement in the US, which, once absorbed into the electoral system, was unable to shape policy in any meaningful way (Jenkins \& Klandermans, 1995). Personal experience and evidence within the literature supports participants' hesitance to engage with partisan politics on various fronts. Additionally, there is a risk of parties (without 
environment as a core focus) supporting the movement while in opposition and then dropping it when in government (Dalton, 1995).

In Aotearoa, the Greens' inclusion in Parliament is a sign that environmental issues are becoming more mainstream (Carroll et al., 2009; O’Brien, 2012). The relationship between the state and environmental movements has become more ambiguous since the 1980s as environmentalism has become more mainstream and less of an outsider position (Downes, 2000). By co-opting environmental groups the state can gain legitimacy. Therefore, state motivations may not be genuine. Additionally, shorter-term coalitions trend towards being more co-optive and to avoid co-option, movements must consider state aspirations (Downes, 2000). The imperatives of the state - economic growth, legitimacy and security - are crucial to remaining in power, superseding other considerations (Downes, 2000; Dryzek, 1996). O’Brien (2012) found that campaign outcomes, while strengthened by protest action, depend on state priorities. Therefore, for a successful alliance movement aims need to complement state imperatives (regardless of the political leaning of the state at the time), and with environmental movements' desire to regulate industry, they are viewed as a risk to economic growth (Downes, 2000). Movements are then engaged with by the state as a form of conflict management (Downes, 2000). O'Brien (2012) also observed state incorporation of movements to reduce protest. Furthermore, if movement organisations are to engage directly with the state and parties, a strong civil society is needed to act as a counterweight to ensure a healthy democracy (Downes, 2000). Civil society monitors and holds the state accountable. This is a role that movements also play, except direct engagement with parties then becomes a conflict of interest in performing this role.

Ultimately, most participants saw party politics as incapable of, and counterproductive to, change: “The party-based system isn't working because it's become more and more tribal, and I don't even know who they represent anymore ... Parties get in and they go 'oh we're going to undo everything the previous the government did'."

(Alicia, interview, 20/08/2020)

In Dalton's (1995) research, environmentalists likewise spoke of doubts about the effectiveness of partisan actions to gain political influence, with negative past experiences fuelling the perception that it is unreliable and futile. This resulted in a hands-off, sceptical stance with political parties, 
not wanting to be tied to their fortunes (Dalton, 1995). Fundamentally, many of my research participants felt that movements could not and should not rely on actors within the system to change the system. Therefore, they choose to work 'outside' the political system:

"We're not seeking the endorsement of political parties or union leaders because a lot of those people actually have stakes in the system, and when push comes to shove won't change it; they'll try to reform it."

(Joe, interview, 18/08/2020)

Partisanship and non-partisanship both fit within the systems and power theory of change, both individual choices and oppositional approaches to that theory. Additionally, from a nonpartisanship perspective, partisanship is seen as conflicting with the interconnected problem and solution theory of change as it is seen to be reinforcing the problematic systems these movements oppose.

\subsubsection{Movements are political and partisan}

The literature on the politics of climate change largely ignores the matter of partisanship within climate movements. Empirical evidence on the partisanship of movements is rare. To date it is more subjective interpretations of both the ties themselves and the perception that the movement has of partisan politics (Dalton, 1995). Bugden (2019) notes that partisanship and social movements are seldom studied, with the relationship taken for granted and intuitive, and concrete analysis impeded by academic silos. Political process theory in SMS analyses and explains movement mobilisation and structure, and includes political parties and their structure, ideology, and composition (Jenkins \& Klandermans, 1995). NSM theories view protest as inherently political, yet also overemphasise the apolitical goals (Jenkins \& Klandermans, 1995). Within social movement studies, the focus often lies in the impact that movements have on the political system and polarisation, rather than the impact of partisanship on the movement and its outcomes (Bugden, 2019; McVeigh et al., 2014). Given that evidence indicates that climate change belief and action is heavily influenced by partisanship, additional inquiry into the partisanship debate within climate movements would be beneficial.

Whether to work within an imperfect system (development) in order to bring about change or improve outcomes also exists within Development Studies, forming a substantial part of both post- 
development literature as well as critiques of post-development as an "intellectual faddism" (Sidaway, 2014, p. 138). Early post-development focused too heavily on critique of the system. This ignored the material realities and needs of the marginalised and also highlighted the privileged background that many post-development thinkers came from: middle class, Western, and relatively affluent (Demaria \& Kothari, 2017; Ferretti \& Pedrosa, 2018; Sidaway, 2014). Sidaway (2014) argues that rejecting development in its entirety would also shut down the possibility of progressive transformations or acknowledging the practical improvements that have occurred in some places. As such, contemporary post-development focuses on alternatives to development as a practical application of critique of the imperfect system.

\subsection{Tension two: conformity versus diversity}

Occasionally, participants inadvertently contradicted themselves, acknowledging that there are many ways to create change (and this should be encouraged), while also referring to their theory of change as the 'only' way they understand change to be possible. This highlights the tension between whether there should be more internal conformity or diversity within climate movements in Aotearoa, which has various implications for climate justice.

\subsection{1 (Internal) Conformity}

Pressures towards internal conformity within climate movements operate in many ways. A prominent form is one theory of change being pushed over others. Sophie notes that these "ideas within the movement that some tactics work better than others ... kind of creates this divide" (Interview, 10/08/2020). These sentiments were even expressed in the interviews by participants, through referring to an action as a "real act of rebellion" or admitting in the past that they, too, had thought "this is what we need to do, and I know what we need to do" (XR, interview, 15/07/2020; Sophie, interview, 10/08/2020). These comments send messages that "unless you do direct action, nothing you do matters", which is "the problem that got [us here] in the first place, that one way is the right or the only way" (De-identified, interview, n.d.). As a participant noted, these narratives are not only harmful, they also reinforce the status quo ideologies that these movements are opposed to. They are also inherently inaccessible: "I think I do get a bit freaked out when people are very strong in their idea of one-way because it doesn't necessarily fit everybody" (Alicia, interview, 20/08/2020). 
Participants also noticed suggestions that one group or banner must be rallied under by all movements, like a "cult" (Alicia, interview, 20/08/2020). Mel worried about the risks of having these movements sit under a single banner, increasing the impact of risks such as failure or sabotage, instead suggesting that:

"The name of an organisation is a little bit irrelevant. The idea that we should draw everyone under this banner because this is the best one is unnecessary; as long as you have some kind of infrastructure where like-minded people can get together (to) plan stuff ... It's the outcomes and the general being part of this big unnamed push towards more climate action from all these different sides, instead of from one group."

(Interview, 08/07/2020)

Fox \& Frye (2010) speak of a tension of praxis (between thought and action) in the environmental movements, and a need to unify theorising. Across actors in various movements there are different worldviews on how opportunities and constraints (or threats) are perceived, as well as how ideology or vision could be translated into action (Fox \& Frye, 2010). Differences in worldviews can result in debates over ends and means, strategies and goals, and intention and effect. This translation process is ambiguous and needs to be negotiated by these movements (Fox \& Frye, 2010). The influence of worldviews on movement debates is evident in potential links between the conformity arguments and ecofascist sentiments which place averting climate change above the everyday considerations of people. In Aotearoa, participants noted a gendered element to this: "I've experienced predominately men pushing back going 'oh we just need to focus on the environment"' (Alicia, interview, 20/08/2020). These conforming narratives were also frequently linked to XR, even by XR themselves:

"I would say in Extinction Rebellion's defence in the context of Aotearoa ... if the end result of that organisation does benefit everybody then it's still a viable institution. ... I understand that argument, but I don't think you can apply that argument to Extinction Rebellion, because Extinction Rebellion's end goal is to prevent a climate catastrophe, which benefits everybody."

(XR, interview, 15/07/2020) 
While ecofascism was not explicitly referred to when discussing XR (above), the belief that if the ends 'benefit everybody' then the means need not be as inclusive is inherently ecofascist. When the end outcome is used to justify questionable or outright problematic means climate action becomes ecofascist. Furthermore, it was often XR's means to create change that participants took issue with regardless of whether their end goal was compatible. As the interconnected problem and solution theory of change highlights, within climate justice the means and ends of change are interconnected and equally important. Ecofascism uses authoritarian measures to protect nature, overriding individual liberties (as people are subordinate to the best interests of the ecosphere), and is grounded in nativist racism (Protopapadakis, 2014; Zimmerman \& Toulouse, 2016). It originated in 19th and 20th century Germany, when ecological concern was interwoven with nationalism, racism, and xenophobia (Dyett \& Thomas, 2019; Protopapadakis, 2014). The origins (and contemporary form) of mainstream American environmentalism (which has had global influence) is also linked to ecofascism, particularly neo-Malthusian overpopulation arguments, anti-migration, and wilderness ideals that are inherently colonial and patriarchal (Dyett \& Thomas, 2019; Zimmerman \& Toulouse, 2016). Ecofascism is inherently self-protective and does not include root causes or other sociocultural, political, and economic factors, pushing blame and responsibility onto the most marginalised (Dyett \& Thomas, 2019). The potential continued presence of these narratives exposes the problematic histories of modern environmental ideologies (radical and mainstream) that need to be challenged. The influence and presence of ecofascist sentiments in present day climate movements is an area where further empirical research and discussion would be beneficial, particularly as climate action movements endeavour to understand and apply climate justice concerns.

The XR member noted that due to perceptions of XR as exclusionary and harmful, some movement actors contend that XR should cease to exist or, at the least, they refuse to work with XR (interview, 15/07/2020). From these responses to XR we can see that these movements are collectively developing several 'non-negotiable' principles that all individuals or movements must conform to in order to remain legitimate. This highlights the possibility of 'positive' and 'negative' expressions of conformity within these movements. These comments were not only directed at $\mathrm{XR}$, but XR was by far the most common example used. 
Collective identity is a concept used by SMS to explain how movements build and retain cohesion (Fominaya, 2010). Created between individuals, it is a sense of shared experiences or attributes that stand in contrast to others (Fominaya, 2010; Snow, 2001). Development of collective identity requires the definition of ends, means, and scope through a common language, then enacted through practices (Fominaya, 2010). It acts as a regulator within the movement, enabling the articulation and mediation of internal differences (Fominaya, 2010; Steinfort et al., 2017). It is both a precondition and outcome of collective action: an iterative process of internal politics towards the coherent unity that the external institutional environment expects (Roth, 2008; Steinfort et al., 2017). Identity work integrates diverse constituencies, defines movement boundaries, and develops collective consciousness in order to interpret and make decisions, and to negotiate the evolution of the movement (Roth, 2008). Through the interviews it became apparent that cohesion and a coherent collective identity within these climate movements are often misinterpreted as conformity to certain tactics or banners within these movements. These conforming narratives can be harmful, off-putting, and verge on ecofascism.

\subsubsection{Disconnection}

Participants sense a disconnection or lack of unity within climate movements, sometimes attributed to insular bubbles and the above conforming pressures:

"We're just so in our own little bubble, so when a movement comes along and it's

like, let's unite behind this kind of vision for climate justice, people are like, well ... I've got my own idea of how this should be done."

(Sophie, interview, 10/08/2020)

This disconnection and forming of silos has occurred over time, building "a history in the climate movement in New Zealand where some groups don't get on with each other super well" (Sophie, interview, 10/08/2020).

Disconnection hinders the maintenance and distribution of knowledge, which Conor has seen occur within grassroots movements “over and over again” (Conor, interview, 29/09/2020). Sophie noted that burnout and capacity issues can play a role in the disintegration of relationships as “people just get so burnt out by what they're working towards ... that they kind of take things out on each other" (Interview, 10/08/2020). The longer the movement exists, the harder it is to avoid 
fragmentation (Nicholls, 2009). While these climate movements are not 'old', they are a continuation of the long-standing environmental and justice movements.

Regardless of the perceived cause, participants feel that our climate movements are not as connected as they could or should be:

"There are still a lot of them that are not engaged with each other, and so there is definitely a lot of operating in silos or having to work really hard to make those connection(s) and connect up with people."

(Kera, interview, 02/10/2020)

This disconnection gets in the way of support, fosters loneliness, and causes duplication. The lack of support is particularly important for movements that are increasingly driven by young and inexperienced activists who could benefit from tapping into the experiences and knowledges of more seasoned activists. On this, Lourdes said:

“There have been so many instances where the groups that I've been a part of have needed help and I've put out call outs, but because we don't know many people or with a formal connection, [there] has been that complete lack of support from other places. ... I feel like the system absolutely loves it when we're all disconnected from each other."

(Interview, 07/09/2020)

Lourdes observed that this disconnection is particularly noticeable between Indigenous and Pākehā spaces. The disconnection between these two spaces impedes the sharing and redistribution of resources and power within movements, as well as the collective identity (and ideology) negotiation work that is essential for climate justice. Groups often work alongside each other, on protests for example, or have overlapping people or personal relationships between groups, but lack formal connections. These formal connections enable resource sharing, as demonstrated by 350 and Greenpeace.

SMS literature talks about intra-movement connection in several ways, through networks, collective identity (including solidarity), and coalitions. Networks impact the stability of the entire movement; the geography of these networks are reflected in their function, with distant, weaker 
ties for information sharing, and local, stronger ties for diverse resource sharing (emotional, symbolic, and material) (Nicholls, 2009). Likewise, coalitions allow the pooling of resources and knowledge to enable greater ambition and leverage and, therefore, success (Gawerc, 2019). The collective is an emotional network of active relationships, setting the collective apart from 'others' (Fominaya, 2010). Della Porta and Rucht (1995) refer to social movement families (SMF), a set of coexisting movements with similar basic values, organisational overlap, and common campaigns despite having different specific goals. SMF are cyclical and change overtime; within SMF there are different strategic preferences but usually the same worldview (della Porta \& Rucht, 1995). However, climate movements (action and justice) in Aotearoa appear to have diverse (and often conflicting) worldviews, not to mention tactics, theories of change, and goals. Therefore, even if there is a shared desire for change, there are many ways in which organisations can differ that impact the ability to form coalitions, from ideological to tactical (Gawerc, 2019).

Shared ideology and culture can enable collaboration but is not enough when there is greater social distance or lack of ties (Gawerc, 2019). Social capital (trust, emotional ties, norms) influences how individuals within a network are coordinated, and solidarity is important for rules and strategies when formalised or centralised functions are absent (Nicholls, 2009). Emotions are an important part of collective identity, and positive emotional ties and experiences can keep activists involved despite not meeting goals (Fominaya, 2010). Trust can be the difference between discourse adoption (or co-option) and the substantive adoption of discourse through action (Nicholls, 2009).

Economic and cultural capital can be used to overcome distance and diversity; essentially, financial capital translates into social capital (Nicholls, 2009). Those with capital are more able to engage on all levels of movement strategy and action (Nicholls, 2009). An imbalance in resources can aggravate internal division in movements and reinforce structural power imbalances in setting norms that favour those who set them (Nicholls, 2009). Power and inequality within movements can hamper efforts to form coalitions, particularly through paternalism and condescending behaviour by the more privileged who dominate leadership roles (Gawerc, 2019). Resource and power imbalances were noted by several participants, including those who recognised themselves or their organisation as privileged. The lack of resources, both material and relational, particularly those from marginalised communities or new to activism, were also seen by 
participants as barriers to activism and community building. These resource and power imbalances also influence self-identification with the movements, especially for Māori. The literature did not specify whether this disconnect between individual and collective identity was necessarily harmful or to be avoided, however, it was clear in the interviews that lack of Māori identification with the movements is harmful for the individuals and the movements.

\subsubsection{Diversity}

Contrasting the conformist approach, a diversity-embracing approach present in participants' comments sees movements as a permaculture or ecosystem where many theories of change, people, and groups exist together:

"The way I see healthy activism as a movement is like a permaculture, so you've not a monoculture, which is if everyone was XR. Permaculture is there's so many different perspectives and different ways that people like to do things, and they're all valuable, and they all complement each other."

(Mel, interview, 08/07/2020)

An ecosystem approach to movements means there is no need for a unifying theory of change with "people focusing in different areas that support each other" (350, interview, 27/08/2020). Permaculture, originally a contraction of 'permanent agriculture', since extended to 'permanent culture', can be applied to resilient relationships (between people, and natural and built environments) (Gaisford, 2010). Permaculture involves decentralisation and system thinking, and, within this, diversity is key (Gaisford, 2010). The autonomous networks in the UK that Fominaya (2010) observed are "biodegradable", popping up and dissolving and resurfacing in other forms as necessary, rather than being permanent (p. 400). This fits within an ecosystem: a resilient and sustainable approach to movements as theorised and desired by participants.

Movement diversity is seen as part of the formula for creating change:

"Political change happens with a variety of different components, and if you've only got some components ... it's not enough on its own ... that's only part of the formula."

(Nicky, interview, 22/08/2020) 
Diversity enables collaboration and cooperation; other metaphors include movements as a puzzle with a focus on finding and filling gaps, with every group having its niche. Crucially, the puzzle metaphor recognises that being aware of how you fit into the bigger picture is important.

As my participants explained, these climate movements are already more diverse than they appear:

"There's parts of the environmental movement that are Pākehā, but I think that's based on what people think activism looks like as opposed to the actual climate space, which is super diverse."

(350, interview, 27/08/2020)

Diversity is seen as crucial and necessary. Alicia noted that each perspective is unique, speaking to their culture and experience (Interview, 20/08/2020). Acknowledging diversity in people and perspectives requires diverse ways of creating change:

"You have to work in different ways. There are different things that cause people to change, and, for some people, it is the disruption caused by Extinction Rebellion; for others it is a gentle spreading of information, and that helps people to be more aware and change."

(Lesley, interview, 23/09/2020)

There is no single answer on how to create societal change (Nicky, interview, 22/08/2020), especially with the complicated (and complex) terrain of climate change (Conor, interview, 29/09/2020). Bugden (2020), found that civil disobedience and peaceful protest were complementary, supporting Johnson et al.'s (2010) argument that tactical diversity within movements is advantageous. Building on my participants comments, the same could be said of complementary and diverse theories of change. Furthermore, within a singular theory of change diverse interpretations and applications can co-exist.

An important benefit of diversity is that it makes movements more resilient, as demonstrated during COVID-19: "[COVID-19 has shown that if you] put all your eggs in a couple of baskets for what your tactics are going to be, how those can all disappear" (350, interview, 27/08/2020). A diversity approach also recognises where people are at and what fits for them, creating more 
accessible movements, which are crucial in climate justice (and counter to ecofascism). People have different paces and capacities at which they create change:

"The best way is to mobilise people in whatever capacity they can, because for different people that'll look different, and that's totally fine, and we need to figure out how we can embrace all forms of activism as part of this movement. ... People might have five minutes in the day; they might have an hour in a day."

(Sophie, interview, 10/08/2020)

Furthermore, infighting about the 'right' theory of change, or moral purity and perfectionism of the left was raised by participants as a potential hindrance. Tina spoke of this:

"We schism into so many different ideas of what is right, and what is helpful, and what is true. It doesn't help us to become collectives. It winds up with issues like entryism where we take advantage of each other's movements to try and bring people over to what we believe the true movement is, and its winds up with just schisms and divisions."

(Interview, 12/08/2020)

Alicia notes that this debate ironically delays action instead of working on the solutions that we have that are 'good enough' for now and that can be adjusted along the way (Interview, 20/08/2020).

Being united is still desired by participants, but they would rather a sense of unity through connection instead of conformity. Participants like Lourdes see greater connection alongside embracing diversity as an important part of strengthening the longevity and effectiveness of these movements:

"It's genuinely more sustainable if we all start connecting a lot more ... doesn't mean we need to get rid of any groups; just really connect them, and if we've got this ability to share all of that knowledge and experience ... we can start really holding people accountable and getting things done."

(Interview, 07/09/2020) 
Collective identity theory argues that complete agreement is not required for individuals to act collectively, particularly in the case of NSMs, which define themselves by their differences (Fominaya, 2010). Movements are often both coherent and diverse, and movement identity is neither stable nor fixed (Steinfort et al., 2017). Diversity and inclusivity are important parts of a collective identity, otherwise identity would become either impossible or meaningless (Fominaya, 2010). A singular collective identity at the movement level does not exist, but rather there are collective identities (Fominaya, 2010; Saunders, 2008). There is a transformative ability within and surrounding collective identity to imagine, perform, and enact alternatives, and there is much variation in how this is translated into performance (Steinfort et al., 2017). Diverse coalitions enable a broader resource and audience base, which can increase mobilisation and leverage (Gawerc, 2019). As well as bridging societal divides, diverse coalitions encourage empathy, creativity, and effective problem solving (Gawerc, 2019). However, diverse coalitions also require more time and energy, and come with an increased risk of misunderstanding and conflict (Gawerc, 2019). "Identity-wars" occur as individuals and groups within movements push to have their identity reflected or centred (Chesters \& Welsh, 2005; Steinfort et al., 2017, p. 1450). Additionally, where conflict arises is not clear cut. Groups can appear to have compatible goals but have issues building alliances, and, conversely, seemingly incompatible groups can form alliances (Fominaya, 2010). Fominaya (2010) states that conflict is an important part of movement identification through reflexivity and understanding the environment in which it exists. This reflexivity and negotiation of collective identity, norms, and theories of change is apparent in the climate movements of Aotearoa as demonstrated by my participants.

\subsubsection{Strategic dilemmas}

Similar to the partisanship versus non-partisanship tension, where there are valid perspectives on either side, the conformity versus diversity tension is not straightforward. There are clearly ways in which conforming can be beneficial. The negotiation of collective identities, even if embracing diversity are a part of those identities, also requires a degree of conformity to be cohesive. The 'non-negotiables' that movement actors collectively identify and enforce are an example of positive conformity. Conformity is when an individual changes their behaviour or beliefs to fit within a group. It is not inherently positive or negative, and the rational and motivation behind the act is key, as is the active, rather than coerced, participation of movement actors. 
Despite non-partisanship and diversity being emphasised by participants more than their counterparts, there is no 'right' or 'wrong' side of these tensions. They are similar to what Jasper (2006) calls strategic dilemmas - the choices and trade-offs that movement actors face that demonstrate their agency. Often overlooked in dominant theories within SMS literature, movement actors are active decision makers (rather than at the whim of structural forces) who when faced with strategic dilemmas (or tensions) act with the bigger picture in mind (Jasper, 2006). Participants' inclinations towards partisanship or non-partisanship, and conformity or diversity are shaped by their personal perspectives and theories of change - what will best serve the outcome they strive for. The final tension, egosystem versus ecosystem is unlike the first two. The flowing tension has a clear 'right' and 'wrong'.

\subsection{Tension three: egosystem versus ecosystem}

Harm caused by actors and organisations within climate movements towards members or communities within the climate justice space, and the subsequent harm reduction work that it requires is a major tension. Not only does the harm create a negative impact on climate justice work, either perpetuating ableist and colonial narratives and structures and/or co-option of climate justice, it also extracts time and energy from climate justice advocates and communities. Instead of doing their own work, time and energy is spent educating, guiding, and countering the harmful actions of others. The harm, in part, comes from, and continues because of, ego, which inevitably prevents good relationship building, a crucial element of a healthy movement ecosystem. This tension reinforces the importance of the interconnected problem and solution theory of change and the equal importance of the means and ends of change.

However, there is reflexivity, awareness, and work happening in our climate movements to do better. In fact, several participants also explicitly or implicitly alluded to their own experiences of making these mistakes and learning from them. However, it is neither across the board, nor is it a linear or timely process. Instead, affected participants recommend 'doing the work' before jumping to act. This involves finding out who else is already doing this work or being affected, and then developing and prioritising genuine, long-term relationships. 


\subsubsection{Egosystem}

Although not widely mentioned by participants, the topic of ableism formed a significant proportion of the interviews for several participants. Often in the form of harmful narratives, it also included inaccessible activism and co-option of disability narratives and individuals. Disabled people have long been excluded from climate movements, and when individuals are included in tokenistic ways, it is used to excuse and reinforce the exclusion of the disabled community. Furthermore, Jason stressed that "one disabled person can't hold a community, and never should they be put in that position" (Interview, 17/09/2020). Jason explained the complicated and frustrating working relationship he and Sustained Ability have had with GenZero. GenZero's roots and approach to the Zero Carbon Act have been ableist, ignoring and dismissing disability as not 'climate action related' and subsequently not adequately engaging with disabled people to better understand the linkages, resulting in a law that is in breach of the UNCRPD". This law has "created 30 years' worth of work for us in terms of thinking about how we get disability on board" (Jason, interview, 17/09/2020). Despite attending the workshop on climate justice and ableism, GenZero have since launched another ableist campaign, and created several issues around collaborating on an Accessible Streets submission. Jason stresses that they're not aggressive, but lack understanding around disability kaupapa, and have dysfunctional and ill-formed relationships.

Colonial harm also featured, not surprising given the history of Aotearoa as well as the racist, ecofascist roots of Western environmental movements (Dyett \& Thomas, 2019; Zimmerman \& Toulouse, 2016). Colonial harms are present in climate movements in several ways. Tina raised the "blatantly racist and paternalistic [nature] towards the mana whenua" of the occupation at Ōwairaka, which is supported by some members of the Greens and other green NGOs (Interview, 12/08/2020). Furthermore, desire for "Indigenous wisdom and knowledge to inform the climate justice movement" is not preceded nor followed by solidarity, passion, and involvement in struggles for Māori language, or wellbeing:

"When we march for our language, which is what houses all of those cultural values and gifts and resources that people want to draw from to inform their movements, we usually are marching alone because people see that as a Māori issue. ... You

\footnotetext{
${ }^{16}$ United Nations Convention on the Rights of Persons with Disabilities.
} 
can't protect Indigenous knowledge, which is one of the core tools in combatting climate change ... if you're not also protecting the bodies that house and carry that knowledge."

(Tina, interview, 12/08/2020)

Additionally, movement groups mimic imperialism, spreading out from the UK or US and claiming to discover or lead the climate movement, what Tina calls "discovery doctrine 2.0. in an NGO format" (Interview, 12/08/2020). These groups lack awareness of their privilege, don't engage with Indigenous communities properly and often inadvertently cause the arrest or brutalisation of Indigenous persons or lands. Racism and classism are inherent to the colonial and imperial echoes in climate action (and climate justice) movements:

"That's just a failure to grasp that people of colour, working class people face existential crises every single day. It's true that the climate crisis will probably be the first crisis to be existential to every group in its scope; that doesn't mean that existential crisis [hasn't] already targeted specific groups."

(XR, interview, 15/07/2020)

In both ableism and colonialism, the co-option and tokenism of climate justice are reoccurring issues with:

"Climate action organisations rebranding themselves as climate justice ... basically co-opting this area that we have fought hard for after years of either ignoring or coopting our rights struggles."

(Jason, interview, 17/09/2020)

This has been amplified through COVID-19, with some ableist organisations having their theories of change fall apart and responding by co-opting disability language and rights (such as accessible streets, accessible internet, equal pay, and flexible work and education options as listed by Jason) once they realise that they were ableist. This frustration is further amplified by the fact that these rights were realised and put in place during COVID-19 when needed by the non-disabled community, despite having been advocated for and needed by the disabled community prior to the pandemic (Jason, interview, 17/09/2020). 
The above harm to the climate justice space and individuals within frontline communities necessitates harm reduction (identifying and dismantling harmful narratives in public forums and individual interactions), which is time, energy, and resource intensive, detracting from their own justice work. Additionally, the deceptive nature of co-option requires energy "for us to have to seek it out and uncover it in order to make our decision about whether we'll work with them or not" (Tina, interview, 12/08/2020). The climate action space demands labour from climate justice communities to de-construct and educate in a way that will be well received:

"So much time and energy has been [spent] on trying to be really nice about educating people like 'hey this isn't appropriate' $\ldots$ and having to try and do that in a kind of self-tone-policing way because you don't want to be the angry radical Māori or disabled person or whatever."

(Kera, interview, 02/10/2020).

It is also not as simple as ignoring the harm and focusing on their own work and communities, as "you can't grow that community if there's not already harm reduction going on" because "as soon as you go 'that's their shit to deal with' ... then those narratives ... inevitably end up affecting your ability to do your job over here" (Kera, interview, 02/10/2020). It can also be difficult to navigate the interconnected professional and personal relationships within the climate space and identity who is safe to work with.

Occasionally participants attributed the blame to ego getting in the way (Alicia, interview, 20/08/2020), preventing "people from considering how they can build good relationships with others" (Kera, interview, 02/10/2020). However, sitting behind individual and collective ego are paternalistic tendencies from imperialism, or white saviourism, all of which reinforce Jason's point that the current allyship model is not working (Interview, 17/09/2020). Tina noted that "colonial paternalism" within movements results in non-Indigenous actors "telling us how to be green. Them telling us how to be sustainable and completely oblivious to the implicit racism in those statements" (Interview, 12/08/2020).

Development, with the power to define, represent, and theorise the 'other' is a "fundamental and invasive white enterprise" (Bandyopadhyay, 2019, p. 328). Paternalist behaviour in development (and activism) involves the substitution of the recipient's values with your own (Davis \& Wells, 
2016). Privileged individuals joining radical social movements alongside the marginalised often reinforce oppression through insisting on their leadership and ideas (Freire, 1970; Straubhaar, 2015). This behaviour is attributed to a lack of trust in the capabilities of the oppressed. That is essentially what development is and has been from the outset. White saviourism in development implies that the privileged have a unique ability to solve 'problems' (Straubhaar, 2015). Volunteering in development (and activism) is a way of exercising power and the embodiment of 'the white man's burden', stepping in to help, implying that there are none from that community that can do that work (Bandyopadhyay, 2019). Volunteering enables actors to provide assistance, but only in ways that benefit the giver, providing purpose and self-growth (Bandyopadhyay, 2019; Vrasti, 2012). This comes from privilege and reinforces the status quo of activism as a luxury:

"We're fairly Pākehā-dominated but not everyone in our networks ... because activism is a pretty privileged thing to be able to do and put time into means that certain people join, and I think that's a reflection that we need to think about how to make it easier for everyone to join."

(350, interview, 27/08/2020)

This privilege goes beyond time, as money and education also have a big impact on those wanting to create community groups (Kera, interview, 02/10/2020).

Much of this, while a replication of the historic and structural reality of Aotearoa as a settler colony, is also attributed to the industrialization of environmental movements, embodied in the NGO industrial complex with NGOs capitalising upon the climate crisis, focused on creating and maintaining a space for themselves (Tina, interview, 12/08/2020). As Jason notes, this reinforces rather than resolves oppression:

"Our oppression is currently existing because people are currently profiting off our oppression whether that's our own narrative or the way service providers are funded"

(Interview, 17/09/2020) 
The industrialisation of movements has resulted in extractive mainstream campaigning practices, with "win at all costs" mentalities, resulting in "wins for climate" that harm disabled peopled and other frontline communities (Jason, interview, 17/09/2020). Jason implied that this was also present in the climate justice space, not just climate action. Additionally, participants observed the reproduction of neoliberal and capitalist behaviour and unequal power in the movement, despite the movement being fundamentally opposed to it:

"It all comes down to, which is a function of capitalism, that within New Zealand everyone wants to be the first, everyone wants to be the founder of something, or everyone wants to be the only organisation."

(Kera, interview, 02/10/2020)

The industrialisation and capitalisation of the movement encourages a focus on brand optics, and when issues such as justice come into fashion or reach "the peak of this being a core issue that needs to be addressed", people rush on board for fear of looking "bad if you're not helping us out" (Jason, interview, 17/09/2020). Organisations tack on the word 'justice' out of fear of being invalid and as a PR exercise (Kera, interview, 02/10/2020):

“There's like a knee-jerk reaction, it's like, 'oh my goodness, like, I thought I was the good person and now I'm not the good person, how do I quickly fix that?' ... and that gets in the way a lot."

(Jason, interview, 17/09/2020)

As well as reinforcing the structural dynamics, this behaviour is inherently self-preserving at the expense of climate justice and movement aims. This self-preserving behaviour comes from the desire or perceived need to remain permanent. Tina contrasts this with the way her tippuna's relationship to the environment was reflected in the impermanence of their material creations:

“There's a real art to knowing when to let it go and die its natural death, and then support rebirth and other forms. That's a natural process that we learn from Papatūānuku is to allow for death, rebirth, growth, death, rebirth, growth. That's a sustainable process, and you learn new things when you're reborn in different ways." 
(Interview, 12/08/2020)

This emphasis on self-preservation can come at the expense of the overall goal, as demonstrated by NGOs who compromise on their values, demand sacrifices from others, and allow corporations to use them as greenwashing or bluewashing exercises, all in order to maintain income, jobs, and existence as an organisation.

XR was the most frequently used example when discussing harm across the climate movements. However, they were by no means the only group: GenZero, SS4C, the Green Party, Greenpeace, the Workshop, and Action Station were also mentioned in examples of problematic behaviour, theory of change, or rhetoric. Despite the egotistical and self-preserving nature of the harmful behaviour, participants recognised that it is not the fault or feature of an individual organisation: "I want to make that clear that I've used them as examples, but I'm not singling them out; this is an issue that sits right across non-Indigenous NGOs" (Tina, interview, 12/08/2020). These issues are systemic and structural, and reflect the duality of structure and agency:

"When talking about systems change, I strongly believe we need to change how we do activism because we uphold so many of the same harmful structures. Power structures, ego, agenda, racism, sexism, and dominating voices. We are part of the society we are trying to change."

(Alicia, interview, 20/08/2020)

Numerous participants talked about this entanglement of day-to-day life in these systems (Greenpeace, interview, 24/08/2020) and the difficulty this placed on everyday New Zealanders (and movement actors) to "live sustainably without just continually perpetuating the same behaviour that makes climate change happen" (Tamatha, interview, 24/08/2020). Additionally, either through self-reflection or witnessed by others, many of these groups have made attempts to remedy the harm they have caused. Movements exist in the real world, complicating the application of theories of changes that focus on idealised future states of existence without leaving room for contradiction and error in the present. 


\subsubsection{Ecosystem}

Greenpeace's climate campaigner spoke of an awakening to the broken system and the need to incorporate different worldviews to challenge these structures: "There is an evolution happening within the climate space and then within organisations, making those connections" (Interview, 24/08/2020). Several actions were mentioned by participants that could facilitate this process: relationship building, education, critically reflecting, and taking ego out of the picture. These restorative actions partially mirror and support the theories of change clusters previously discussed, in particular relationships and education.

As noted previously, relationships featured heavily through all interviews. Regarding harm and harm reduction, participants saw them as the core element of how this behaviour can be overcome. Kera explained that being better allies or more justice-oriented in climate work:

"Fundamentally needs to come down to being in relationship(s) with other activists, with other organisers, with other organisations, and that means that you actually need to know what's happening in that space. ... if it's appropriate to engage or not and how to do that and building relationships with people and organisations who are able to hold space effectively for the nuance and for the issues of our frontline communities."

(Interview, 02/10/2020)

She has seen this progression in practice, with those who have maintained relationships with Sustained Ability producing work that she feels she can support. Furthermore, Kera recognises that education of both self and others are important parts of relationship-building:

"The only reason I can say this now, talk about the things I talk about now, is because people have educated me or put labour into me."

(Interview, 02/10/2020)

Several participants mentioned that they were new to activism and initially "had no idea what we were doing at all" (Mel, interview, 08/07/2020). Similarly, Sophie referred to her ongoing, on-thefly learning being challenged by a lack of mentorship (Interview, 10/08/2020). Elkington \& Smeaton (2020) note that "when we know more, we do more" and this is evident in participants 
observations and experiences (p. 12). Lourdes recommends learning about Aotearoa history, particularly from non-Pākehā, understanding more about communities and the issues affecting them from those with first-hand experience (Interview, 07/09/2020). Tina noted that there's still a lot of learning to do with movements (Interview, 12/08/2020), as did Jason, who was also concerned about the lack of suitable role models given the re-perpetuation of the same power dynamics and injustice in the climate action space that continue to be passed on (interview, 17/09/2020). Within post-development there is an argument that the role of the privileged is in research, teaching, public speaking, and advocacy in "one's own society" in order to challenge the imperialist policies that impact the 'third world' (Matthews, 2008, p. 1037). Similar responsibilities and roles have been articulated for Pākehā activists within the domestic landscape of climate justice and decolonisation.

Reflexivity alongside, and often preceding, relationship development is necessary for all who participate in climate justice and activism, especially for those who do not come from frontline communities and who have been complicit in harmful behaviour. When organisations or individuals in the movement are called out or realise they have been perpetuating inequalities and oppressions, Kera suggests critically reflecting on:

"How am I benefiting from these systems that are oppressing other people and contributing to climate change? What am I doing that upholds it? What is my place in dismantling this? What skills can I offer to the movement to decolonise or to dismantle ableism?"

(Interview, 02/10/2020)

Sometimes this includes recognising when groups do not need to exist, and the time, energy and resources put into that group can then be used to support groups that centre and are led by frontline communities. Additionally, Kera feels like this realisation and subsequent end of the organisation should be celebrated.

This links to Freirean theory of praxis (reflection and action) and continuous self-evaluation towards critical consciousness (Freire, 1970; Straubhaar, 2015). Matthews (2008) explores the question in (and of) post-development around how the privileged should respond to their own privilege as well as inequality - a complex terrain that cannot just be avoided. Reflecting and 
debating is insufficient; we, the privileged, have something to learn, but marginalised communities may also need our help in bringing their ideas to fruition (Matthews, 2008). However, any support provided needs to be done in a way that is sensitive to the power dynamics of that relationship to change the relationship between poverty and wealth you also need to change wealth, too (Matthews, 2008). Sachs (2013) notes that "poverty alleviation ... cannot be separated from wealth alleviation" (p. 27). Within climate movements, this means increased attention to privilege. The need for material support and the lack of attention to over-consumption and privilege was also reflected in the interviews.

Participants offered up numerous examples of reflexivity in action, recognising that they have "not been immune" to the tensions that they see playing out in the movement (Kera, interview, 02/10/2020). Additionally, remembering that, to a degree, we all participate in the systems we analyse and rally against, which are "so easy to just get sucked up in and continually perpetuate" (Sophie, interview, 10/08/2020). Education plays a significant role in these self-improvement journeys: "For a long time, I was like, 'no it's not racist, it's not racist', but it is, because I've learnt more about racism" (Mel, interview, 08/07/2020). Other movements and the societal shift in consciousness also plays a role, particularly recently with the Black Lives Matter movement (Sophie, interview, 10/08/2020). For others, it comes with time and experience:

"I've also started seeing things a bit different when it comes to the climate fight; when I was younger it would be very much, 'there's a deadline on this and we have to achieve change by the deadline."”

(Greenpeace, interview, 24/08/2020)

Lesley even offered an example within the Quakers of recognising that their 'futures committee' was surplus to movement needs and disbanding it (Interview, 23/09/2020).

Relationships, education, and reflexivity combine to enable the intersectional lens necessary for climate justice work:

"Once you develop that thinking, it really helps you acknowledge things deeper than surface level and develop that intersectional lens. ... Once you start developing that thinking, it's clear to BIPOC ... and once you've got that thinking, you know how to make it a safer space." 
(Lourdes, interview, 07/09/2020)

Intersectionality came about as a term in the late 1980s as an analysis of power and structural inequality to examine the dynamics of difference and sameness (Cho et al., 2013). Without intersectionality, movements are ineffective, as they are exclusionary and ignore the complex mechanisms that produce and maintain inequality (Ward, 2008). If the 'matrix of domination' (intersectionality) is not challenged, then diversity work often results in reproducing and reinforcing power imbalances (Ward, 2008). Throughout the interviews, it became clear that intersectionality and ecosystem thinking is a work in progress in Aotearoa climate movements.

\subsection{Conclusion}

The same political, economic, cultural, and social structural forces that shape society and climate change are reproduced within climate movements, causing strategic dilemmas and tensions. These tensions hinder the expression, development, and expansion of climate justice within Aotearoa. They are numerous, interconnected, and contradictory, and are fundamentally linked to power structures and theories of change. This chapter explores three key tensions within the climate movement in Aotearoa: partisanship versus non-partisanship, conformity versus diversity, and 'egosystem' versus ecosystem. These tensions mirror the abstract debates Dietz (2013) observed in the international climate change movements, which also feature questions around compromise and co-option. These abstract debates centred around approaches to activism, solutions, and cooperation (Dietz, 2013).

The analysis of the tensions that arise between actors and organisations, often as a result and replication of the structural forces, is not mature within Development Studies literature. Given the increase in alternative forms of development, there is both room and a need to further unpack these tensions, particularly within post- and critical development. For now, the analysis primarily lies elsewhere, within sociology and political science. Nevertheless, analysis and evidence of intra- and inter-movement conflict was still harder to locate within the SMS literature than external contention between movements and targets. Collective identity is particularly useful for understanding why and how conflict can play out in NSMs, however, there appear to be few specific analyses of intra-movement conflict in regard to the climate movements or climate justice movements. 
Debates focused on whether to work inside or outside the political system to change it influence individual and organisational decisions to be partisan or non-partisan. Despite the limitations of working within the system to change it, two of the four politicians interviewed stated that there was still a role for this approach. Non-partisanship was preferred by those who saw party politics as counterproductive, co-opting, and not sufficiently justice-oriented. The desire for (or perception of) neutrality was evident, as was the choice to work outside the system. Despite this, it was implied several times that climate movements are inherently partisan, swinging towards the left (and, in the case of Aotearoa, towards the Green Party).

Participants have observed narratives pushing internal conformity within these movements, extoling theory of change above others or suggesting that all should be united under one banner (organisation). These narratives are implicitly ecofascist. Instead of 'unifying' the movement, participants noted that these pressures to conform have often resulted in a history of bad relationships, insular bubbles, and disconnect across movements. An alternative approach to navigating the different organisations and theories of change within climate movements is a permaculture or ecosystem model. Within this model, diversity is seen as a necessary part of the formula for creating change and providing resilience. Furthermore, the infighting or 'moral purity' of the left is seen as a hindrance to both progress and connection. Connection, collaboration, and coordination between groups within movements is ultimately more important than movement conformity.

Participants revealed that, at present, the climate movement ecosystem is negatively impacted by ego. As detailed in this chapter, persistent harm, primarily ableist and colonial, often co-opting or tokenistic, is carried out in climate movements through the replication of structural harms. Drawing parallels to the development sector, activism in Aotearoa is influenced by ideologies of imperialism, colonisation, capitalism, and neoliberalism. This results in white saviourism, the privileged, extractive, and self-preserving behaviours of Pākehā (in the Aotearoa context) at the expense of marginalised communities and climate justice. An ecosystem's approach to activism entails greater emphasis placed on relationships, education, and reflexivity. These tools can enable a more intersectional approach and negate ego.

These three tensions operate across climate movements of Aotearoa, including within the narrower climate justice space, despite often appearing to be antithetical to its principles and aims. However, 
as explained in the literature on collective identity, these tensions are not unexpected nor inherently negative. These tensions are a form of collective identity development and negotiation and are an important part of the evolution of climate action movements into climate justice movements. While these growing pains may be necessary, the real harm and disruption caused to climate justice spaces, communities, and people still need to be addressed. There are multiple courses that all members of the climate community can embark on, supporting others through the process while working towards more inclusive, accessible, and just movements. 


\title{
Chapter 5: Conclusion
}

\author{
"We need to slow down, move at the speed of trust, and understand that allyship \\ is a journey."
}

(Jason, interview, 17/09/2020)

\subsection{Introduction}

Climate justice movements are emerging that are distinct from climate action movements in Aotearoa. However, climate activism in Aotearoa is experiencing growing pains, and a rush to adopt climate justice framing often comes at the expense of climate justice itself as well as the frontline communities it serves. As Jason notes above, there is a need, contrary to some interpretations of the 'climate emergency' framing, to slow down and operate from relationships, the development and nurturing of which takes time. Whyte, (2020), likewise noted that climate justice, particularly for Indigenous people, requires trust, consent, and reciprocity, without which any climate solutions would result in the exacerbation of marginalisation and harm. Relationships were the single most prominent theme across these interviews and this theme is woven throughout the thesis. This final chapter will use these findings to answer the research questions and expand upon both the centrality of relationships and how this research can inform development.

This thesis sought to understand how radical change, climate justice in particular, is envisaged and enacted in Aotearoa in the present, and how this might influence the future of Aotearoa. I began this thesis at the beginning of March 2020. At this point, COVID-19 had spread around much of the globe, including Aotearoa. By the end of March, the Government had announced a state of emergency, and the country entered a month-long lockdown (Henrickson, 2020). This had a significant impact on people's lives and livelihoods, restricting mobility, work, and leisure. COVID-19 is the third zoonotic coronavirus outbreak in the last 20 years, and a growing body of literature links COVID-19 to climate change, noting similarities in root cause and the way in which they directly interact (Agar, 2020; Barouki et al., 2021; Deka et al., 2020; Edelman, 2020). Government and behavioural responses to COVID-19 and historic pandemics are also linked to 
significant changes in society, noted as setting potential precedents for the scale and pace of societal change required for climate change (Hannam, 2020; Heidt, 2020; Klenert et al., 2020). These links were also highlighted by my participants, who rightly questioned that if this scale and speed of response is possible when humanity is under threat from COVID-19, then why is society not willing to do the same for climate change (which is an equally devasting threat)? ${ }^{17}$

\subsection{Thesis summary}

This thesis began with an overview of the context in which climate justice operates. For Aotearoa, climate change means a continued increase in variations and extremes of temperature and precipitation, sea level rise, and extreme weather events (Reisinger et al., 2014; Renwick et al., 2016). Large proportions of our population and infrastructure (especially irreplaceable historical and cultural sites) are at risk of inundation, due to flood plains and sea level rise (Hopkins et al., 2015; Reisinger et al., 2014; Renwick et al., 2016). The government's agenda, centrally and locally, falls within internationally constructed frameworks and agreements. This space continues to evolve, impacted by the outcome of the Climate Change Commission's first report and legislation reforms. Public perception, which influences government decision making, is becoming increasingly aware of climate change (Hopkins et al., 2015; Salmon et al., 2017). Aotearoa's history of movements begins with Māori in the 1800s, resisting colonisation and land confiscation, and being subjected to state violence. This sets the tone, and while not all forms of people power in Aotearoa have been met with overt state violence, the characteristics and impacts of movements, especially environmental and climate movements, continue to be heavily influenced by the state and their relationship to it.

Drawing on two key bodies of literature (Development Studies and Social Movement Studies), this thesis is influenced by and contributes to a diverse academic tradition. Situated within postdevelopment theory, this thesis takes a critical and alternative approach to development, recognising social movements as a mechanism of societal change (Silvey \& Rankin, 2011; Veltmeyer \& Delgado Wise, 2018). Climate change is an outcome of historic and present-day development practices that have prioritised and enforced Western models of social, political, and economic organisation to the detriment of the environment. Sustainable development, the

\footnotetext{
17 The interconnection between climate justice and COVID-19 was directly explored in the interviews and will form the focus of a subsequent publication.
} 
mainstream approach to climate change, neglects these underlining causes (Sachs, 1999). Social movements have long been a tool for societal change, and social movement studies deploys various theories and methods in order to study their origins, mobilisation, structure, and impact. Climate movement literature often acknowledges links to environmental movements and utilises much of the same theories and frameworks used to study it, such as new social movement theory, political process theory, framing, emotions, and social networks. However, climate action movements and emerging climate justice movements are increasingly transnational and are mobilising and acting in ways that no existing theory can encapsulate (della Porta, 2017). As SMS theories are heavily influenced by the movements present at the time of their development, no singular theory can be deployed to understand contemporary mobilisations, and theories need to be updated to consider the increasingly diverse contemporary movements (della Porta, 2017). However, as this research demonstrates, multiple theories can be utilised simultaneously to account for these weaknesses.

Participants indicated that the emerging climate justice movements in Aotearoa are a continuation and culmination of other justice movements. They are born from Indigenous rights, disability rights, workers' rights and intersectional feminism and incorporate an intergenerational view. Currently there are several individuals and groups that operate in this space, though not all associate with the term climate justice, or even climate change action. Perceptions of what activism is or is not, as well as the characteristics of the mainstream climate action movements, influence this identification process. Theories of change, organisations, and movements have often been imported from overseas, with the strategies and tactics then translated to the national or local context. Additionally, with the rising prominence, popularity, and co-option of climate justice, the line between climate action and climate justice is neither clear nor fixed, and this invariably leads to conflict. Co-option of climate justice at present includes but is not limited to the use of the term in branding and media by movements, organisations, groups and individuals who have yet to ground themselves in the growing climate justice community in Aotearoa. Identifying with climate justice without 'doing the work' and building relationships, often means that they lack the full understanding of the term with respect to the intersecting communities, forms of justice and application of core principles. This results in 'climate justice' being used alongside ableist or racist actions that risk the safety of other climate justice spaces. 
As experienced by my participants, there are several interconnected points of contention in the climate change movements in Aotearoa. These tensions create the opportunity for growth and are essential in the development and negotiation of collective identity (Fominaya, 2010; Roth, 2008; Steinfort et al., 2017). However, tensions can also impede connection and understanding, and can even lead to substantial harm to individuals, communities, and climate justice movements. Debates over whether to be partisan or non-partisan link to theories of change, how much of oneself to give to the system, and, fundamentally, whether the system can be changed from within. Despite most participants being non-partisan, they refer to the Green Party more than any other party, as does the literature, implying an inherent partisanship to the movement. In terms of theories of change, while the core 'people power' premise reigns supreme, there are a variety of different interpretations of this, which clash at times as demonstrated by the three core tensions highlighted in Chapter 4, going against the desire of most participants to connect across movements. A permaculture or ecosystem model would enable this connection through enabling diverse theories of change to co-exist. At present, behaviours stemming from ego replicate structural oppression within movements, and are holding back this ecosystem approach. This is largely attributed to reactive, self-interested activism as opposed to genuine allyship. Various remedies, which largely overlap with the theories of change identified in chapter 3 , are mentioned by participants as possible ways of bridging the gap between the egosystem and the ecosystem: education, reflexivity, relationships, and intersectionality. These are core tenets of climate justice, and they shape how it operates externally and internally.

\subsection{Returning to the research questions}

The data collected through interviews, encapsulating the experiences and opinions of participants, enables the initial questions posited by this thesis to be answered.

What is climate justice in Aotearoa, and how does it contribute to the advancement of radical, progressive societal change?

In Aotearoa, climate justice is a lens, framework, process, approach, and collection of emerging movements in the landscape of climate change. Increasingly distinct and at conflict with climate action, it is neither large nor connected enough to be a movement. It currently sits, uneasily, within the wider climate movements that remains dominated by climate action. The definition of climate 
justice and the way in which it is enacted overlap, prioritising and valuing accessibility, relationships, representation, interconnection, centring of marginalised or frontline communities, accountability, and responsibility. It is antithetical to the current systems and structures of our society that are problematised as the root cause of climate change. The UN COP in Copenhagen often cited in the literature as the origin of climate justice featured little in the participant interviews. However, the influence of justice movements past and present, as well as climate mobilisations of the 'global south' were referred to by participants as the whakapapa of the climate justice movements in Aotearoa. In Aotearoa, climate justice is Indigenous justice, disability justice, intergenerational justice, socio-economic justice, and intersectional feminist justice. While the genealogy of climate justice is grounded in justice movements (and, to a lesser degree, climate and environmental movements), the origins and catalysts for many participant groups, either climate justice or allies, were from the state or international governing bodies of the UN. Additionally, many groups were imported or replicated from overseas. Climate change is an international problem, so it is unsurprising that climate action and climate justice are transnational movements. However, the localisation of these international organisations, kaupapa, and theories of change causes issues, particularly in the way it echoes imperialism and neglects or undermines pre-existing local and Indigenous movements. In our local context of a settler colony, the decolonisation movement is a fundamental part of climate justice in Aotearoa. Resisting systems of domination and centring concepts of relationality, Te Ao Māori is pivotal to the actualisation of climate justice and post-development in the Aotearoa context.

\section{Who is involved?}

Several individuals and organizations are involved, although to varying degrees. Te Ara Whatu, Pacific Climate Warriors, 4 The Kulture, and Sustained Ability were identified as explicitly climate justice organisations. However, it was noted that the definition of climate justice is subjective and prone to co-option. This means that there are individuals and organisations that do not identify or associate with climate justice (or even climate action) but are doing climate justice work (or work that supports climate justice objectives). Additionally, there are groups that identify as climate justice or use the term who do or say things that are inherently antithetical to climate justice: ableism, racism, sexism, classism, transphobic, and/or homophobic (a non-exhaustive list). The misidentification, both not associating as well as co-opting, has been linked by participants to 
the Pākehā dominance of climate activism, which then perpetuates structurally oppressive patterns, alienating tangata whenua and other minorities, encouraging unsafe spaces. Accompanying this contested space are climate justice allies; those who are not grounded in frontline communities but are committed to learning what climate justice and allyship mean. This includes many large, wellknown E-NGOs from climate movements, such as Greenpeace and 350, as well as non-climate specific groups such as Tauiwi mō Matike Mai Aotearoa, Oxfam, and New Zealand Alternative.

Climate justice is subjective and deeply personal - definitions are often heavily tied to individual perspectives, experiences, and histories. This often means that some individuals or organisations, such as the ones below, that are classified as allies to some may be considered problematic by others: Extinction Rebellion, Generation Zero, the Green Party, School Strike for Climate, Action Station, and Forest and Bird.

\section{What (theories of change) guides their approach?}

While an overarching 'people power' social movement theory of change is engaged with by all participants, there are various interpretations and applications of this. The most prominent interpretations within the interviews were: 1) interconnected problem solution;2) accessibility, inclusion, and democracy; 3) information and education; 4) relationships; and 5) systems and power. The interconnected nature of climate change and inequality means going beyond solutions focused on the symptoms of climate change, and addressing the social, political, and economic systems. Climate justice is creating the world we want to live in. Practically, this is tangible goals that increase people's wellbeing, and recognising that the means of change are just as relevant as the end goal. Frontline communities are often excluded from the political and economic systems. In order to include, represent, and be accountable to those communities, climate justice must be accessible, inclusive, and democratic. The definition (and geography) of what is considered activism must expand to meet people where they are at, to enable the 'people' in 'people power'. Education and information, especially everyday conversations, are seen by participants as mobilisation tools. As previously mentioned, relationships are central to climate justice. This 'invisible work' can fundamentally change the way in which we relate to each other and the environment. High-level strategies on system change and disrupting the imbalance of power in society include: utilising unions as a structure, resources base, and method for building power; 
grappling with what defines a revolution; and recognising that structures and systems are only half of the puzzle, with culture (and individual agency) the other.

\subsection{Key findings}

\subsubsection{Relationships and relationality}

The importance of relationships was prevalent in every interview, as well as in my overall experience of conducting research on climate justice. Relationships and relationality manifested in the data in a variety of ways: personal and professional relationships within movements; relationality or intersectionality between and within issues, structures, communities, and ideologies; the imbalance of power within relationships; and the social construction of movements and knowledge. Additionally, all the core tensions raised are relational in nature: relationship to the political system; intra- and inter-movement relationships, and the negotiation of collective identity and diversity; informal connections and disconnection; the replication of relationships of unequal power that exist in society and development within these movements (paternalism, white saviourism, imperialism); and how ideologies relate to strategies and actions. These relationships, especially when neglected or ignored, impede the actualisation of climate justice.

Climate justice is a politics based in connection, grounded in existing community and capacity (Derman, 2019). As noted by Greenpeace in the opening quote to the introduction chapter, climate change is not an 'if', but a 'when' and 'how much'. The challenge that our climate movements must mobilise around is not how to stop climate change, as climate change is already in action, rather the opportunity we have is deciding how to adapt and transform our society in order to (reduce as much as possible and) manage the impacts equitably. Changing our relationships to each other and to the environment, is a central part of this. Participants highlight that alternative worldviews, especially Māori and disabled within the context of Aotearoa and this research, need to be centred in discussions on climate change, development, and justice. Tina, Tamatha, Lourdes, Kera, and Jason explained that Te Ao Māori and Crip Wisdom provide frameworks for relating to each other and the environment in diverse ways, and this is evident in the literature on Indigenous contributions (Hartendorp \& Bradford, 2016; Nairn et al., 2021; Whyte, 2020). In Te Ao Māori, whakapapa is the source of knowledge and relationships. Relationships extend across time, and when damaged by conflict, resolution, restoration and balance are guided by respect and the 
"reciprocity of aroha" (M. Jackson, 2020, p. 142). Additionally, Māori scholar Moana Jackson (2020) affirms that "in whakapapa no relationship is ever beyond repair" (p. 141). However, the values of trust, consent, accountability and reciprocity are not well embedded in our society, something that Whyte (2020) links to the history of violating relationships through colonisation, capitalism, and industrialisation. These value systems have had long-lasting impacts on the conceptualisation and construction of relationships (Ross, 2020). This reinforces the need for climate justice to be frontline community-led and centred. However, these communities and their struggle for justice, rights, and relationality to the environment have historically been, and continue to be, excluded and dismissed.

Exclusion and unequal geographies of power impact material vulnerability to climate change and shape the terms of solidarity within movements (Chatterton et al., 2013; Perkins, 2019). The power within relationships was present in discussions with participants in a multitude of ways: the imbalance of power between actors within the movement/s; the imbalance of power between individuals and the system; and the imbalance of power amongst individuals within (and because of) the system/structure. These imbalances constrain the realisation of climate justice in a multitude of ways. Crucially, power can also be built through relationships. The 'people power' of collective action is a product of the relationships between individuals, groups, and communities within the collective, and diverse relationships or coalitions can increase empathy, effectiveness and leverage of movements (Gawerc, 2019).

As noted explicitly and implicitly by participants, Pākehā and other non-frontline communities (those with relative privilege within these movements and society) have an important role in easing the burden of education that currently weighs on frontline communities, organisations, and individuals. This responsibility goes beyond education. However, anti-racism and disability education as a form of harm reduction were highlighted as important tools for enabling an intersectional approach and centring climate justice. In Imagining Decolonisation, Thomas (2020) emphasises that "what decolonisation looks like for Pākehā and how we engage in it depends a lot on our relationships" (p. 108). This involves listening, trusting and taking cues from Māori, "questioning relationships of power and control", and "through good relationships within our communities" (Thomas, 2020, pp. 117 \& 132). As evident from participant comments, these statements are equally relevant to climate justice, and should be expanded to include other frontline 
communities alongside Māori as leaders. The role of the privileged in developing relationships through support and power-sharing (and through privilege/wealth alleviation), as well as being critical of the power they hold in a relationship with the marginalised, is also noted in postdevelopment literature (Matthews, 2008; Sachs, 2013).

Gawerc (2019) notes that shared ideology and culture are not enough to enable collaboration across and within movements, and social ties and trust are crucial for the formation of networks, coalitions, and solidarity (Nicholls, 2009). Emotional ties are an important part of developing the collective identity and overall resilience of the movement (Fominaya, 2010). Involution or fracturing of the movement can present a challenge to cohesion, connections, and bonds of trust (O'Brien, 2013b). Trust can be the difference between co-option and substantive allyship (Nicholls, 2009). There are different kinds of trust: thick trust which is important for intramovement bonding and collective identity formation, and thin trust which enables intra- and intermovement collaboration (O'Brien, 2015). O'Brien (2015) found that trust within the environmental movements in Aotearoa is robust and pragmatic (albeit cautious) with actors viewing the benefits of collective action as outweighing risks. These theories in the literature are substantiated by my participants' comments and experience of relationships, co-option, and resilience in our climate movements. Trust, reciprocity, and consent are also important for cooperation across society as a whole to act quickly and justly (Whyte, 2020). Relationships to enable the realisation of these values can take time to build or restore, clashing with various interpretations of the 'climate emergency' framing (Whyte, 2020). The 'climate emergency' framing rightly emphasises the need for urgent action, however, it is also "associated with exceptional powers of government that suspend day-to-day democratic decision making" and the oversimplification of complex issues into narrow metrics (Hayward, 2020). As stated by Jason at the beginning of this chapter, "Allyship is a journey". Relationships are not a fixed goal or activity, they are an ongoing process of connecting and reconnecting, learning, and communicating. Similarly, the process of climate justice is also an ongoing process. These concepts of time within relationality more closely align with Indigenous conceptions of time, as well as the evolving relationship between place and people exemplified by Ihumātao (Nairn et al., 2021). There is an ongoing, changing, relational, socially constructed and mediated space that is climate justice in Aotearoa. Promisingly, participants were able to acknowledge the urgency of climate change and 
recognise that transformational social change is an ongoing generational process. Additionally, urgency does not need to be realised at the expense of well-thought-out means of change.

Despite the reproduction of the structures and unequal power of development (paternalism and imperialism) within development alternatives (movements), there is more agency within activism than there is in development to change those behaviours. Movements have greater fluidity in power structures and are not reliant on the system staying the same to operate. Furthermore, a relational or whakapapa paradigm within activism can provide agency and counter the exhausting and disempowering nature of decolonisation (and climate justice) work (Mercier, 2020).

\subsubsection{The role of development/development studies}

This thesis has primarily been articulated as understanding climate justice as an alternative form of development, however, what is the role of development within climate justice? Can development understand and/or incorporate climate justice without co-opting and sedating it as it did with sustainable development? What is the nature of the relationship between development and movements generally? Escobar (1992) sees development and revolution (including movements) as opposites, top-down versus bottom-up. However, are they fundamentally incompatible, or should they be viewed as balancing forces of societal change? While the status quo in many ways has resulted in the development of climate justice in order to highlight and fight the inequalities of the system, climate justice is not dependent on the continuation of the status quo, even if, as we have seen in this thesis, the expression or realisation of climate justice can at times include the reproduction of the status quo values and power relations.

Climate justice is antithetical to the current system, and development is a machine of the current system (or, for some, is the system). As an often-anti-capitalist movement or collection of movements, climate justice conceptions of the good life "differ in almost every respect from those at the centre of developmentalist renderings" (Silvey \& Rankin, 2011, p. 697). Jafry et al. (2019) see climate justice as a chance to redefine a 'development' that centres human rights and environment over economic growth. Likewise, Nuñez (2019) views climate justice as vehicle through which Indigenous peoples propose an alternative development paradigm based on their worldviews, knowledge and values. However, there is also the risk that climate justice, if incorporated into development, follows in the path of sustainable development and environmental 
movements, co-opted and detached from their radical grassroots (Carruthers, 2001; Downes, 2000; Elliot, 2016; Matthew \& Hammill, 2009; O’Brien, 2013b; Veltmeyer \& Delgado Wise, 2018). Through this process of becoming mainstream it increases its leverage, but at what cost? The history of rhetorical alignment but substantive opposition or neglect (due to economic imperatives) by the state of the environmental concerns is replicated today in the narrative of climate change as “my generation's nuclear free moment” alongside an 'insufficient' government response (Climate Action Tracker, 2020; Downes, 2000; O’Brien, 2012; Trevett, 2017).

This raises this question whether development can ever be progressive, reformed, bottom-up, and in the case of climate, just? Sitting within the UN framework, development remains a fundamentally state-defined and driven mechanism that remains within the hands of the elite, who are entwined in the economic, political, cultural and social system and structures. More likely, climate justice will operate in pockets of development, with some development workers or projects influenced by a climate justice approach, or climate justice advocates doing development within their communities through service provision. Climate justice and post-development are both critiques of and alternatives to mainstream development and are, therefore, compatible. Likewise, concepts of relationality and the plurality of alternatives within the "diverse economy (or ecologies of non-capitalist productivity)" complement notions of climate justice (Gibson-Graham, 2005, p. 17). However, there are still no real answers around how to reconcile or detach mainstream development from its paternalistic and extractive history. The concept of justice is not well understood or enacted by development, and there can be no climate justice without justice.

\subsection{Conclusion}

The title of this thesis is 'Moving at the speed of trust'. All participants, when talking about climate justice, referred to the importance of relationships and within this an often implicit (and occasionally explicit) need for trust. The possibility of radical change emerges from this space. However, this is complicated when acknowledging the radical and rapid change that occurred during COVID-19. There was no time for relationship or trust building, so how does this context remain relevant? Chlöe, during interviews, explained that the high compliance in Aotearoa demonstrated that there was already a subliminal trust in place: 
"It required a massive amount of trust in the social contract to go into lockdown and to follow those rules, because if we all decided not to abide by them, we wouldn't have the police force to stop us doing that."

(Interview, 07/08/2020)

There is a degree of social capital already existing in our society that we have failed to recognise in our contemporary period. Additionally, the success of the COVID-19 response in Aotearoa is not clear-cut. The "communication victory" was also "an exercise in whiteness" with the voices, leadership and narratives of Māori neglected (Jones, 2020, as cited by Appleton et al., 2020, p. 54). The rapid and radical change that occurred has been seriously detrimental to many people, in particular Māori, Pasifika, disabled people, and other frontline communities. Experiences and observations of the inequities of COVID-19, in the literature and by my participants, reinforce the need to move at the speed of relationships and trust for climate change. These "(alter)narratives" are not "counter or anti" to the urgency of climate change nor the speed of radical change demonstrated by COVID-19, but rather are an "essential and adjacent" factor in transformational change (Appleton et al., 2020, p. 51). Furthermore, radical change is often envisaged or articulated as a rapid, stand-alone event, and trust building is often depicted as slow. Participants' comments on timescale and relationship building challenge these assumptions and the way in which they are used to justify the lack of engagement with climate justice communities. Jackson (2020) states that "restoration (like colonisation) is also a process, not an event, and it will require a change of mind and heart as much as a change of structure" (p. 149). Radical change, particularly through climate justice, is an on-going process. This does not negate the need for urgency, instead concepts of time and radical change need to be reworked to acknowledge that climate change does not have an end date, and therefore, neither does climate justice.

This thesis explores radical, progressive change as envisaged and enacted through climate justice in Aotearoa. Climate justice is a collection of emerging movements, space, and lens connected to the larger and more established climate action movements in Aotearoa. It centres the perspectives of 'frontline communities', the structurally oppressed, and the marginalised at the forefront of the impacts of anthropogenic climate change. Principles of accessibility, inclusion, accountability, intersectionality, and opposition to the status quo are central to its definition and expression. There are numerous tensions within and between climate action and climate justice that are negotiated 
across theoretical and practical levels, causing friction and harm as well as reflexivity and growth. These conflicts stem from alternative worldviews and theories of change, with climate justice movements drawing on, and associating with, other justice and rights movements more than climate movements themselves.

Responding to the need to pay closer attention to the relationships that occur within and between movements, and how these relate to theories of change, this thesis reveals that relationships and relationality to issues or communities have a direct impact on the constructions of the definition, theory and actions of climate justice. Additionally, through mapping out climate justice, this thesis builds upon the existing literature on social, environmental, and climate movements of Aotearoa, highlighting the interconnected and evolutionary nature of resistance. Furthermore, in utilising a post-development theoretical framework, this thesis places climate justice alongside diverse economies as a practical application of post-development theory and ethics. The reproduction of development norms and oppressive structures within climate movements does not negate the possibility for change that climate justice offers. Rather, it demonstrates the complex reality of societal change. Fundamentally, climate justice is the ongoing process of constructing an alternative society. Built on and through relationships, it can only develop and progress at the rate at which trust is repaired and built. 


\section{References}

Agar, N. (2020, October 22). Let's depoliticise both COVID-19 and the climate| Victorious online. Victoria University of Wellington.

https://www.wgtn.ac.nz/victorious/issues/victorious-2020/lets-depoliticise-both-covid19-and-the-climate

Ahmed, N. (2019, October 31). The flawed science behind Extinction Rebellion's change strategy. Medium. https://medium.com/insurge-intelligence/the-flawed-science-behindextinction-rebellions-change-strategy-af077b9abb4d

Alakavuklar, O. N., \& Dickson, A. (2016). Social movements, resistance and social change in Aotearoa/New Zealand: An intervention for dialogue, collaboration and synergy.

Kōtuitui: New Zealand Journal of Social Sciences Online, 11(2), 83-88.

Allen, M., Babiker, M., Chen, Y., de Coninck, H., Connors, S., van Diemen, R., Dube, O., Ebi, K., Engelbrecht, F., Ferrat, M., Ford, J., Forster, P., Fuss, S., Guillén Bolaños, T., Harold, J., Hoegh-Guldberg, O., Hourcade, J.-C., Huppmann, D., \& Zickfeld, K. (2018). Summary for policymakers. In IPCC, V. Masson-Delmotte, P. Zhai, H.-O. Pörtner, D. Roberts, J. Skea, P. R. Shukla, A. Pirani, W. Moufouma-Okia, C. Péan, R. Pidcock, S. Connors, J. B. R. Matthews, Y. Chen, X. Zhou, M. I. Gomis, E. Lonnoy, T. Maycock, M. Tignor, \& T. Waterfield (Eds.), Global Warming of $1.5^{\circ} \mathrm{C}$. An IPCC Special Report on the Impacts of Global Warming of $1.5^{\circ} \mathrm{C}$ Above Pre-Industrial Levels and Related Global Greenhouse Gas Emission Pathways, in the Context of Strengthening the Global Response to the Threat of Climate Change, Sustainable Development, and Efforts to Eradicate Poverty (p. 32). World Meteorological Organization. 
Almeida, P. (2018). The role of threat in collective action. In D. A. Snow, S. A. Soule, H. Kriesi, \& H. J. McCammon (Eds.), The Wiley Blackwell Companion to Social Movements (pp. 43-62). John Wiley \& Sons, Ltd.

Almeida, P. (2019a). Social Movements: The Structure of Collective Mobilization. University of California Press.

Almeida, P. (2019b). Climate justice and sustained transnational mobilization. Globalizations, 16(7), 973-979.

Anisin, A. (2020). Debunking the myths behind nonviolent civil resistance. Critical Sociology, 46(7-8), 1121-1139.

Appleton, N. S., Long, N. J., Aikman, P. J., Davies, S. G., Deckert, A., Fehoko, E., Holroyd, E., Jivraj, N., Laws, M., Martin-Anatias, N., Roguski, M., Simpson, N., Sterling, R., Trnka, S., \& Tunufa'i, L. (2020). (Alter)narratives of 'winning': Supermarket and healthcare workers' experiences of COVID19 in Aotearoa New Zealand. Sites: A Journal of Social Anthropology and Cultural Studies, 17(2).

Atapattu, S. (2015). Human Rights Approaches to Climate Change: Challenges and Opportunities (1st ed.). Routledge.

Ayres, L. (2012). Semi-structured interview. In L. Given (Ed.), The SAGE Encyclopedia of Qualitative Research Methods (p. 811). SAGE Publications, Inc.

Bandyopadhyay, R. (2019). Volunteer tourism and "the white man's burden": Globalization of suffering, white savior complex, religion and modernity. Journal of Sustainable Tourism, 27(3), 327-343.

Barouki, R., Kogevinas, M., Audouze, K., Belesova, K., Bergman, A., Birnbaum, L., Boekhold, S., Denys, S., Desseille, C., Drakvik, E., Frumkin, H., Garric, J., Destoumieux-Garzon, 
D., Haines, A., Huss, A., Jensen, G., Karakitsios, S., Klanova, J., Koskela, I.-M., ... Vineis, P. (2021). The COVID-19 pandemic and global environmental change: Emerging research needs. Environment International, 146, 106272.

Benski, T., Langman, L., Perugorría, I., \& Tejerina, B. (2013). From the streets and squares to social movement studies: What have we learned? Current Sociology, 61(4), 541-561.

Binns, T. (2014). Dualistic and unilinear concepts of development. In V. Desai \& R. Potter (Eds.), The Companion to Development Studies (3rd ed., pp. 100-105). Taylor \& Francis Group.

Bond, S., Diprose, G., \& McGregor, A. (2015). 2Precious2Mine: Post-politics, colonial imaginary, or hopeful political moment? Antipode, 47(5), 1161-1183.

Bond, S., Diprose, G., \& Thomas, A. C. (2019). Contesting deep sea oil: Politicisationdepoliticisation-repoliticisation. Environment and Planning C: Politics and Space, 37(3), $519-538$.

Bond, S., Thomas, A. C., \& Diprose, G. (2018). Seeking Climate Justice. Findings Report on Oil Free Activism and Oil and Gas Development 2013-2016 (p. 17) [Project Report]. The Climate Justice Research Collective. http://hdl.handle.net/10523/7866

Boraman, T. (2016). The independent left press and the rise and fall of mass dissent in Aotearoa since the 1970s. Counterfutures, 1, 31-70-31-70.

Boran, I. (2019). On inquiry into climate justice. In T. Jafry, M. Mikulewicz, \& K. Helwig (Eds.), Routledge Handbook of Climate Justice (pp. 26-41). Routledge.

Boyd, E. (2014). Climate change and development. In V. Desai \& R. Potter (Eds.), The Companion to Development Studies (3rd ed., pp. 341-346). Taylor \& Francis Group. 
Braun, V., \& Clarke, V. (2006). Using thematic analysis in psychology. Qualitative Research in Psychology, 3(2), 77-101.

Briggs, J. (2014). Indigenous knowledge and development. In V. Desai \& R. Potter (Eds.), The Companion to Development Studies (3rd ed., pp. 127-131). Taylor \& Francis Group.

Bugden, D. E. (2019). Social Movements and Mass Partisanship: Convergent Identities, Centrifugal Forces, and the Case of Climate Activism [Ph.D.]. Cornell University.

Bugden, D. E. (2020). Does climate protest work? Partisanship, protest, and sentiment pools. Socius: Sociological Research for a Dynamic World, 6, 1-13.

Bührs, T. (2003). From diffusion to defusion: The roots and effects of environmental innovation in New Zealand. Environmental Politics, 12(3), 83-101.

Burr, V. (2015). Social Constructionism (3rd ed.). Routledge.

Came, H. (2013). Doing research in Aotearoa: A pākehā exemplar of applying te ara tika ethical framework. Kotuitui: New Zealand Journal of Social Sciences Online, 8(1-2), 64-73.

Carroll, P., Casswell, S., Huakau, J., Perry, P., \& Chapman, P. H. (2009). Environmental attitudes, beliefs about social justice and intention to vote green: Lessons for the New Zealand green party? Environmental Politics, 18(2), 257-278.

Carruthers, D. (2001). From opposition to orthodoxy: The remaking of sustainable development. Journal of Third World Studies, 18(2), 93-112.

Castleberry, A., \& Nolen, A. (2018). Thematic analysis of qualitative research data: Is it as easy as it sounds? Currents in Pharmacy Teaching and Learning, 10(6), 807-815.

Chatterton, P., Featherstone, D., \& Routledge, P. (2013). Articulating climate justice in Copenhagen: Antagonism, the commons, and solidarity. Antipode, 45(3), 602-620. 
Chesters, G., \& Welsh, I. (2005). Complexity and social movement(s): Process and emergence in planetary action systems. Theory, Culture \& Society, 22(5), 187-211.

Cho, S., Crenshaw, K. W., \& McCall, L. (2013). Toward a field of intersectionality studies: Theory, applications, and praxis. Signs: Journal of Women in Culture and Society, 38(4), 785-810.

Climate Action Tracker. (2020, July 30). New Zealand. https://climateactiontracker.org/countries/new-zealand/

Cook, K. E. (2012). In-depth interview. In L. Given (Ed.), The SAGE Encyclopedia of Qualitative Research Methods (p. 423). SAGE Publications, Inc.

Crenshaw, K. (1991). Mapping the margins: Intersectionality, identity politics, and violence against women of color. Stanford Law Review, 43(6), 1241-1299.

Cretney, R., \& Nissen, S. (2019). Climate politics ten years from Copenhagen: Activism, emergencies, and possibilities. Women Talking Politics, 15, 15-19.

Cretney, R., Thomas, A., \& Bond, S. (2016). Maintaining grassroots activism: Transition towns in Aotearoa New Zealand. New Zealand Geographer, 72(2), 81-91.

Dalton, R. J. (1995). Strategies of partisan Influence: West European environmental groups. In C. J. Jenkins \& B. Klandermans (Eds.), The Politics of Social Protest: Comparative Perspectives on States and Social Movements (Vol. 3, pp. 296-323). University of Minnesota Press.

Davis, J. B., \& Wells, T. R. (2016). Transformation without paternalism. Journal of Human Development and Capabilities, 17(3), 360-376.

Dawson, A. (2010). Climate justice: The emerging movement against green capitalism. South Atlantic Quarterly, 109(2), 313-338. 
Dean, S. M., Rosier, S., Carey-Smith, T., \& Stott, P. A. (2013). The role of climate change in the two-day extreme rainfall in Golden Bay, New Zealand, December 2011. Bulletin of the American Meteorological Society, 94(9), S61-S63.

Deka, B. J., Bohra, V., Alam, W., Sanasam, S., Guo, J., Borana, L., \& An, A. K. (2020). Environment impact assessment of COVID-19. In Integrated Risk of Pandemic: Covid19 Impacts, Resilience and Recommendations (pp. 169-195). Springer.

della Porta, D. (2014a). In-depth interviews. In D. della Porta (Ed.), Methodological Practices in Social Movement Research (pp. 228-261). Oxford University Press.

della Porta, D. (2014b). Social movement studies and methodological pluralism. In D. della Porta (Ed.), Methodological Practices in Social Movement Research (pp. 1-20). Oxford University Press.

della Porta, D. (2017). Political economy and social movement studies: The class basis of antiausterity protests. Anthropological Theory, 17(4), 453-473.

della Porta, D., \& Diani, M. (2015). Introduction: The field of social movement studies. In D. della Porta \& M. Diani (Eds.), The Oxford Handbook of Social Movements (Vol. 1, pp. 1-28). Oxford University Press.

della Porta, D., \& Parks, L. (2013). Framing process in the climate movement: From climate change to climate justice. In M. Dietz \& H. Garrelts (Eds.), Routledge Handbook of the Climate Change Movement (pp. 19-30). Taylor \& Francis Group.

della Porta, D., \& Rucht, D. (1995). Left-libertarian movements in context: A comparison of Italy and West Germany, 1965-1990. In C. J. Jenkins \& B. Klandermans (Eds.), The Politics of Social Protest: Comparative Perspectives on States and Social Movements (NED-New edition, Vol. 3, pp. 229-272). University of Minnesota Press. 
Demaria, F., \& Kothari, A. (2017). The post-development dictionary agenda: Paths to the pluriverse. Third World Quarterly, 38(12), 2588-2599.

Derman, B. (2019). 'Climate change is about us': Fence-line communities, the NAACP and the grounding of climate justice. In T. Jafry, M. Mikulewicz, \& K. Helwig (Eds.), Routledge Handbook of Climate Justice (pp. 407-419). Routledge.

Desai, V., \& Potter, R. (Eds.). (2014a). Environment and development. In The Companion to Development Studies (3rd ed., pp. 329-331). Taylor \& Francis Group.

Desai, V., \& Potter, R. (Eds.). (2014b). The nature of development and development studiesEditorial introduction. In The Companion to Development Studies (3rd ed., pp. 1-3). Taylor \& Francis Group.

Desai, V., \& Potter, R. (Eds.). (2014c). Theories and strategies of development-Editorial introduction. In The Companion to Development Studies (3rd ed., pp. 79-81). Taylor \& Francis Group.

Dietz, M. (2013). Debates and conflicts in the climate movement. In M. Dietz \& H. Garrelts (Eds.), Routledge Handbook of the Climate Change Movement (pp. 292-307). Taylor \& Francis Group.

Dietz, M., \& Garrelts, H. (2013). Introduction: Contours of the transnational climate movement - Conception and contents of the handbook. In M. Dietz \& H. Garrelts (Eds.), Routledge Handbook of the Climate Change Movement (pp. 1-15). Taylor \& Francis Group.

Diprose, G., Bond, S., Thomas, A., Barth, J., \& Urquhart, H. (2017). The violence of (in)action: Communities, climate and business-as-usual. Community Development Journal, 52(3), $488-505$. 
Diprose, G., Thomas, A., \& Bond, S. (2016). 'It's who we are': Eco-nationalism and place in contesting deep-sea oil in Aotearoa New Zealand. Kōtuitui: New Zealand Journal of Social Sciences Online, 11(2), 159-173.

Dodson, G., \& Papoutsaki, E. (2017). Youth-led activism and political engagement in New Zealand: A survey of Generation Zero. Communication Research and Practice, 3(2), 194-211.

Doig, T. (2020). Introduction. In T. Doig (Ed.), Living with the Climate Crisis: Voices from Aotearoa (pp. 7-28). Bridget Williams Books.

Downes, D. (2000). The New Zealand environmental movement and the politics of inclusion. Australian Journal of Political Science, 35(3), 471.

Dryzek, J. S. (1996). Political inclusion and the dynamics of democratization. American Political Science Review, 90(3), 475-487.

Dyett, J., \& Thomas, C. (2019). Overpopulation discourse: Patriarchy, racism, and the specter of ecofascism. Perspectives on Global Development and Technology, 18(1-2), 205-224.

Edelman, G. (2020, March 25). The analogy between Covid-19 and climate change is eerily precise. Wired. https://www.wired.com/story/the-analogy-between-covid-19-andclimate-change-is-eerily-precise/

Elkington, B., \& Smeaton, J. (2020). Introduction. In R. Kiddle (Ed.), Imagining Decolonisation (1st ed., pp. 7-20). Bridget Williams Books.

Elliot, B. (2016). Sustainable development as neoliberal environmentalism. In Natural Catastrophe: Climate Change and Neoliberal Governance (pp. 89-123). Edinburgh University Press. 
Enarson, E. (2012). Women Confronting Natural Disaster: From Vulnerability to Resilience. Lynne Rienner Publishers.

Escobar, A. (1992). Imagining a post-development era? Critical thought, development and social movements. Social Text, 31/32, 20-56.

Escobar, A. (1995). Encountering Development: The Making and Unmaking of the Third World. Princeton University Press.

Featherstone, D. (2013). The contested politics of climate change and the crisis of neoliberalism. ACME: An International E-Journal for Critical Geographies, 12(1), 44-64.

Ferretti, F., \& Pedrosa, B. V. (2018). Inventing critical development: A Brazilian geographer and his northern networks. Transactions of the Institute of British Geographers, 43(4), 703717.

Fforde, A. (2017). Reinventing Development: The Sceptical Change Agent (1st ed. 2017.). Springer International Publishing.

Fominaya, C. F. (2010). Collective identity in social movements: Central concepts and debates. Sociology Compass, 4(6), 393-404.

Fox, R. L., \& Frye, J. J. (2010). Tensions of praxis: A new taxonomy for social movements. Environmental Communication, 4(4), 422-440.

Freire, P. (1970). Pedagogy of the oppressed. Herder and Herder.

Fukuda-Parr, S., \& Muchhala, B. (2020). The southern origins of sustainable development goals: Ideas, actors, aspirations. World Development, 126, 104706.

Gaisford, T. (2010). An Alternative to Development Framework: A Study of Permaculture and Anarchism in Global Justice Movements in New Zealand [Masters]. Victoria University of Wellington. 
Gale, R. P. (1986). Social movements and the state: The environmental movement, countermovement, and government agencies. Sociological Perspectives, 29(2), 202-240.

Gawerc, M. I. (2019). Diverse social movement coalitions: Prospects and challenges. Sociology Compass, 14(1), 1-15.

Gergen, K. J., \& Gergen, M. M. (2012). Social constructionism. In L. Given (Ed.), The SAGE Encyclopedia of Qualitative Research Methods (pp. 817-820). SAGE Publications, Inc.

Gibbs, B. J. (2017). Structuration theory| sociology. Encyclopedia Britannica. https://www.britannica.com/topic/structuration-theory

Gibson-Graham, J. K. (2005). Surplus possibilities: Postdevelopment and community economies. Singapore Journal of Tropical Geography, 26(1), 4-26.

Goodrich, M. M. (2019, February 15). The Climate Movement's Path to the Green New Deal. Dissent Magazine. https://www.dissentmagazine.org/online_articles/sunrise-movementgreen-new-deal

Goodwin, J., \& Rojas, R. (2015). Revolutions and regime change. In D. della Porta \& M. Diani (Eds.), The Oxford Handbook of Social Movements (Vol. 1, pp. 793-804). Oxford University Press.

Gudynas, E. (2017). Post-development and other critiques of the roots of development. In H. Veltmeyer \& P. Bowles (Eds.), The Essential Guide to Critical Development Studies (1st ed., pp. 84-93). Routledge.

Hannam, P. (2020, May 4). 'Blown away': Safe climate niche closing fast, with billions at risk. The Sydney Morning Herald. https://www.smh.com.au/environment/climatechange/blown-away-safe-climate-niche-closing-fast-with-billions-at-risk-20200504p54pod.html 
Hartendorp, K., \& Bradford, S. (2016). Transforming our future in te Moana Nui a Kiwa. Counterfutures, 2, 171-182-171-182.

Haslett, B. B. (2013). Introductory remarks: Structuration theory. Management Communication Quarterly, 27(4), 596-598.

Hayward, B. (2020, December 2). NZ joins a groundswell in sounding the climate emergency alarm. Can it make any real difference? The Spinoff. https://thespinoff.co.nz/politics/0212-2020/nz-joins-a-groundswell-in-sounding-the-climate-emergency-alarm-can-it-makeany-real-difference/

Heidt, A. (2020, July 8). COVID-19 Lockdowns Will Have Negligible Effect on Climate Change. The Scientist Magazine. https://www.the-scientist.com/news-opinion/covid-19lockdowns-will-have-negligible-effect-on-climate-change-67808

Henrickson, M. (2020). Kiwis and COVID-19: The Aotearoa New Zealand response to the global pandemic. The International Journal of Community and Social Development, 2(2), $121-133$.

Heron, J. (2014). Co-operative inquiry. In D. Coghlan \& M. Brydon-Miller (Eds.), The SAGE Encyclopedia of Action Research (pp. 188-192). SAGE Publications Ltd.

Heron, J., \& Reason, P. (2011). Extending epistemology within a co-operative inquiry. In P. Reason \& H. Bradbury (Eds.), The SAGE Handbook of Action Research (pp. 366-380). SAGE Publications Ltd. https://doi.org/10.4135/9781848607934.n32

Hestres, L. E., \& Hopke, J. E. (2020). Fossil fuel divestment: Theories of change, goals, and strategies of a growing climate movement. Environmental Politics, 29(3), 371-389. 
Hetland, G., \& Goodwin, J. (2013). The strange disappearance of capitalism from social movement studies. In C. Barker, L. Cox, J. Krinsky, \& A. G. Nilsen (Eds.), Marxism and Social Movements (1st ed., pp. 83-102). BRILL.

Hopkins, D., Campbell-Hunt, C., Carter, L., Higham, J. E., \& Rosin, C. (2015). Climate change and Aotearoa New Zealand. Wiley Interdisciplinary Reviews: Climate Change, 6(6), 559-583.

Hosking, D. M., \& Bass, A. (2001). Constructing changes in relational processes: Introducing a social constructionist approach to change work. Career Development International, 6(7), $348-360$.

Hourigan, N. (2001). New social movement theory and minority language television campaigns. European Journal of Communication, 16(1), 77-100.

Ilișanu, G., \& Andrei, V. (2019). Analyzing social movements from multiple perspectives: Key concepts and methodologies of study. Journal of Comparative Research in Anthropology and Sociology, 10(1), 33-48.

Jackson, M. (2020). Where to next? Decolonisation and the stories in the land. In R. Kiddle (Ed.), Imagining Decolonisation (1st ed., pp. 133-155). Bridget Williams Books.

Jackson, M., Taylor, D., \& Thomas, A. (2017). We have come too far not to go further. Counterfutures, 4, 27-51-27-51.

Jackson, T., \& Dixon, J. (2007). The New Zealand Resource Management Act: An exercise in delivering sustainable development through an ecological modernisation agenda. Environment and Planning B: Planning and Design, 34(1), 107-120. 
Jafry, T., Mikulewicz, M., \& Helwig, K. (2019). Introduction: Justice in the era of climate change. In T. Jafry, M. Mikulewicz, \& K. Helwig (Eds.), Routledge Handbook of Climate Justice (pp. 1-9). Routledge.

Jasper, J. (2006). A strategic approach to collective action: Looking for agency in socialmovement choices. Mobilization: An International Quarterly, 9(1), 1-16.

Jenkins, C. J., \& Klandermans, B. (1995). The politics of social protest. In C. J. Jenkins \& B. Klandermans (Eds.), The Politics of Social Protest: Comparative Perspectives on States and Social Movements (3rd ed., pp. 3-13). University of Minnesota Press.

Johnson, E. W., Agnone, J., \& McCarthy, J. D. (2010). Movement organizations, synergistic tactics and environmental public policy. Social Forces, 88(5), 2267-2293.

Johnson, J. M., \& Rowlands, T. (2014). The interpersonal dynamics of in-depth interviewing. In J. Gubrium, J. Holstein, A. Marvasti, \& K. McKinney (Eds.), The SAGE Handbook of Interview Research: The Complexity of the Craft (pp. 99-114). SAGE Publications, Inc.

Jordaan, S. M., Siddiqi, A., Kakenmaster, W., \& Hill, A. C. (2019). The climate vulnerabilities of global nuclear power. Global Environmental Politics, 19(4), 3-13.

Karampampas, S., Temple, L., \& Grasso, M. (2020). Violent political action during the European economic crisis: An empirical investigation of four theoretical paradigms from social movement research. Comparative European Politics, 18(3), 420-436.

Kelly-Costello, Á., Watts, K., \& Currie, A. (2020, December 2). Give power to Māori and marginalised communities and we'll get through the climate emergency. The Spinoff. https://thespinoff.co.nz/atea/02-12-2020/give-power-to-maori-and-marginalisedcommunities-and-well-get-through-the-climate-emergency/ 
King, D. N. T., Penny, \& Severne. (2010). The climate change matrix facing Māori society. In R. A. C. Nottage, D. S. Wratt, J. F. Bornman, \& K. Jones (Eds.), Climate Change Adaptation in New Zealand: Future Scenarios and Some Sectoral Perspectives (pp. 100111). New Zealand Climate Change Centre.

Klarin, T. (2018). The concept of sustainable development: From its beginning to the contemporary issues. Zagreb International Review of Economics and Business, 21(1), 67-94.

Klenert, D., Funke, F., Mattauch, L., \& O’Callaghan, B. (2020). Five lessons from COVID-19 for advancing climate change mitigation. Environmental \& Resource Economics, 76, 751-778.

Kleres, J., \& Wettergren, А. (2017). Fear, hope, anger, and guilt in climate activism. Social Movement Studies, 16(5), 507-519. https://doi.org/10.1080/14742837.2017.1344546

Knox, K. (2019). Climate justice in the UK: Reconciling climate change and equity issues in policy and practice in a developed country context. In T. Jafry, M. Mikulewicz, \& K. Helwig (Eds.), Routledge Handbook of Climate Justice (pp. 114-127). Routledge.

Krueger, R. J. (2010). Sustainable development alternatives. In Encyclopedia of Geography (pp. 2753-2754). SAGE Publications, Inc.

Lapadat, J. C. (2012). Thematic analysis. In A. Mills, G. Durepos, \& E. Wiebe (Eds.), Encyclopedia of Case Study Research (pp. 926-927). SAGE Publications, Inc.

Mark, A. F., Turner, K. S., \& West, C. J. (2001). Integrating nature conservation with hydroelectric development: Conflict resolution with lakes Manapouri and Te Anau, Fiordland National Park, New Zealand. Lake and Reservoir Management, 17(1), 1-25. 
Matthew, R. A., \& Hammill, A. (2009). Sustainable development and climate change. International Affairs (Royal Institute of International Affairs 1944-), 85(6), 1117-1128.

Matthews, S. (2008). The role of the privileged in responding to poverty: Perspectives emerging from the post-development debate. Third World Quarterly, 29(6), 1035-1049.

McAdam, D., \& Tarrow, S. (2010). Ballots and barricades: On the reciprocal relationship between elections and social movements. Perspectives on Politics, 8(2), 529-542.

McConnell, G. (2020, June 18). Black Lives Matter protests are about more than statues for New Zealand. Stuff. https://www.stuff.co.nz/dominionpost/comment/columnists/300036489/black-lives-matter-protests-are-about-more-thanstatues-for-new-zealand

McCreanor, T., Hancock, F., \& Short, N. (2018). The mounting crisis at Ihumātao: A high cost special housing area or a cultural heritage landscape for future generations? Counterfutures, 6, 139-148-139-148.

McMichael, P. (2012). Development and Social Change: A Global Perspective (5th ed.). SAGE Publications Ltd.

McVeigh, R., Cunningham, D., \& Farrell, J. (2014). Political polarization as a social movement outcome: 1960s Klan activism and its enduring impact on political realignment in southern counties, 1960 to 2000. American Sociological Review, 79(6), 1144-1171.

Meduna, V. (2015). Towards a Warmer World: What Climate Change Will Mean for New Zealand's Future (1st ed.). Bridget Williams Books.

Memon, P. A. (1993). Keeping New Zealand Green: Recent Environmental Reforms. University of Otago Press. 
Mercier, O. R. (2020). What is decolonisation? In R. Kiddle (Ed.), Imagining Decolonisation (1st ed., pp. 40-82). Bridget Williams Books.

Meyer, D. S. (2004). Protest and political opportunities. Annual Review of Sociology, 30(1), 125145.

Meyer, D. S., \& Minkoff, D. C. (2004). Conceptualizing political opportunity. Social Forces, 82(4), 1457-1492.

Mills, K. (2009). The changing relationship between Māori and environmentalists in 1970s and 1980s New Zealand. History Compass, 7(3), 678-700.

Morris, A. (2018). A Practical Introduction to In-Depth Interviewing. SAGE Publications Ltd. https://doi.org/10.4135/9781473921344

Morse, J. M. (2011). Purposive sampling. In M. Lewis-Beck, A. Bryman, \& T. Futing Liao (Eds.), The SAGE Encyclopedia of Social Science Research Methods (pp. 884-885). Sage Publications, Inc.

Nairn, K., Kidman, J., Matthews, K. R., Showden, C. R., \& Parker, A. (2021). Living in and out of time: Youth-led activism in Aotearoa New Zealand. Time \& Society, 30(2), 247-269.

Nathan, S. (2015, August 3). Conservation-A history-Environmental activism, 1966-1987 [Web page]. Te Ara - the Encyclopedia of New Zealand. https://teara.govt.nz/en/conservation-a-history/page-8

Ngata, T. (2020, June 14). Racism, monuments and ethical remembering. Stuff. https://www.stuff.co.nz/national/politics/opinion/121823266/racism-monuments-andethical-remembering

Nicholls, W. (2009). Place, networks, space: Theorising the geographies of social movements. Transactions of the Institute of British Geographers New Series, 34(1), 78-93. 
Nowell, L. S., Norris, J. M., White, D. E., \& Moules, N. J. (2017). Thematic analysis: Striving to meet the trustworthiness criteria. International Journal of Qualitative Methods, 16(1), 112.

Nuñez, A. J. (2019). Mother Earth and climate justice: Indigenous peoples' perspectives of an alternative development paradigm. In T. Jafry, M. Mikulewicz, \& K. Helwig (Eds.), Routledge Handbook of Climate Justice (pp. 420-430). Routledge.

O’Brien, T. (2012). Environmental protest in New Zealand (1997-2010). The British Journal of Sociology, 63(4), 641-661.

O'Brien, T. (2013a). Fires and flotillas: Opposition to offshore oil exploration in New Zealand. Social Movement Studies, 12(2), 221-226.

O’Brien, T. (2013b). Fragmentation or evolution? Understanding change within the New Zealand environmental movement. Journal of Civil Society, 9(3), 287-299.

O’Brien, T. (2015). Social control and trust in the New Zealand environmental movement. Journal of Sociology, 51(4), 785-798.

O’Brien, T. (2016). Camping, climbing trees and marching to parliament: Spatial dimensions of environmental protest in New Zealand. Kōtuitui: New Zealand Journal of Social Sciences Online, 11(1), 11-22.

O’Brien, T. (2017). 'Cut pollution, create jobs? Yeah, nah': Partisan effects on environmental protest in Aotearoa New Zealand. Political Science, 69(3), 264-281.

O’Leary, Z. (2017). The Essential Guide to Doing Your Research Project (3rd ed.). SAGE Publications Ltd.

Oosterman, J. (2016a). Making Climate Action Meaningful: Communication Practices in the New Zealand Climate Movement [Masters]. Victoria University of Wellington. 
Oosterman, J. (2016b). Making climate action meaningful: Communication practices in the New Zealand climate movement. New Zealand Sociology, 31(5), 131-157.

Overton, J., Murray, W. E., Prinsen, G., Ulu, A. J., \& Wrighton, N. (2019). Aid, Ownership and Development-The Inverse Sovereignty Effect in the Pacific Islands. Rowman \& Littlefield.

Pachauri, R. K., Allen, M. R., Barros, V. R., Broome, J., Cramer, W., Christ, R., Church, J. A., Clarke, L., Dahe, Q., Dasgupta, P., Dubash, N. K., Edenhofer, O., Elgizouli, I., Field, C. B., Forster, P., Friedlingstein, P., Fuglestvedt, J., Gomez-Echeverri, L., Hallegatte, S., ... van Ypserle, J.-P. (2014). Climate Change 2014: Synthesis Report. Contribution of Working Groups I, II and III to the Fifth Assessment Report of the Intergovernmental Panel on Climate Change (R. K. Pachauri \& L. Meyer, Eds.). IPCC.

Patterson, J. (2020, December 17). Ihumātao: Deal struck between government and Fletcher Building to buy disputed land. RNZ. https://www.rnz.co.nz/news/political/433043/ihumatao-deal-struck-between-governmentand-fletcher-building-to-buy-disputed-land

Perkins, P. E. (2019). Climate justice, gender and intersectionality. In T. Jafry, M. Mikulewicz, \& K. Helwig (Eds.), Routledge Handbook of Climate Justice (pp. 349-358). Routledge.

Phipps, A. G. (2010). Structuration theory. In Encyclopedia of Geography (pp. 2709-2711). SAGE Publications, Inc.

Phoenix, A., \& Pattynama, P. (2006). Intersectionality. European Journal of Women's Studies, 13(3), 187-192. 
Potter, R. B. (2014). Theories, strategies and ideologies of development-An overview. In V. Desai \& R. Potter (Eds.), The Companion to Development Studies (3rd ed., pp. 83-87). Taylor \& Francis Group.

Power, M. (2014). Enlightenment and the era of modernity. In V. Desai \& R. Potter (Eds.), The Companion to Development Studies (3rd ed., pp. 95-100). Taylor \& Francis Group.

Powless, B. (2012). An Indigenous movement to confront climate change. Globalizations, 9(3), 411-424.

Protopapadakis, E. D. (2014). Environmental ethics and Linkola's ecofascism: An ethics beyond humanism. Frontiers of Philosophy in China, 9(4), 586-601.

Reisinger, A., Kitching, R., Chiew, F., Hughes, L., Newton, P., Schuster, S., Tait, A., Whetton, P., Barnett, J., Becken, S., Blackett, P., Boulter, S., Campbell, A., Collins, D., Davies, J., Dear, K., Dovers, S., Finlay, K., \& Glavovic, B. (2014). Australasia. In Intergovernmental Panel on Climate Change (Ed.), Climate Change 2014 - Impacts, Adaptation and Vulnerability: Part B: Regional Aspects: Working Group II Contribution to the IPCC Fifth Assessment Report: Volume 2: Regional Aspects (Vol. 2, pp. 13711438). Cambridge University Press.

Renwick, J., Anderson, B., Greenaway, A., Ngaru King, D., Mikaloff-Fletcher, S., Reisinger, A., \& Rouse, H. (2016). Climate change implications for New Zealand (p. 72). The Royal Society of New Zealand. https://www.royalsociety.org.nz/assets/documents/Climatechange-implications-for-NZ-2016-report-web.pdf

Ripple, W. J., Wolf, C., Newsome, T. M., Galetti, M., Alamgir, M., Crist, E., Mahmoud, M. I., Laurance, W. F., \& 15,364 scientist signatories from 184 countries. (2017). World scientists' warning to humanity: A second notice. BioScience, 67(12), 1026-1028. 
RNZ. (2021, February 1). Changes to 'fundamentally unfair' process to make way for Māori wards. https://www.rnz.co.nz/news/te-manu-korihi/435579/changes-to-fundamentallyunfair-process-to-make-way-for-maori-wards

Rose, G. (1997). Situating knowledges: Positionality, reflexivities and other tactics. Progress in Human Geography, 21(3), 305.

Ross, M. (2020). The throat of Parata. In R. Kiddle (Ed.), Imagining Decolonisation (1st ed., pp. 21-39). Bridget Williams Books.

Roth, S. (2008). Dealing with diversity: The coalition of labor union women. In J. Reger, D. T. Myers, \& R. L. Einwohner (Eds.), Identity Work in Social Movements (NED-New edition, Vol. 30, pp. 213-232). University of Minnesota Press.

Rucht, D. (1999). The impact of environmental movements in Western societies. In M. Giugni, D. McAdam, \& C. Tilly (Eds.), How Social Movements Matter (NED-New edition, Vol. 10, pp. 204-224). University of Minnesota Press.

Sachs, W. (1999). Planet Dialectics: Explorations in Environment and Development. Zed Books Ltd.

Sachs, W. (2010). Environment. In The Development Dictionary (2nd ed., pp. 24-37). Zed Books Ltd.

Sachs, W. (2013, March). Liberating the world from development. New Internationalist, 460, $22-27$.

Sailor, W. C., Bodansky, D., Braun, C., Fetter, S., \& Zwaan, B. van der. (2000). A nuclear solution to climate change? Science, 288(5469), 1177-1178. 
Salmon, R., Priestley, R., Fontana, M., \& Milfont, T. L. (2017). Climate change communication in New Zealand. In R. Salmon, R. Priestley, M. Fontana, \& T. L. Milfont, Oxford Research Encyclopedia of Climate Science. Oxford University Press.

Sanneh, E. S. (2018). Introduction. In E. S. Sanneh (Ed.), Systems Thinking for Sustainable Development: Climate Change and the Environment (pp. 1-11). Springer International Publishing.

Saunders, C. (2008). Double-edged swords? Collective identity and solidarity in the environment movement. The British Journal of Sociology, 59(2), 227-253.

Schlosberg, D., \& Collins, L. B. (2014). From environmental to climate justice: Climate change and the discourse of environmental justice. WIREs Climate Change, 5(3), 359-374.

Schreuder, Y. (2010). Sustainable development. In Encyclopedia of Geography (pp. 2748-2752). SAGE Publications, Inc.

Scott, D. (2014). Parihaka Invaded. Bridget Williams Books.

Segre, S. (2016). Social constructionism as a sociological approach. Human Studies, 39(1), 9399.

Shi, L., Han, L., Yang, F., \& Gao, L. (2019). The evolution of sustainable development theory: Types, goals, and research prospects. Sustainability, 11(24), 7158.

Shiva, V. (1997). Economic globalization, ecological feminism and sustainable development. Canadian Woman Studies, 17(2), 22-27.

Shiva, V. (2010). Resources. In The Development Dictionary (2nd ed., pp. 228-242). Zed Books Ltd.

Sidaway, J. D. (2014). Post-development. In D. Vandana \& R. Potter (Eds.), The Companion to Development Studies (3rd ed., pp. 147-152). Taylor \& Francis Group. 
Silvey, R., \& Rankin, K. (2011). Development geography: Critical development studies and political geographic imaginaries. Progress in Human Geography, 35(5), 696-704.

Snow, D. A. (2001). Collective identity and expressive forms. In International Encyclopedia of the Social \& Behavioral Sciences (pp. 2212-2219). Elsevier.

Steinfort, L., Hendrikx, B., \& Pijpers, R. (2017). Communal performativity-A seed for change? The solidarity of Thessaloniki's social movements in the diverse fights against neoliberalism. Antipode, 49(5), 1446-1463.

Stone, D. (2015). Part III: Methods. In M. Bevir \& R. A. W. Rhodes (Eds.), Routledge Handbook of Interpretive Political Science (pp. 155-224). Taylor \& Francis Group.

Straubhaar, R. (2015). The stark reality of the 'white saviour' complex and the need for critical consciousness: A document analysis of the early journals of a Freirean educator. Compare: A Journal of Comparative and International Education, 45(3), 381-400.

Stuart, D., Gunderson, R., \& Petersen, B. (2020). The climate crisis as a catalyst for emancipatory transformation: An examination of the possible. International Sociology, $35(4), 433-456$.

Suh, D. (2001). How do political opportunities matter for social movements? Political opportunity, misframing, pseudosuccess, and pseudofailure. The Sociological Quarterly, $42(3), 437-460$.

Tagg, N. T., \& Jafry, T. (2018). Engaging young children with climate change and climate justice. Research for All, 2(1), 34-42.

Tarrow, S. G. (2011). Threats, opportunities, and regimes. In Power in Movement: Social Movements and Contentious Politics (3rd ed., pp. 157-180). Cambridge University Press. 
Taylor, D. (2008). What's Left? An Exploration of Social Movements, the Left and Activism in New Zealand Today [Masters]. Victoria University of Wellington.

Taylor, D., \& Grey, S. (2014). From class-struggle to neoliberal narratives: Redistributive movements in Aotearoa/New Zealand. New Zealand Sociology, 29(3), 69-89.

Te Punga Somerville, A. (2020). 250 Ways to Start an Essay about Captain Cook. Bridget Williams Books Ltd.

Terry, G. (2009). No climate justice without gender justice: An overview of the issues. Gender \& Development, 17(1), 5-18.

Terry, G., Hayfield, N., Clarke, V., \& Braun, V. (2017). Thematic analysis. In C. Willig \& W. S. Rogers (Eds.), The SAGE Handbook of Qualitative Research in Psychology (pp. 17-36). SAGE Publications Ltd.

Thom, K., \& Quince, K. (2020, July 9). Black Lives Matter outrage must drive police reform in Aotearoa New Zealand too. The Conversation. http://theconversation.com/black-livesmatter-outrage-must-drive-police-reform-in-aotearoa-new-zealand-too-139965

Thomas, A. (2018). Political organisation and the environment. Economic and Social Research Aotearoa, 10, 1-8.

Thomas, A. (2020). Pākehā and doing the work of decolonisation. In R. Kiddle (Ed.), Imagining Decolonisation (1st ed., pp. 107-132). Bridget Williams Books.

Thomas, A., Cretney, R., \& Hayward, B. (2019). Student Strike 4 Climate: Justice, emergency and citizenship. New Zealand Geographer, 75(2), 96-100.

Tokar, B. (2019). On the evolution and continuing development of the climate justice movement. In T. Jafry, M. Mikulewicz, \& K. Helwig (Eds.), Routledge Handbook of Climate Justice (pp. 13-25). Routledge. 
Tolich, M. (2002). Pākehā 'paralysis': Cultural safety for those researching the general population of Aotearoa. Social Policy Journal of New Zealand, 19, 164-178.

Trevett, C. (2017, August 20). Jacinda Ardern's rallying cry: Climate change the nuclear-free moment of her generation. NZ Herald. https://www.nzherald.co.nz/nz/jacinda-ardernsrallying-cry-climate-change-the-nuclear-free-moment-of-hergeneration/6LEDCNATMAFX2PWA3GHNLK7NUU/

Tucker, C. (2011). The social construction of clean and green in the genetic engineering resistance movement of New Zealand. New Zealand Sociology, 26(1), 110-121.

Tucker, C. (2013). Using social network analysis and framing to assess collective identity in the genetic engineering resistance movement of Aotearoa New Zealand. Social Movement Studies, 12(1), 81-95.

Veltmeyer, H., \& Delgado Wise, R. (2018). Critical Development Studies: An Introduction. Practical Action Publishing.

Vrasti, W. (2012). Volunteer Tourism in the Global South: Giving Back in Neoliberal Times. Taylor \& Francis Group.

Walker, R. (2004). Ka Whawhai Tonu Mātou—Struggle Without End. Penguin.

Ward, J. (2008). Diversity discourse and multi-identity work in lesbian and gay organizations. In J. Reger, D. T. Myers, \& R. L. Einwohner (Eds.), Identity Work in Social Movements (NED-New edition, Vol. 30, pp. 233-256). University of Minnesota Press.

Webb, D. (2020). A socialist compass for Aotearoa: Envisioning Māori socialism. Counterfutures, 8, 73-97-73-97.

Weinberg, D. (2014). Contemporary Social Constructionism: Key Themes. Temple University Press. 
Whyte, K. (2017). Indigenous climate change studies: Indigenizing futures, decolonizing the Anthropocene. English Language Notes, 55(1-2), 153-162.

Whyte, K. (2020). Too late for Indigenous climate justice: Ecological and relational tipping points. WIREs Climate Change, 11(1), 1-7.

Wilson, R. (1982). From Manapouri to Aramoana: The Battle for New Zealand's Environment. Earthworks Press.

Wright, E. O. (2016, April 27). How to Think About (And Win) Socialism. Jacobin. https://jacobinmag.com/2016/04/erik-olin-wright-real-utopias-capitalism-socialism/

Wright, L. W. (1980). Decision making and the logging industry: An example from New Zealand. Biological Conservation, 18(2), 101-115.

Xu, C., Kohler, T. A., Lenton, T. M., Svenning, J.-C., \& Scheffer, M. (2020). Future of the human climate niche. Proceedings of the National Academy of Sciences, 117(21), 1135011355.

Zimmerman, M. E., \& Toulouse, T. A. (2016). Ecofascism. In J. Adamson, W. A. Gleason, \& D. N. Pellow (Eds.), Keywords for Environmental Studies (pp. 64-68). NYU Press. 